\title{
Application of Characteristic Time Concepts for Hydraulic Fracture Configuration Design, Control, and Optimization
}

\section{Final Report}

S.H. Advani, Lehigh University

T.S. Lee, Lehigh University H. Moon, Ohio State University

Work Performed Unider Contract No.: DE-FG21-90MC27351

For

U.S. Department of Energy

Office of Fossil Energy

Morgantown Energy Technology Center

P.O. Box 880

Morgantown, West Virginia 26507-0880

By

Lehigh University

526 Brodhead Avenue

Bethlehem, Pennsylvania 18015

October 1992 


\section{TABLE OF CONTENTS}

FOREWORD

1.0 EXECUTIVE SUMMARY 1

2.0 NUMERICAL EXPERIMENTS AND DISCUSSION

3.0 FRACTURE DESIGN, CONTROL AND OPTIMIZATION 39 GUIDELINES

4.0 REFERENCES

APPENDICES

A Characteristic Time Concept in Hydraulic Fracture Configuration Evolution and Optimization

B Energy Considerations Associated with the Mechanics of Hydraulic Fracture

C Variational Principles for Hydraulic Fracturing

Appendices A and B have been removed from this report. 


\section{FOREWORD}

This research program, initiated during summer 1990, was an outgrowth of previous developments detailed in the paper, "Characteristic Time Concept Associated with Hydraulic Fracture Configuration Evolution and Optimization," presented as SPE Paper No. 19000 and subsequently published in SPE Production Engineering (pp. 323-330, 1991). The multi-task effort was sponsored primarily by the Morgantown Energy Technology Center (USDOE), Chevron, Conoco Inc., and Mobil. Supplemental funding was also received from Cray Research Inc. and Amoco through their doctoral fellowship award program. In addition to acknowledging feedback from the sponsors, the authors wish to express their appreciation to Dr. Norman Warpinski (Sandia National Laboratory) and Dr. Rick H. Dean (Arco Oil and Gas) for their technical input. Computational facilities were generously provided by the Ohio Supercomputer Center and Lehigh University Computer Center. 


\subsection{EXECUTIVE SUMMARY}

The analysis of pertinent energy components or affiliated characteristic times for hydraulic stimulation processes serves as an effective tool for fracture configuration design, optimization, and control (Appendix A). This evaluation, in conjunction with parametric sensitivity studies, provides a rational base for quantifying dominant process mechanisms and the roles of specified reservoir properties relative to controllable hydraulic fracture variables for a wide spectrum of treatment scenarios.

Results are detailed for the following multi-task effort:

(a) Application of characteristic time concept and parametric sensitivity studies

for specialized fracture geometries (rectangular, penny-shaped, elliptical) and

three-layered elliptic crack models (in situ stress, elastic moduli, and

fracture toughness contrasts).

(b) Incorporation of leak-off effects for models investigated in (a).

(c) Simulation of generalized hydraulic fracture models and investigation of the role of controllable variables and uncontrollable system properties.

(d) Development of guidelines for hydraulic fracture design and optimization.

Detailed evaluations of the roles of fracturing fluid rheology, flow rate, reservoir elastic properties, fracture toughness and in situ stress contrasts for rectangular, penny shaped and thre-layered elliptic fracture models are presented in Appendix B (SPE Paper No. 21296). No leak-off solutions for constant height, circular, and elliptic fracture modele in the dissipation and fracture dominant time regimes are presented in Tables 1 and 2 of Appendix $B$. The fracture fluid rheology and injection flow rate effects primarily control the fracture geometry and responses in the dissipation dominant domain while, the reservoir fracture toughness and flow rate are important in the fracture dominant domain. The characteristic times defining the dissipation, fracture, and transition influence domains, for simple fracture geometries, are presented in Table 3 of Appendix B. In lieu of employing the characteristic time concept, the pertinent energy-rate (power) ratios and measures can be used to identify the governing domain(s).

Rectangular, penny-shaped, and elliptical hydraulic fracture configurations are revealed in Fig. 1 along with a listing of uncontrollable reservoir parameters and controllable process variables. Practical discussions of various uncontrollable 
Injection Flow Rate

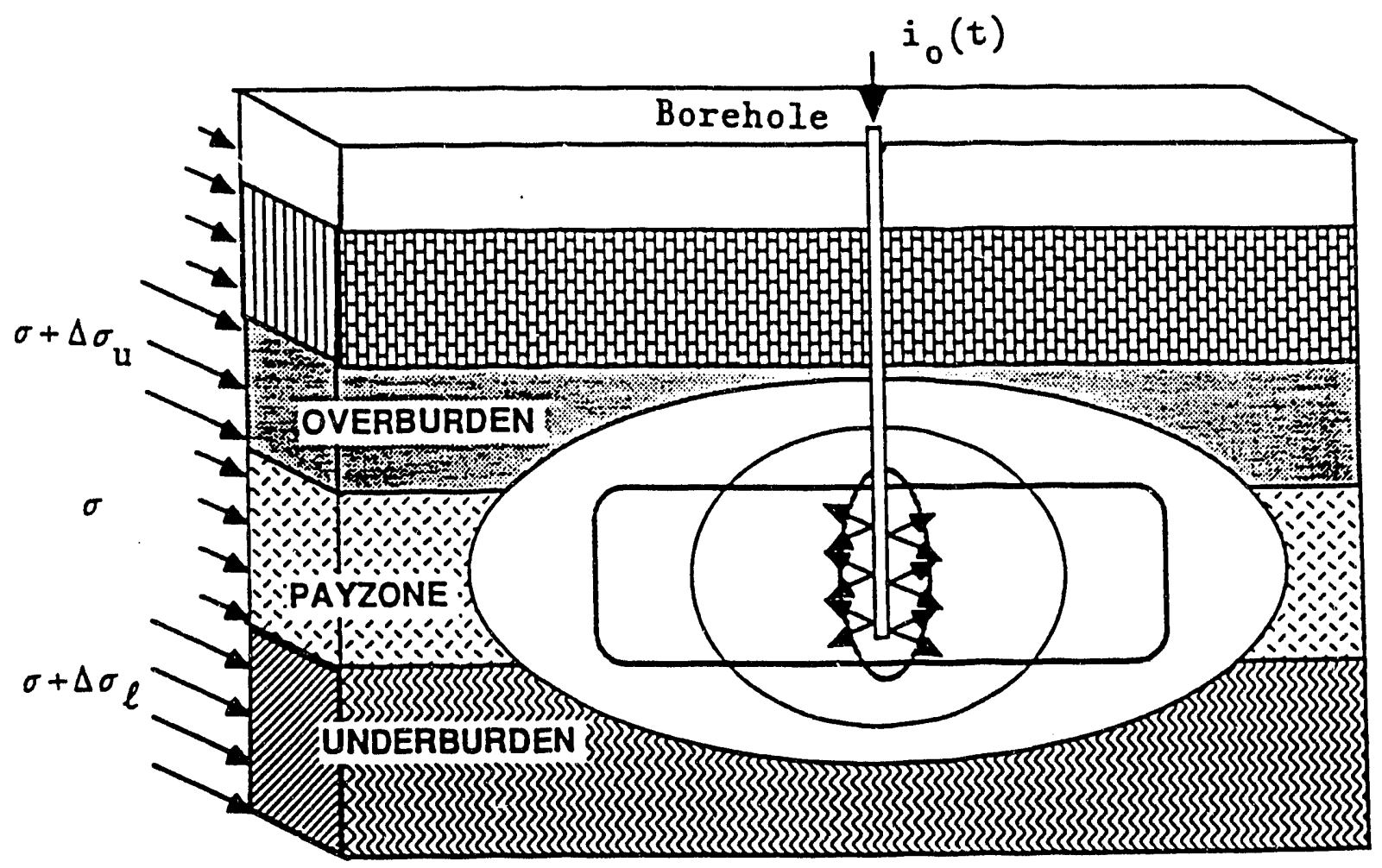

Uncontrollable Paraneters :

Payzone Height $(H)$ \& Interface

Elastic Moduli $(\mu, \nu)$

In situ Stress $(\sigma)$

Critical Energy Release Rate $\left(G_{C r}\right)$
Controllable Variables :

Fluid Injection Rate ( $i_{0}$ )

Fluid Bheology $(\eta, \mathrm{m}, \rho)$

Leak- off coefficient $\left(C_{L}\right)$

Perforation Characteristics

Fig. 1 Various Hydraulic Fracturing Planar Configurations with Uncontrollable Prameters and Controllable Variables 
parameters and their interactive role in fracture treatment design are presented by Nierode [1] and Brown and Economides [2]. Theoretical considerations, numerical results and conclusions presented here are based on the unsymmetric three-layered elliptic model presented in Fig. 2. This semi-general model accommodates reservoir characteristics exemplified by in situ stress, modulus, leak-off and fracture toughness contrasts with the penny-shaped, rectangular, and symmetric layered elliptical crack models representing special cases. Associated numerical experiments and results are presented in section 2.0.

The major conclusions of this project, using the ELLIP2D and ERATE2D model simulators [3], are presented below:

(i) The delineation of the governing energy domain(s) (dissipation, fracture surface, and/or leak-off dominant energy domains) using the uncontrollable reservoir properties and controllable fracture fluid variables, and the methodology in Appendix $\mathrm{A}$ is an important design tool Asymptotic time-explicit solutions with small and large leak-offs for PKN, GDK or penny-shaped models can be utilized in the preliminary assessments.

(ii) Three-layered models smearing the reservoir mechanical properties, layering conditions, and in situ stress contrasts are generally adequate as well as computationally efficient for a majority of the field simulations. The unsymmetric elliptic crack models developed here facilitate parametric sensitivity, response simulations as well as vertical fracture penetration evaluations.

(iii) In situ stress contrasts along with layer interface conditions play a significant role in governing fracture penetration with fracture fluid viscosity and injection rate having a secondary influence. The effects of elastic moduli contrast also have a secondarly role in the vertical fracture evolution and are primarily reflected in the fracture width-effective pressure relation and resulting dissipation energy rate variations.

(iv) Perforation placement in relation to the prevailing in situ stress field can be effectively utilized to govern fracture evolution and symmetry. The payzone fracture effective area and volume efficiencies are more realistic measures 


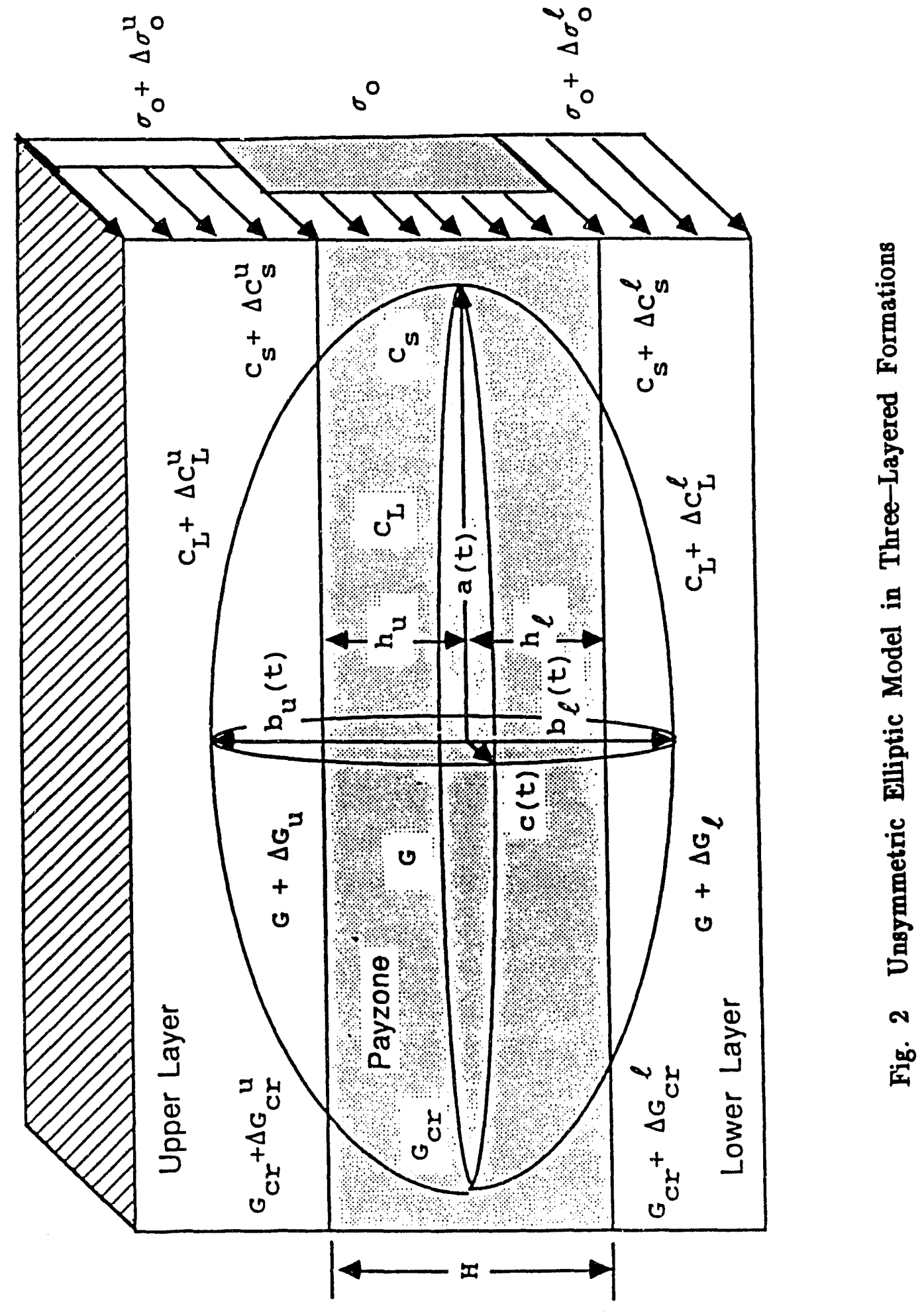


for optimum fracture design than the traditional fracture efficiency definition in the case of multi-layered media and are significantly influenced by perforation placement. Parametric sensitivity configuration studies highlighting the role of fracture fluid rheology, injection rate, and leak-off are useful for optimal stimulation treatment design. A higher injection rate, for the same treatinent volume size, reduces leak-off but decreases fracture containment in the payzone. Similarly, a higher fluid viscosity increases fracture width and vertical penetration.

(v) The energy efficiency of the hydraulic fracture process, evaluated using effective bottom hole pressure (BHTP) or wellhead treatment pressure (WHTP) values, is an important diagnostic measure. The available hydraulic horsepower $\left(i_{0} P_{0}\right)$ at the wellhead or bottomhole is converted into the time dependent, dissipative, strain, leak-off, and fracture surface energy rates during the fracture evolution. The conversion of the fracture fluid leak-off energy loss to reservoir strain energy recovery, for example, should be optimized during the dissipation dominant fracture evolution. 


\subsection{NUMERICAL EXPERIMENTS AND DISCUSSION}

\subsection{Elastic Modulus Contrasts}

The effects of reservoir strata elastic modulus contrasts for a three-layered symmetric elliptic crack model with major semi-axis (a), minor semi-axis (b), and payzone height (h) are illustrated in Fig. 3. Fractures are uncontained for $a / b>$ 3 , even with a barrier to payzone elastic modulus of 10 . Complete containment is evident when the modulus ratio is equal to 100 . These results are a generalization of the empirical results reported by Van Eekelen [4].

\subsection{In Situ Stress Contrasts}

The effects of reservoir symmetrically imposed in situ stress contrasts, in conformance with the presentation in Fig. 3, are revealed in Fig. 4. Corresponding trends for unsymmetric in situ stress differentials are shown in Fig. 5. These results quantitatively demonstrate the significant elliptic fracture configuration evolution bias in terms of in situ stress contrasts and they provide a sound reference base for fracture geometry characterization and design in three-layered reservoirs.

\subsection{Model Response Calibrations and Comparisons}

Selected-ELLIP2D model validations, comparisons with reported results, and parametric sensitivity studies are presented in Appendix B and Reference [3]. Additional ELLIP2D and ERATE2D model penny shaped comparisons, incorporating the SFE3 benchmark input data [5] in Table I with uniform in situ stresses, are shown in Fig. 6 (Newtonian frac fluid) and Fig. 7 (non-Newtonian frac fluid). Also, comparisons of the principal fracture dimensions and effective bottom hole treatment pressure using the in situ stress contrasts in Table I, for the ELLIP2D, HYFRAC3D, and ERATE2D simulators, are given in Tables II and III. Considering the width profile assumptions inherent in these models, the relatively large deviations in the fracture length responses are reasonable. The ELLIP2D and ERATE2D models, for simplicity, assume an elliptical width profile with a uniform pressure (Appendix B) and two term width as well as pressure approximation (Appendix C), respectively. On the other hand, the HYFRAC3D finite element model response representation is general [6]. 


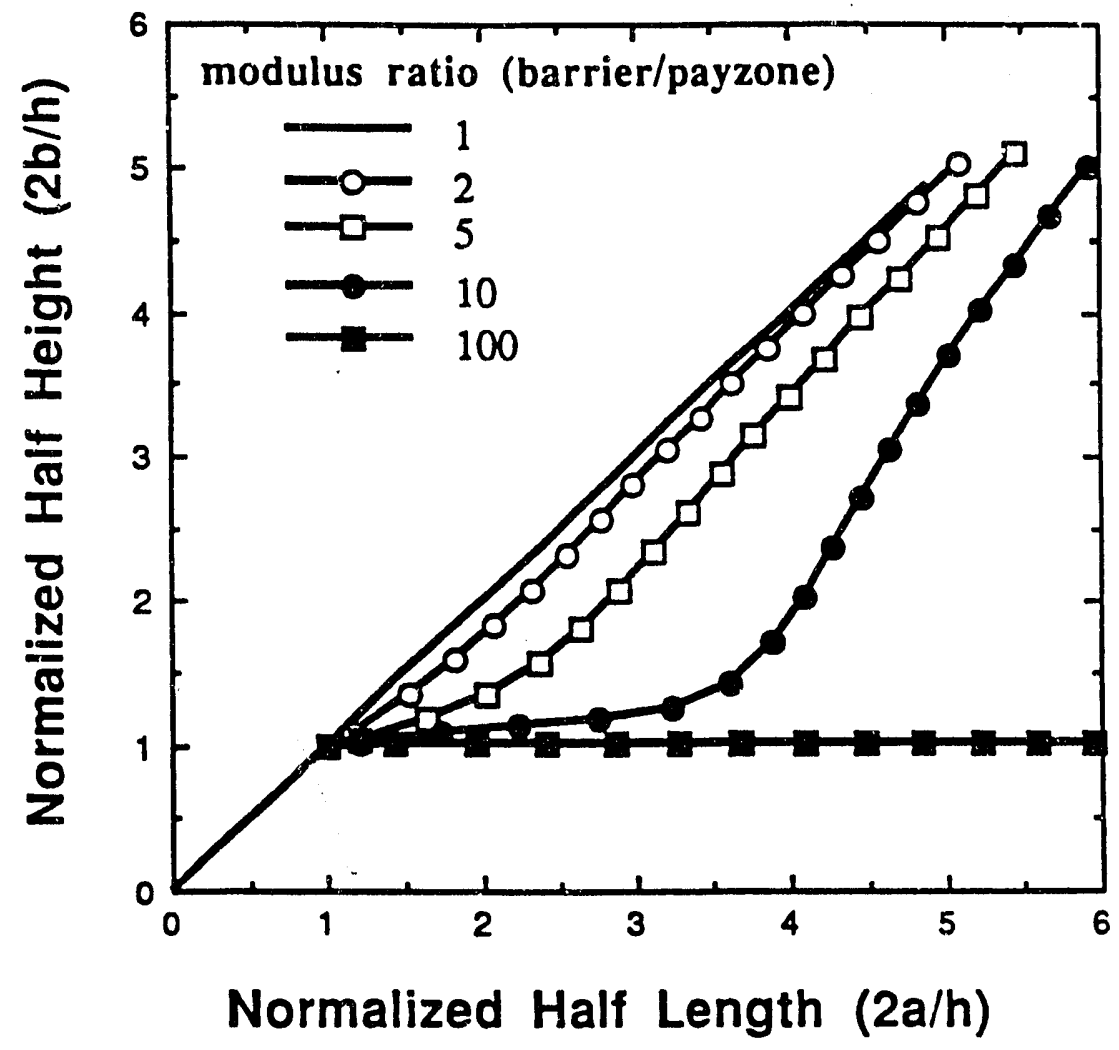

Fig. 3 Effects of Reservoir Elastic Modulus Contrasts for a Three-Layered Symmetric Model 


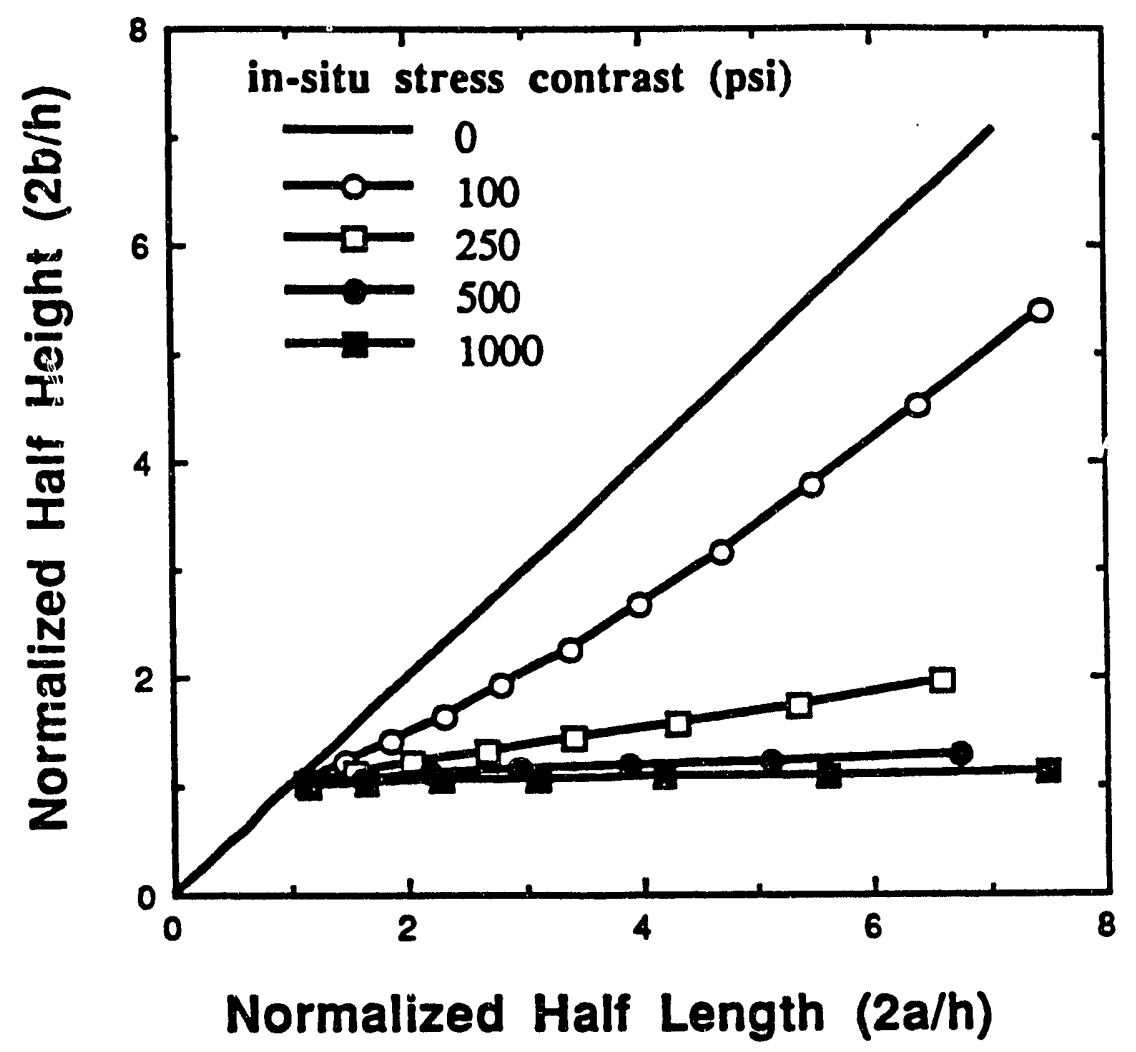

Fig. 4 Effects of Reservoir In-ritu Stress Contrasts for a Three-Layered Symmetric Model 


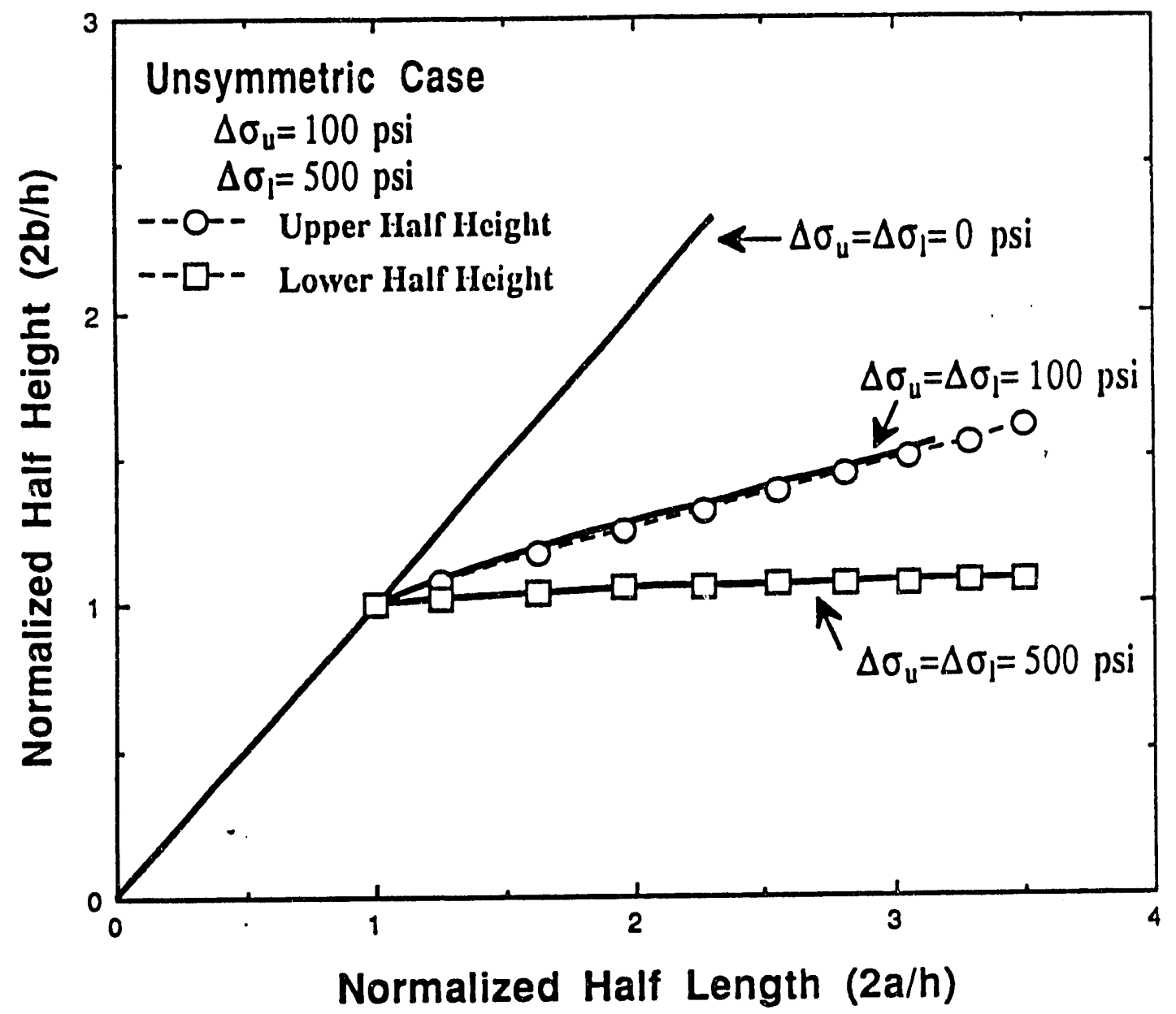

Fig. 5 Effects of Reservoir In-situ Stress Contrasts for a Three-Layered Unsymmetric Model 
Table I Input data for SFE No.3 Cases 5 and 6

\begin{tabular}{|c|c|c|}
\hline & \multicolumn{2}{|c|}{ Case 5 and Case 6} \\
\hline $\begin{array}{l}\text { Formation Properties } \\
\text { Shear modulus (GPa) } \\
\text { Poisson's ratio } \\
\text { In situ stress (MPa) } \\
\text { Energy release rate ( } \mathrm{Pa}-\mathrm{m} \text { ) } \\
\text { Payzone height (m) }\end{array}$ & \multicolumn{2}{|c|}{$\begin{array}{c}\text { Upper/Payzone/Lower } \\
24.218 / 24.218 / 24.218 \\
0.21 / 0.21 / 0.21 \\
49.299 / 39.302 / 50.678 \\
78.78 / 78.78 / 78.78 \\
51.51 \text { (170ft) }\end{array}$} \\
\hline \multirow[b]{2}{*}{$\begin{array}{l}\text { Fluid Properties } \\
\text { Consistency index }\left(\mathrm{Pa}-\mathrm{min}^{\mathrm{m}}\right) \\
\text { Behavior index, } \mathrm{m} \\
\text { Leak-off coefficient }(\mathrm{m} / \sqrt{\min }) \\
\text { Spurt loss }(\mathrm{m})\end{array}$} & Case 5 & Case 6 \\
\hline & $\begin{array}{l}3.333 \times 10^{-3} \\
1.0 \\
0.76 \times 10^{-4} \\
0.0\end{array}$ & $\begin{array}{l}0.37089 \\
0.5 \\
0.76 \times 10^{-4} \\
0.0\end{array}$ \\
\hline $\begin{array}{l}\text { Injection scheme } \\
\text { Injection rate }\left(\mathrm{m}^{3} / \mathrm{min}\right) \\
\text { Total time (min) }\end{array}$ & \multicolumn{2}{|c|}{$\begin{array}{c}7.9494 \quad(50 \mathrm{BPM}) \\
200^{\circ}\end{array}$} \\
\hline
\end{tabular}

* Benchmark tests for a penny shaped model also use the same input data of the payzone for Case 5 (Newtonian) and Case 6 (Non-Newtonian fluid case). 


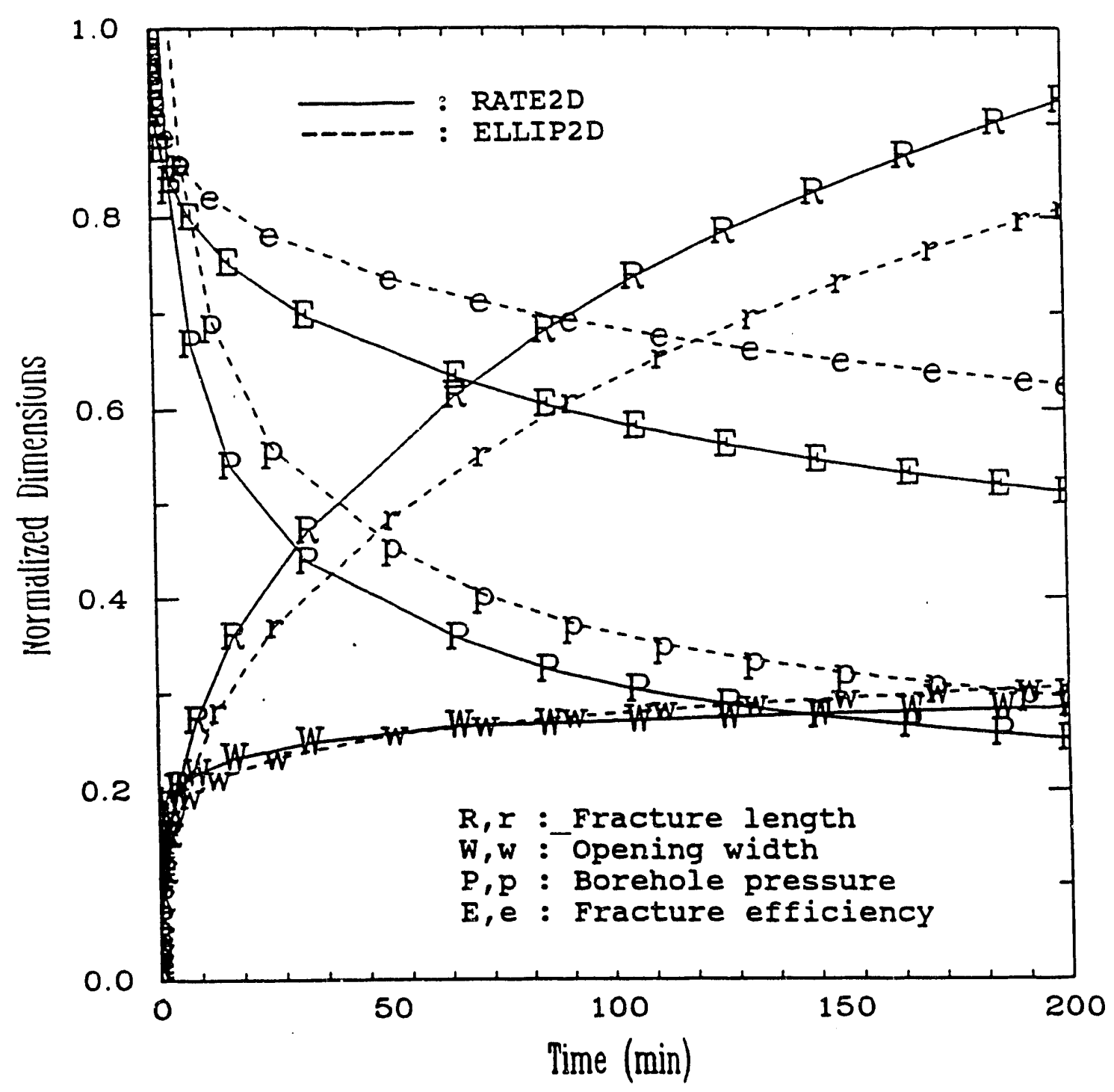

Fig. 6 Comparisons of Principal Fracture Responses for a Penny-Shaped Model by ELLIP2D and ERATE2D (SFE No.3 Case 5 with normalizing dimensions: $\mathrm{R}_{*}=1000 \mathrm{ft}, \mathrm{W}_{*}=1$ in, $\mathrm{P}_{*}=500 \mathrm{psi}$ ) 


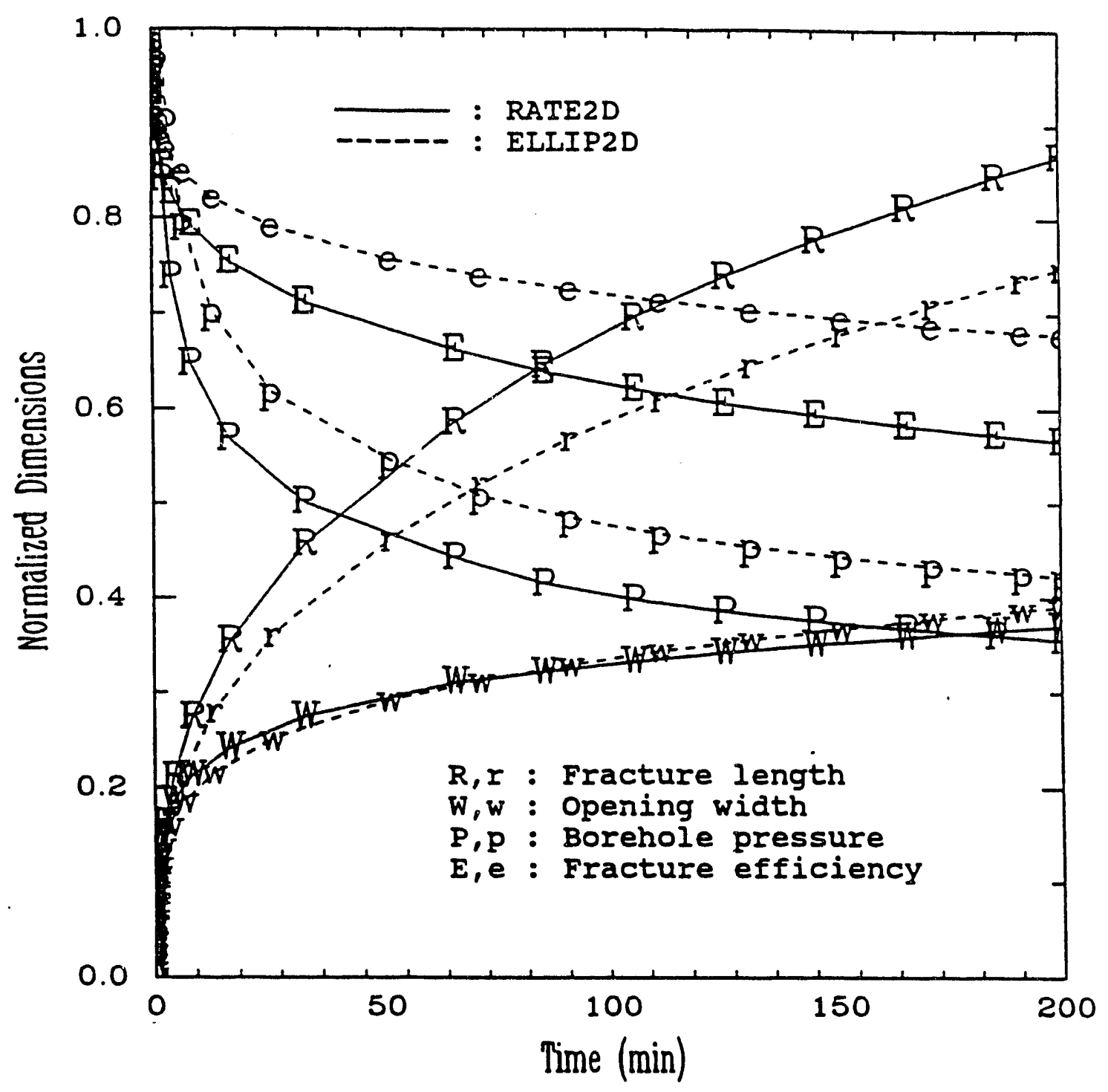

Fig. 7 Comparisons of Principal Fracture Responses for a Penny-Shaped Model by ELLIP2D and ERATE2D (SFE No.3 Case 6 with normalizing dimensions: $R_{*}=1000 \mathrm{ft}, \mathrm{W}_{*}=1$ in, $\mathrm{P}_{*}=500 \mathrm{psi}$ ) 
Table II Fracture Response Comparisons (SFE No. 3 Case 5: Newtonian Fluid)

\begin{tabular}{|c|c|c|c|c|c|c|}
\hline $\begin{array}{c}\text { Time } \\
\text { (min) }\end{array}$ & $t$ & $\begin{array}{l}\text { Half } \\
\text { Length } \\
(a: f t)\end{array}$ & $\begin{array}{c}\text { Frac. } \\
\text { Height } \\
\left(b_{u}: f t\right)\end{array}$ & $\begin{array}{c}\text { Frac. } \\
\text { Height } \\
\left(b_{\ell}: f t\right)\end{array}$ & $\begin{array}{c}\text { Average } \\
\text { Width } \\
\text { (W:in) }\end{array}$ & $\begin{array}{l}\text { Effect. } \\
\text { Pressure } \\
\text { ( } \Delta \mathrm{P}: \text { psi) }\end{array}$ \\
\hline \multirow{2}{*}{25} & $A$ & 865.1 & 143.9 & 136.9 & 0.176 & 889.2 \\
\hline & B & 654.2 & 124.2 & 115.8 & 0.218 & 884.7 \\
\hline \multirow{2}{*}{50} & $\mathrm{~A}$ & 1304.1 & 155.8 & 146.5 & 0.209 & 990.1 \\
\hline & B & 1068.5 & 143.3 & 130.6 & 0.220 & 971.6 \\
\hline \multirow{2}{*}{75} & A & 1661.3 & 163.8 & 152.7 & 0.230 & 1046.8 \\
\hline & B & 1303.0 & 158.0 & 140.5 & 0.245 & 1039.6 \\
\hline \multirow{2}{*}{100} & $\mathrm{~A}$ & 1961.1 & $170 . n$ & 157.4 & 0.245 & 1089.2 \\
\hline & B & 1501.4 & 168.8 & 147.0 & 0.248 & 1047.7 \\
\hline \multirow{2}{*}{125} & $\mathrm{~A}$ & 2225.4 & 175.4 & 161.4 & 0.259 & 1123.9 \\
\hline & B & 1635.1 & 176.7 & 151.0 & 0.265 & 1077.2 \\
\hline \multirow{2}{*}{150} & A & 2462.8 & 180.1 & 165.0 & 0.271 & 1152.7 \\
\hline & B & 1777.7 & 185.2 & 154.6 & 0.265 & 1089.9 \\
\hline \multirow{2}{*}{175} & $A$ & 2677.8 & 184.3 & 168.2 & 0.281 & 1176.2 \\
\hline & B & 1982.5 & 192.7 & 159.4 & 0.238 & 1112.0 \\
\hline \multirow{2}{*}{200} & A & 2879.0 & 188.3 & 171.2 & 0.290 & 1197.0 \\
\hline & B & 2088.9 & 194.9 & 161.7 & 0.250 & 1112.6 \\
\hline
\end{tabular}

$\dagger \quad A:$ ELLIP2D

$B$ : HYFRAC3D 
Table II Fracture Response Comparisons (continued) (SFE No. 3 Case 5: Newtonian Fluid)

\begin{tabular}{|c|c|c|c|c|c|c|}
\hline \multirow{2}{*}{$\begin{array}{c}\text { Time } \\
(\min )\end{array}$} & \multirow{2}{*}{$\star$} & $\begin{array}{l}\text { Half } \\
\text { Length } \\
(a: f t)\end{array}$ & $\begin{array}{c}\text { Frac. } \\
\text { Height } \\
\left(b_{u}: f t\right)\end{array}$ & $\begin{array}{c}\text { Frac. } \\
\text { Height } \\
\left(b_{\ell}: f t\right)\end{array}$ & $\begin{array}{c}\text { Average } \\
\text { width } \\
\text { (w:in) }\end{array}$ & $\begin{array}{l}\text { Effect. } \\
\text { Pressure } \\
\text { ( } \Delta \mathrm{P}: \text { psi) }\end{array}$ \\
\hline & & $\begin{array}{l}\text { Pressure } \\
\text { Response } \\
\operatorname{Var} . \alpha_{\mathrm{p}}\end{array}$ & $\begin{array}{c}\text { Press. } \\
\text { Response } \\
\text { Var. } \alpha_{\mathrm{u}}\end{array}$ & $\begin{array}{c}\text { Press. } \\
\text { Response } \\
\text { Var. } \alpha_{\ell}\end{array}$ & $\begin{array}{c}\text { Max. } \\
\text { width } \\
\left(w_{1}: i n\right)\end{array}$ & $\begin{array}{c}\text { Max. } \\
\text { width } \\
\left(w_{2}: \text { in }\right)\end{array}$ \\
\hline \multirow{2}{*}{25} & \multirow{2}{*}{$C$} & 1039.9 & 145.0 & 138.9 & 0.146 & 626.9 \\
\hline & & 1.602 & $3.1 E-2$ & $2 \cdot 9 E-2$ & 0.017 & 0.335 \\
\hline \multirow{2}{*}{50} & \multirow{2}{*}{$C$} & 1689.0 & 152.2 & 143.9 & 0.164 & 685.2 \\
\hline & & 1.600 & 1. $3 \mathrm{E}-2$ & $1.2 \mathrm{E}-2$ & 0.015 & 0.386 \\
\hline \multirow{2}{*}{75} & \multirow{2}{*}{$C$} & 2232.2 & 155.1 & 147.0 & 0.176 & 722.7 \\
\hline & & 1.595 & $7.7 \mathrm{E}-3$ & $6.9 E-3$ & 0.013 & 0.417 \\
\hline \multirow{2}{*}{100} & \multirow{2}{*}{ C } & 2714.2 & 158.0 & 149.4 & 0.184 & 750.4 \\
\hline & & 1.590 & $5.4 \mathrm{E}-3$ & $4.8 E-3$ & 0.013 & 0.440 \\
\hline \multirow{2}{*}{125} & \multirow{2}{*}{ C } & 3155.1 & 160.4 & 151.2 & 0.191 & 772.5 \\
\hline & & 1.586 & $4 \cdot 1 E-3$ & $3.6 \mathrm{E}-3$ & 0.012 & 0.458 \\
\hline \multirow{2}{*}{150} & \multirow{2}{*}{$C$} & 3563.8 & 162.3 & 152.8 & 0.197 & 790.7 \\
\hline & & 1.582 & $3 \cdot 3 E-3$ & $2.9 E-3$ & 0.011 & 0.473 \\
\hline \multirow{2}{*}{175} & \multirow{2}{*}{ C } & 3948.4 & 164.1 & 154.2 & 0.202 & 806.3 \\
\hline & & 1.578 & $2.7 E-3$ & $2.4 E-3$ & 0.011 & 0.487 \\
\hline \multirow{2}{*}{200} & \multirow{2}{*}{$C$} & 4312.4 & 165.6 & 155.3 & 0.206 & 819.8 \\
\hline & & 1.574 & $2.3 E-3$ & $2 . O E-3$ & 0.010 & 0.498 \\
\hline
\end{tabular}

$\star \quad C:$ ERATE2D 
Table III Fracture Response Comparisons

(SFE No. 3 Case 6: non-Newtonian Fluid)

\begin{tabular}{|c|c|c|c|c|c|c|}
\hline $\begin{array}{l}\text { Time } \\
\text { (min) }\end{array}$ & $t$ & $\begin{array}{l}\text { Half } \\
\text { Length } \\
(a: f t)\end{array}$ & $\begin{array}{c}\text { Frac. } \\
\text { Height } \\
\left(b_{u}: f t\right)\end{array}$ & $\begin{array}{c}\text { Frac. } \\
\text { Height } \\
\left(\mathrm{b}_{\ell}: f t\right)\end{array}$ & $\begin{array}{c}\text { Average } \\
\text { Width } \\
\text { (w:in) }\end{array}$ & $\begin{array}{l}\text { Effect. } \\
\text { Pressure } \\
\text { ( } \Delta \mathrm{P} \text { :psi) }\end{array}$ \\
\hline \multirow{2}{*}{25} & A & 831.5 & 152.1 & 143.8 & 0.174 & 901.5 \\
\hline & B & 904.8 & 131.4 & 117.1 & 0.165 & 854.8 \\
\hline \multirow{2}{*}{50} & A & 1306.4 & 162.5 & 151.8 & 0.199 & 970.4 \\
\hline & B & 1322.8 & 157.1 & 138.7 & 0.191 & 995.1 \\
\hline \multirow{2}{*}{75} & A & 1708.9 & 169.1 & 156.8 & 0.213 & 1005.4 \\
\hline & B & 1615.9 & 169.0 & 146.3 & 0.198 & 1017.4 \\
\hline \multirow{2}{*}{100} & A & 2058.7 & 173.7 & 160.3 & 0.225 & 1032.8 \\
\hline & B & 1789.9 & 178.5 & 150.7 & 0.218 & 1048.2 \\
\hline \multirow{2}{*}{125} & $A$ & 2373.7 & 177.5 & 163.1 & 0.234 & 1055.7 \\
\hline & B & 2017.8 & 196.3 & 164.8 & 0.206 & 1105.6 \\
\hline \multirow{2}{*}{150} & A & 2662.4 & 180.8 & 165.6 & 0.242 & 1074.2 \\
\hline & B & $2188 \quad 2$ & 201.6 & 170.5 & 0.213 & 1104.3 \\
\hline \multirow{2}{*}{175} & $A$ & 2929.6 & 183.7 & 167.7 & 0.250 & 1090.3 \\
\hline & B & 2380.9 & 225.7 & 180.4 & 0.216 & 1142.3 \\
\hline \multirow{2}{*}{200} & $A$ & 3181.0 & 186.3 & 169.7 & 0.256 & 1104.0 \\
\hline & B & 2424.2 & 244.0 & 190.5 & 0.211 & 1170.9 \\
\hline
\end{tabular}

$\dagger \quad A$ : ELIIP2D

$B$ : HYFRAC3D 
Table III Fracture Response Comparisons (continued) (SFE No. 3 Case 6: non-Newtonian Fluid)

\begin{tabular}{|c|c|c|c|c|c|c|}
\hline \multirow{2}{*}{$\begin{array}{c}\text { Time } \\
\text { (min) }\end{array}$} & \multirow{2}{*}{$\star$} & $\begin{array}{l}\text { Half } \\
\text { Length } \\
(a: f t)\end{array}$ & $\begin{array}{c}\text { Frac. } \\
\text { Height } \\
\left(b_{u}: f t\right)\end{array}$ & $\begin{array}{c}\text { Frac. } \\
\text { Height } \\
\left(b_{\ell}: f t\right)\end{array}$ & $\begin{array}{c}\text { Average } \\
\text { width } \\
\text { (w:in) }\end{array}$ & $\begin{array}{l}\text { Effect. } \\
\text { Pressure } \\
(\Delta P: p s i)\end{array}$ \\
\hline & & $\begin{array}{l}\text { Pressure } \\
\text { Response } \\
\operatorname{Var} \cdot \alpha_{p}\end{array}$ & $\begin{array}{c}\text { Press. } \\
\text { Response } \\
\text { Var. } \alpha_{\mathrm{u}}\end{array}$ & $\begin{array}{l}\text { Press. } \\
\text { Response } \\
\text { Var. } \alpha_{\ell} \\
\end{array}$ & $\begin{array}{c}\text { Max. } \\
\text { width } \\
\left(w_{1}: i n\right)\end{array}$ & $\begin{array}{c}\text { Max. } \\
\text { width } \\
\left(w_{2}: i n\right)\end{array}$ \\
\hline \multirow{2}{*}{25} & \multirow{2}{*}{ C } & 1030.1 & 144.7 & 138.6 & 0.147 & 633.5 \\
\hline & & 1.600 & $5.5 E-2$ & 5. OE-2 & 0.017 & 0.338 \\
\hline \multirow{2}{*}{50} & \multirow{2}{*}{ C } & 1608.9 & 153.1 & 145.5 & 0.171 & 711.2 \\
\hline & & 1.596 & $2.6 E-2$ & $2.4 E-2$ & 0.014 & 0.403 \\
\hline \multirow{2}{*}{75} & \multirow{2}{*}{ C } & 2079.2 & 158.5 & 149.8 & 0.186 & 761.3 \\
\hline & & 1.588 & $1.7 \mathrm{E}-2$ & $1.5 E-2$ & 0.012 & 0.446 \\
\hline \multirow{2}{*}{100} & \multirow{2}{*}{$C$} & 2487.9 & 162.6 & 153.1 & 0.198 & 798.5 \\
\hline & & 1.580 & 1. $3 \mathrm{E}-2$ & 1. $1 \mathrm{E}-2$ & 0.011 & 0.477 \\
\hline \multirow{2}{*}{125} & \multirow{2}{*}{$\cdot c$} & 2855.5 & 166.0 & 155.7 & 0.208 & 828.2 \\
\hline & & 1.573 & 1. OE-2 & $9.0 E-3$ & 0.011 & 0.502 \\
\hline \multirow{2}{*}{150} & \multirow{2}{*}{ C } & 3193.5 & 169.0 & 158.0 & 0.216 & 852.9 \\
\hline & & 1.566 & $8.4 E-3$ & $7.4 \mathrm{E}-3$ & 0.010 & 0.524 \\
\hline \multirow{2}{*}{175} & \multirow{2}{*}{ C } & 3507.2 & 171.6 & 160.0 & 0.223 & 874.1 \\
\hline & & 1.560 & $7.2 E-3$ & $6.3 E-3$ & 0.010 & 0.542 \\
\hline \multirow{2}{*}{200} & \multirow{2}{*}{ C } & 3802.2 & 173.9 & 161.7 & 0.230 & 892.6 \\
\hline & & 1.554 & $6.3 E-3$ & $5.4 E-3$ & 0.009 & 0.559 \\
\hline
\end{tabular}

* C : erate2D 


\section{$2.4 \quad$ Fracture Design Diagnostic Measures}

The energy-rate formulations, detailed in Appendix C, provide the underpinnings for deriving applicable energy-rate (power) balance laws. The instantaneous individual energy rate components derived from the input hydraulic power are useful fracture design diagnostic measures. The fracture fluid and reservoir control volumes are considered separately in the energy balance and the overall process energy rate conservation law is derived by eliminating the crack pressure reservoir wall velocity coupling term.

The energy-rate components from the fracture fluid control volume energy rate principle can be rewritten, after neglecting the body force contribution in the form:

where

$$
D_{I}=D_{f}+D_{L}+D_{\eta}
$$

$$
\begin{aligned}
& \mathrm{D}_{\mathrm{I}}=\int_{\partial \mathrm{A}_{\mathrm{q}}} \mathrm{pq}_{\mathrm{n}} \mathrm{ds} \\
& \mathrm{D}_{\mathrm{f}}=\int_{\mathrm{A}}^{\mathrm{pw} \mathrm{dA}} \\
& \mathrm{D}_{\mathrm{L}}=\int_{\mathrm{A}}^{\mathrm{pq}} \mathrm{L} \mathrm{dA}, \text { and } \\
& \mathrm{D}_{\eta}=-\int_{\mathrm{A}} \mathrm{g} \cdot(\mathrm{\nabla p}-\mathrm{f}) \mathrm{dA}
\end{aligned}
$$

The total power input $\left(D_{I}\right)$ derived from the pressurized injection of the treatment fluid is the sum of the energy rate components associated with the formation opening due to the fluid pressure distribution $\left(D_{\mathrm{f}}\right)$, power loss due to fluid leak-off into the formations $\left(D_{L}\right)$, and fracturing fluid dissipation $\left(D_{\eta}\right)$.

The power component due to the fluid pressure induced fracture opening $\left(D_{f}\right)$, transmitted by the crack surface, is further transformed into the instantaneous change of strain energy component $\left(\frac{d}{d t} \mathrm{U}_{s}^{*}\right)$ and the fracture surface energy rate $\left(U_{f}\right)$ expended for the crack propagation. Therefore the reservoir energy rate conservation principle governing the formation structural responses is given by

$$
D_{f}=\frac{d}{d t} U_{s}^{*}+U_{f}
$$

where the fracture energy rate is

$$
\tilde{U}_{\mathrm{f}}=\frac{\mathrm{d}}{\mathrm{dt}} \int_{A} G_{c r} d A
$$


and the total strain energy rate can be rewritten as

$$
\begin{aligned}
\frac{d}{d t} U_{s}^{*} & =\frac{d}{d t}\left\{\int_{A} \frac{1}{2} w_{A}[w] d A+\int_{A} \sigma_{0}(x) w d A\right\} \\
& =\int_{A} \dot{w K}_{A}[w] d A+\int_{A} \sigma_{0}(x) \dot{w} d A-\int_{\partial A} G \dot{a}_{n} d s \\
& =U_{s}+\dot{U}_{\Gamma}+\dot{U}_{\sigma}^{*}
\end{aligned}
$$

The work rate term due to the in-situ stress can be decomposed into the payzone in - situ stress and its contrasts i.e.

$$
\begin{gathered}
\tilde{U}_{\sigma}^{*} \equiv \int_{\mathrm{A}} \sigma_{0}(\mathrm{x}) \dot{\mathrm{w}} \mathrm{dA}=\sigma_{\mathrm{op}} \int_{\mathrm{A}} \dot{\mathrm{w}} \mathrm{dA}+\Sigma \int_{\mathrm{A}_{\mathrm{j}}} \Delta \sigma_{0}(\mathrm{x}) \dot{\mathrm{w}} \mathrm{dA} \\
\equiv \mathrm{U}_{\sigma}+\hat{U}_{\Delta \sigma}
\end{gathered}
$$

We note that $\mathcal{U}_{\sigma}$ and $U_{\Delta \sigma}$ are the energy rate components associated with the payzone minimum in situ stress and stress differentials in the barriers, respectively.

The total input power balance equation, obtained by combining Eqs. (1) and $(2)$, is

$$
\mathrm{D}_{\mathrm{I}}=\hat{U}_{\mathrm{s}}+\hat{U}_{\mathrm{\Gamma}}+\hat{U}_{\sigma}+\hat{U}_{\Delta \sigma}+\hat{U}_{\mathrm{f}}+\mathrm{D}_{\eta}+\mathrm{D}_{\mathrm{L}}
$$

The energy rate due to the leak-off term can be divided into two components, comprising of the borehole effective pressure and the minimum in situ stress terms as follows:

$$
\begin{gathered}
\mathrm{D}_{\mathrm{L}} \equiv \int_{\mathrm{A}} \mathrm{p}(\mathrm{x}) \mathrm{q}_{\mathrm{L}}(\mathrm{x}) \mathrm{dA}=\int_{\mathrm{A}} \Delta \mathrm{p}(\mathrm{x}) \mathrm{q}_{\mathrm{L}}(\mathrm{x}) \mathrm{dA}+\sigma_{\mathrm{op}} \int_{\mathrm{A}} \mathrm{q}_{\mathrm{L}}(\mathrm{x}) \mathrm{dA} \\
\equiv \mathrm{D}_{\mathrm{L} 1}+\mathrm{D}_{\mathrm{L} 2}
\end{gathered}
$$

Similarly, the total input power can be also expressed in the form

$$
\begin{gathered}
D_{I} \equiv \int_{\partial A_{q}} p q_{n} d s=P_{0} i_{0}+\sigma_{o p} i_{0} \\
\equiv D_{\text {Ieff }}+D_{I 2}
\end{gathered}
$$

where $\mathrm{D}_{\text {Ieff }}=\mathrm{P}_{0} \mathrm{i}_{\mathrm{o}}$ represents the power available for transformation into other forms of energy rate during the fracturing stimulation and $D_{I 2}=\sigma_{0 p} i_{0}$ denotes the base line power required to negate payzone in situ stress effects.

Therefore the total input power can be expressed in terms of six power components in the form

$$
D_{I}=\left\{\frac{d}{d t} U_{s 1}+\frac{d}{d t} U_{s 2}\right\}+U_{f}+D_{\eta}+D_{L 1}+D_{L 2}
$$

where $\frac{d}{d t} U_{s 1}=\hat{U}_{s}+U_{\Gamma}+U_{\Delta \sigma}$ and $\frac{d}{d t} U_{s 2}=U_{\sigma}$. 
Normalization of Eq. (6) with respect to $D_{I}$ provides a useful basis for assessing pertinent energy rate components

$$
\frac{\frac{d}{d t} U_{s 1}+\frac{d}{d t} U_{s 2}}{D_{I}}+\frac{U_{f}}{D_{I}}+\frac{D_{\eta}}{D_{I}}+\frac{D_{L 1}}{D_{I}}+\frac{D_{L 2}}{D_{I}}=1
$$

Eq. 7 expresses the relative energy-rate expenditures associated with the hydraulic fracture process mechanisms at a particular time instant. This equation includes the power components associated with the reservoir in situ stress which can be considered as a baseline term and can be isolated through the equation

or alternatively

$$
\sigma_{o p} i_{0}=\sigma_{o p} \int_{A} \dot{w} \mathrm{dA}+\sigma_{o p} \int_{A} q_{L}(x) d A
$$

$$
\mathrm{D}_{\mathrm{I} 2}=\frac{\mathrm{d}}{\mathrm{dt}} \mathrm{O}_{\mathrm{s} 2}+\mathrm{D}_{\mathrm{L} 2}
$$

Eq. 8 is equivalent to the fracture fluid mass conservation equation multiplied by the payzone in situ stress.

The available effective power relation can be simplified in the form

$$
\mathrm{D}_{\text {Ieff }}=\frac{\mathrm{d}}{\mathrm{dt}} \mathrm{U}_{\mathrm{s} 1}+\mathrm{U}_{\mathrm{f}}+\mathrm{D}_{\eta}+\mathrm{D}_{\mathrm{L} 1}
$$

Eq. 9 can now be normalized with respect to the available effective power, $D_{\text {Ieff }}$ to give

$$
\frac{\frac{d}{t} U_{s 1}}{D_{\text {Ieff }}}+\frac{U_{f}}{D_{\text {Ieff }}}+\frac{D_{\eta}}{D_{\text {Ieff }}}+\frac{D_{L 1}}{D_{\text {I eff }}}=1
$$

Eq. 10 expresses the available effective energy-rate expenditures for fracture propagation, opening, as well as fracture fluid related losses at a time instant. Since each component in eq. 10 is directly related to the fracture process parameters and variables, the time history of each component demonstrates the efficacy of energy rate transfer from the bottom hole treatment effective pressure cum injection flow rate source.

In addition to the energy-rate considerations and related transfer-efficiencies, the optimum generation of fracture surface areas and/or volumes in the payzone layer for multi-layered reservoirs is a vital design consideration. Accordingly, we define the normalized effective fracture area $\left(A_{\text {eff }}^{*}\right)$ and normalized effective fracture volume $\left(\mathrm{V}_{\text {eff }}^{*}\right)$ within the payzone as follows [3]: 


$$
\begin{aligned}
& A_{\text {eff }}^{*} \equiv(A)_{\text {payzone }} / H^{2} \\
& =\underset{j}{\sum}\left[\frac{\pi}{2} a b_{j}-a b_{j} \sin ^{-1}\left\{1-\left(\xi_{j}\right)^{2}\right\}^{1 / 2}+\underset{j}{h_{j} / b_{j}}\left\{1-\left(\xi_{j}\right)^{2}\right\}^{2 / 1}\right] / H^{2} \\
& \text { for } j=u, l
\end{aligned}
$$

and

$$
\begin{aligned}
& \mathrm{V}_{\text {eff }}^{*} \equiv\left(\mathrm{V}_{\mathrm{F}}\right)_{\text {payzone }} / \mathrm{V}_{\mathrm{I}} \\
& =\sum_{\mathrm{j}}\left[\frac{\pi}{3} a b_{j} \mathrm{~W}_{1}\left\{1-\mathrm{R}_{1}\left(\xi_{\mathrm{j}}\right)\right\}+\frac{\pi}{5} a b_{j} \mathrm{~W}_{2}\left\{1-\mathrm{R}_{2}\left(\xi_{\mathrm{j}}\right)\right\}\right] /\left(\mathrm{i}_{\mathrm{o}} t\right) \\
& \text { for } \mathrm{j}=\mathrm{u}, 1
\end{aligned}
$$

where $\xi_{j}=h_{j} / b_{j}, R_{1}$ and $R_{2}$ represent the ratios of integrals for barrier area to the integrals for the payzone area with the integrands given by $\left(1-\rho^{2}\right)^{1 / 2}$ and $\left(1-\rho^{2}\right)^{2 / 3}$, respectively. The evaluation of pertinent energy-rate, effective fracture area, and fracture volume efficiencies from an integrated systems viewpoint are essential elements in the hydraulic fracturing design process. Numerical experiments on the role of the fracture fluid controllable variables and perforation placement on these design metrics are essential steps towards the optimization and control of fracture configuration evolution.

\subsection{Evaluation of Energy-Rate Components: Penny-Shaped Fracture Benchmarking}

The asymptotic responses for a penny-shaped fracture, in the absence of leak-off, can be obtained from the closed form time explicit solutions presented in Appendix C. The dissipation energy dominant regime solution $\left(\mathrm{G}_{\mathrm{Cr}}=0\right)$ yields the ratio

$$
D_{\eta} / \frac{d}{d t} U_{s 1}=\frac{10+7 m}{4}
$$

where $m$ is the flow behavior index. The ratio in [13] is maximum when the fluid is Newtonian $(m=1)$, with a value of 4.25 . Therefore the percentages of $D_{\eta}$ and $\frac{d}{d t} U_{s 1}$ with respect to the effective input power $\left(D_{\text {Ieff }}\right)$ for this case are $81 \%$ and $19 \%$, respectively.

When the dissipation energy is negligible $\left(\eta_{0}=0\right)$, the solutions yield the energy ratio

$$
\mathrm{U}_{\mathrm{f}} / \frac{\mathrm{d}}{\mathrm{dt}} \mathrm{U}_{\mathrm{s} 1}=3 / 2
$$


This result reveals the percentages of $\frac{d}{d t} U_{f}$ and $\frac{d}{d t} U_{s 1}$ with respect to the effective input power $\left(D_{\text {Ieff }}\right)$ for this case are approximately $60 \%$ and $40 \%$, respectively.

Fig. 8 illustrates the asymptotic no-leak off power conservation responses depicted by Eqs. $13(\mathrm{~m}=1)$ and 14. The baseline and available effective energy-rate responses for the benchmark SFE3 case in Table I, in the absence of in situ stress contrasts, are plotted in Fig. 9a with the available effective power responses highlighted in Fig. 9b. These responses are obviously dissipation dominant since the fracture energy component is negligible and the relatively small leak-off component leads to a large fracture volume efficiency. Figs. 10 and 11 reveal the trade-offs in the energy-rate components due to different fracture fluid viscosities and leak-off coefficients, respectively. Minimization of leak-off and pressure gradient energy rate dissipation can be controlled by the judicious selection of the fracture fluid slurry.

\subsection{Hydraulic Fracture Design Evaluations in Three-Layered Reservoirs}

Numerical experiments detailing the fracture design diagnostic measures are presented here for variations in the controllable variables (frac fluid rheological properties, injection flnw rate, fluid leak-off coefficients, and perioration placement) specified in the three-layered SFE3 model data (Table I). These evaluations facilitate the development of hydraulic fracture design guidelines.

Table IV lists the input data for 13 cases (cases $a-m$ ), using the three-layered SFE3 model data in Table I. The hydraulic fracture dimensions, effective pressure, fracture efficiency, effective area efficiency, and effective volume efficiency responses are summarized in Table V. Figs. 12, 13, and 14 illustrate plots of the fracture efficiency, effective area efficiency, and effective volume efficiency, respectively for cases $(\mathrm{a}-\mathrm{g})$. Although the perforation placement has a negligible effect on the fracture efficiency (Fig. 12, cases a-c), the effective fracture area and volume efficiencies are significantly influenced $b_{j}$ the perforation source. An increased injection rate for case $d\left(i=2 i_{0}\right.$ with $j_{0}=50$ BPM) apparently yields a better fracture efficiency than case $e\left(i=i_{0} / 2\right)$ with a higher borehole effective pressure. However, this increased injection rate in case $d$ yields a lower normalized effective area and higher normal effectirs volume than in case e. This is an obvious result of less containment in the payzone and a higher fracture width for the increased injection flow rate case. The fluid leak-off coefficient is 


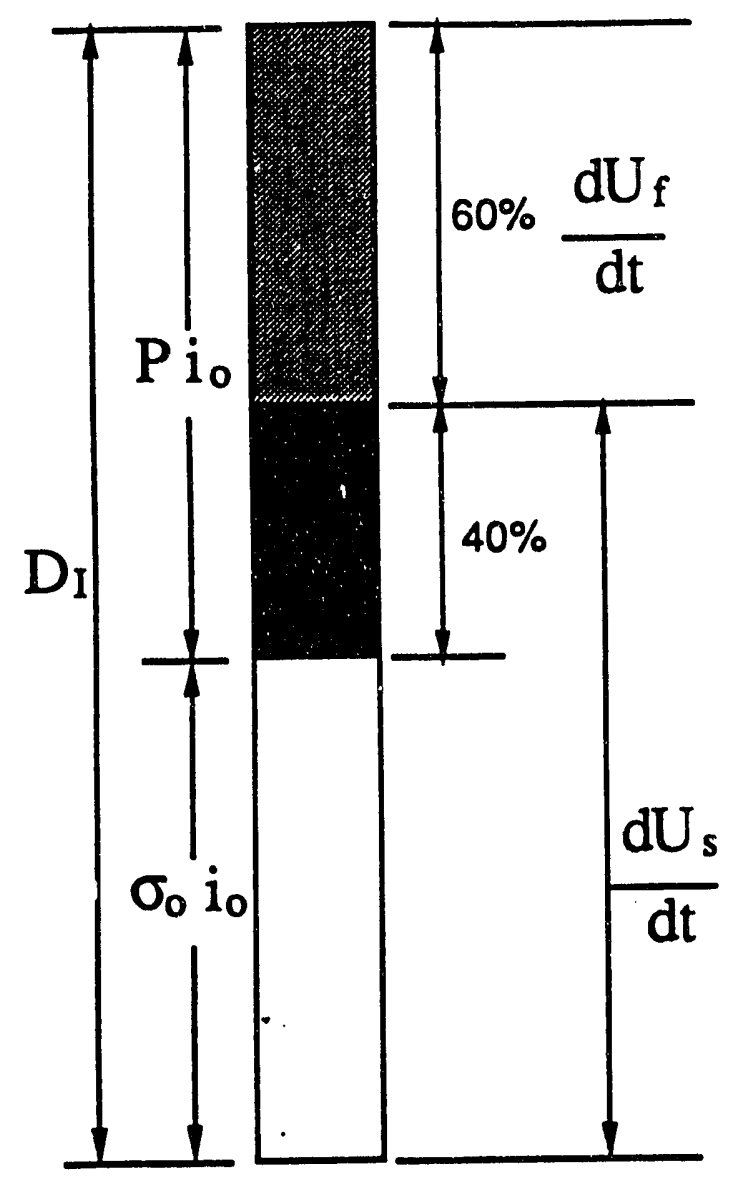

FRACTURE ENERGY DOMINANT REGIME

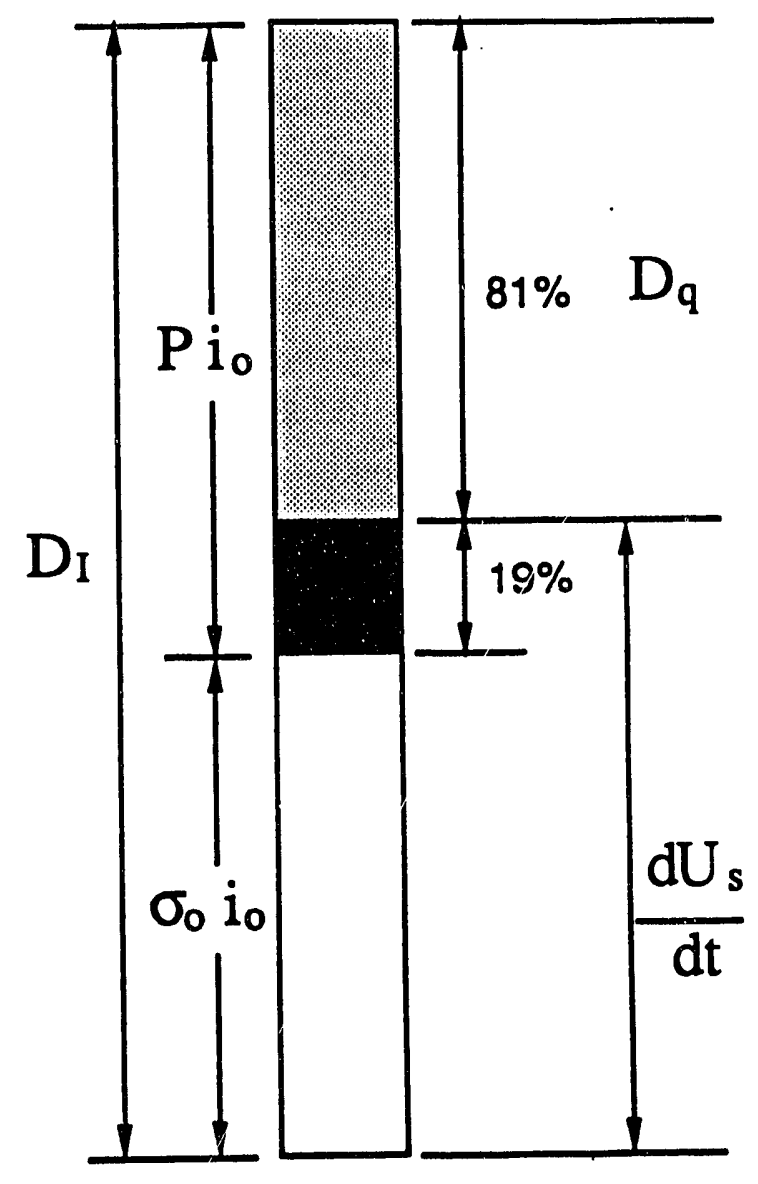

DISSIPATION ENERGY DOMINANT REGIME

Fig. 8 Asymptotic Power Conservation Responses for a Penny-shaped Model without Leak-off 


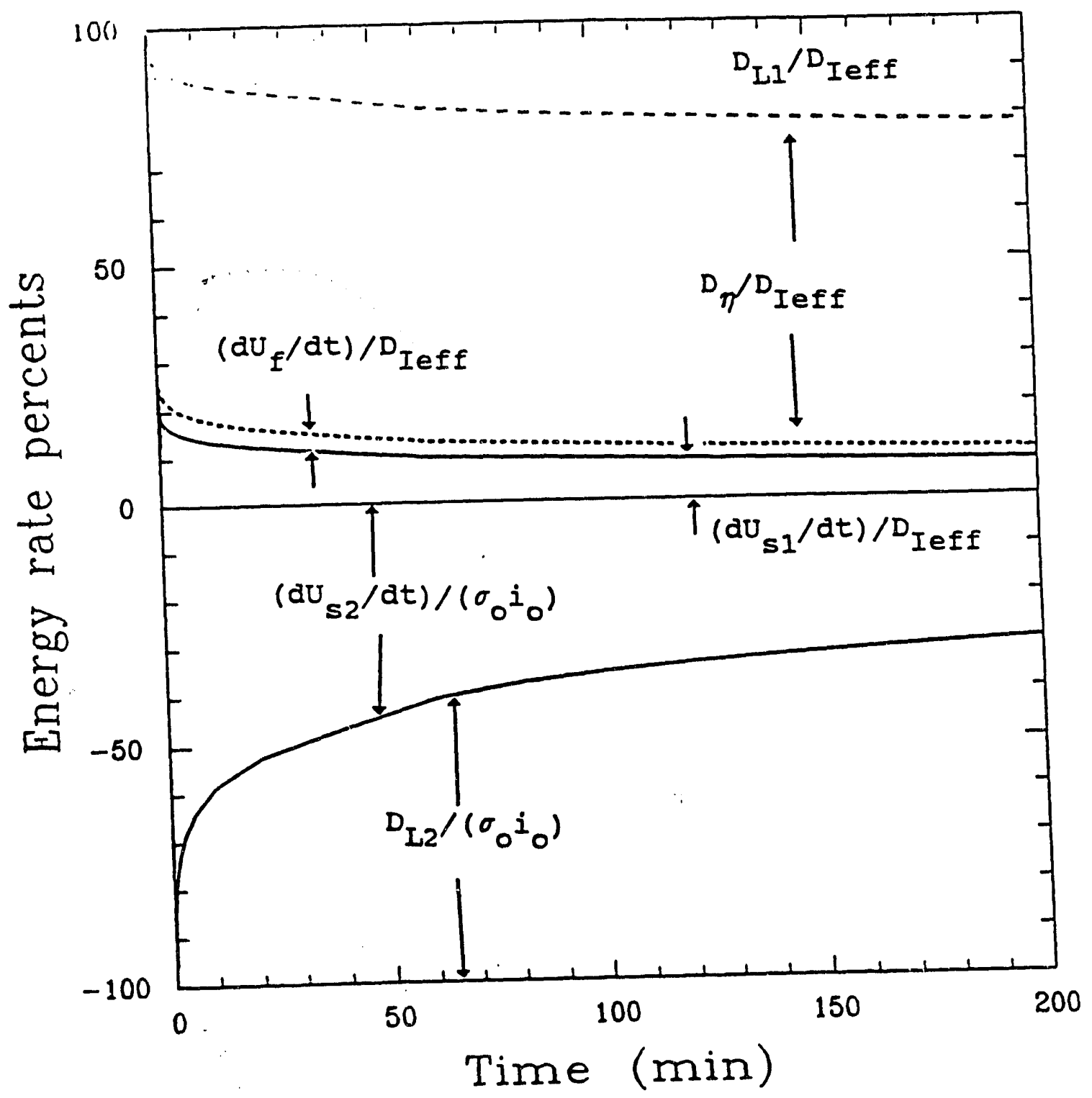

Fig. 9a Báse Line and Available Energy Rate Component Evolution for a Penny-shaped Benchmark Model Corresponding to SFE No. 3 Case 5 


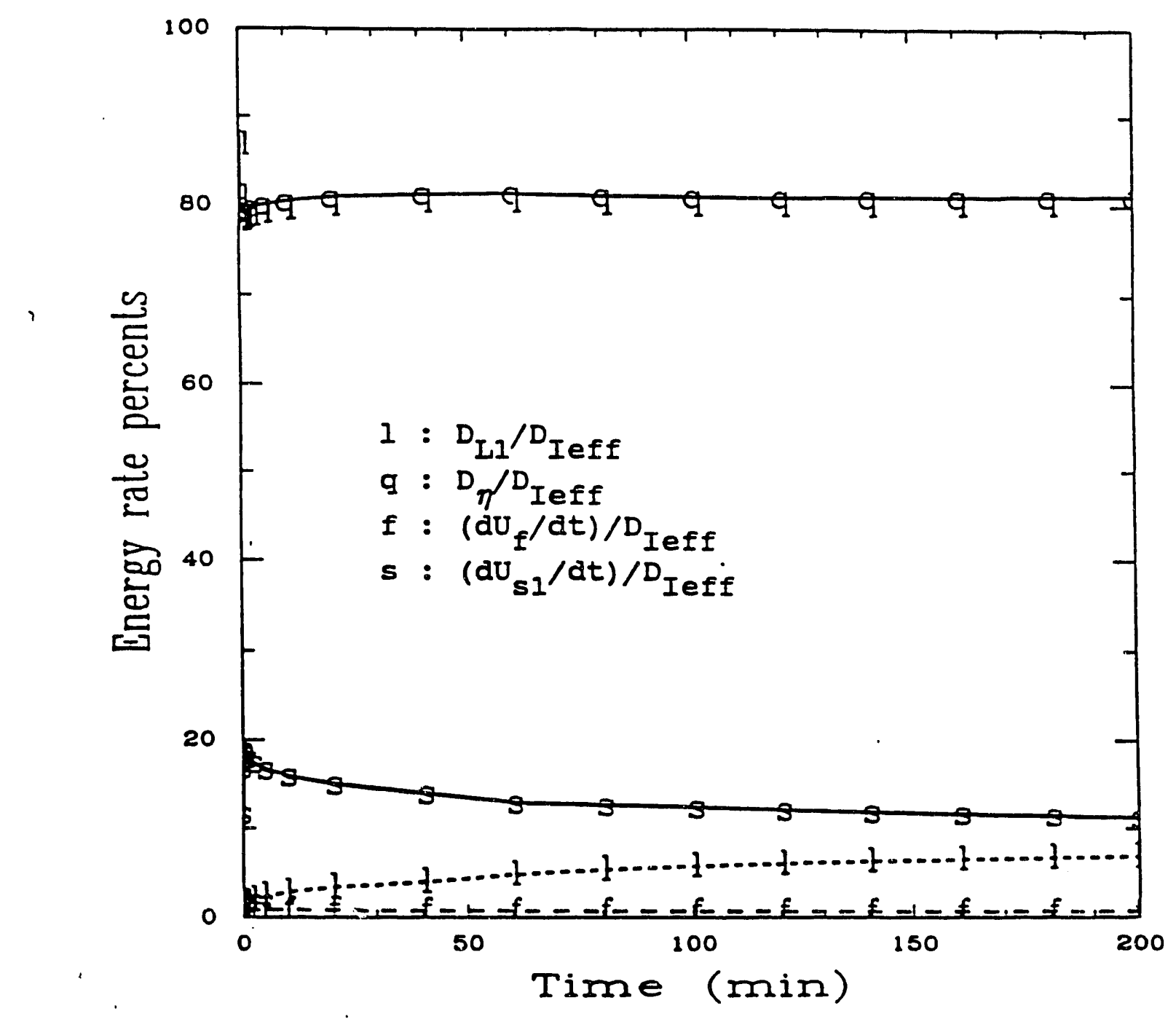

Fig. 9b Effective Energy Rate Component Time Evolution for a Penny-shaped Benchmark Model Corresponding to SFE No. 3 Case 5 


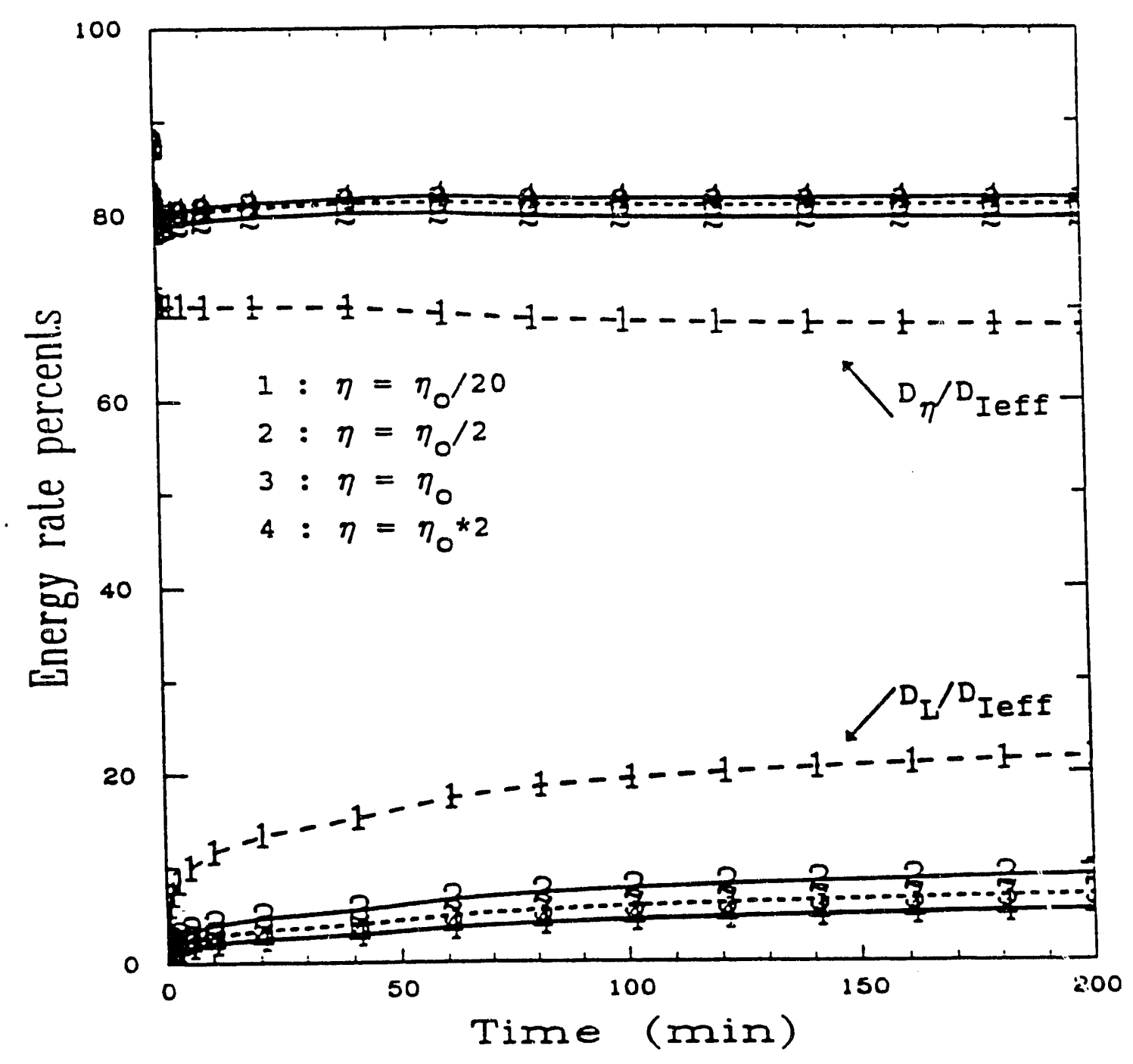

Fig. 10 Effective Energy Rate Component Changes due to Fluid Viscosity Variation (Penny-shaped Benchmark Model for SFE No. 3 Case 5) 


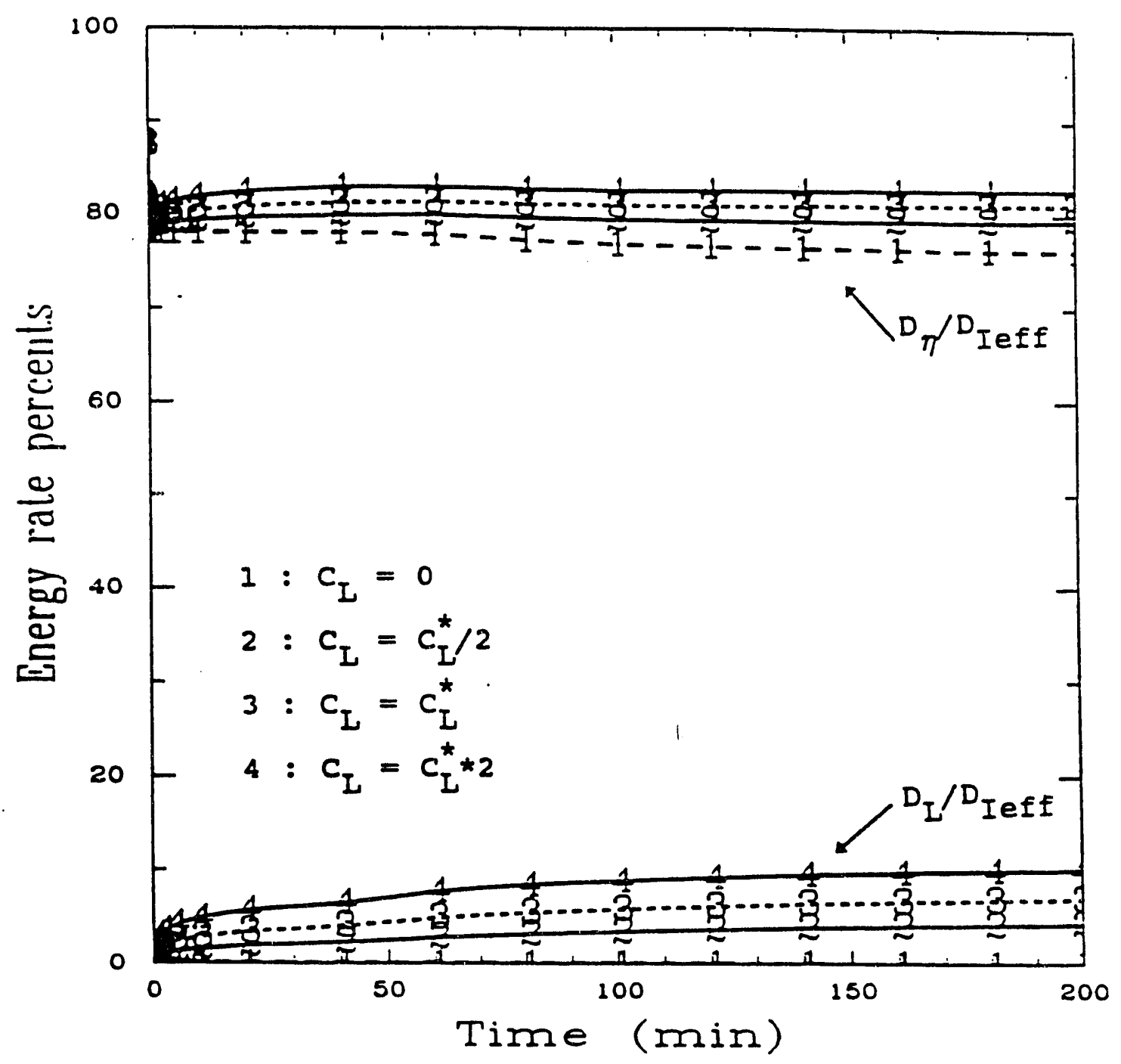

Fig. 11 Effective Energy Rate Component Changes due to Fluid Leak-off Variation (Penny-shaped Benchmark Model for SFE No. 3 Case 5) 


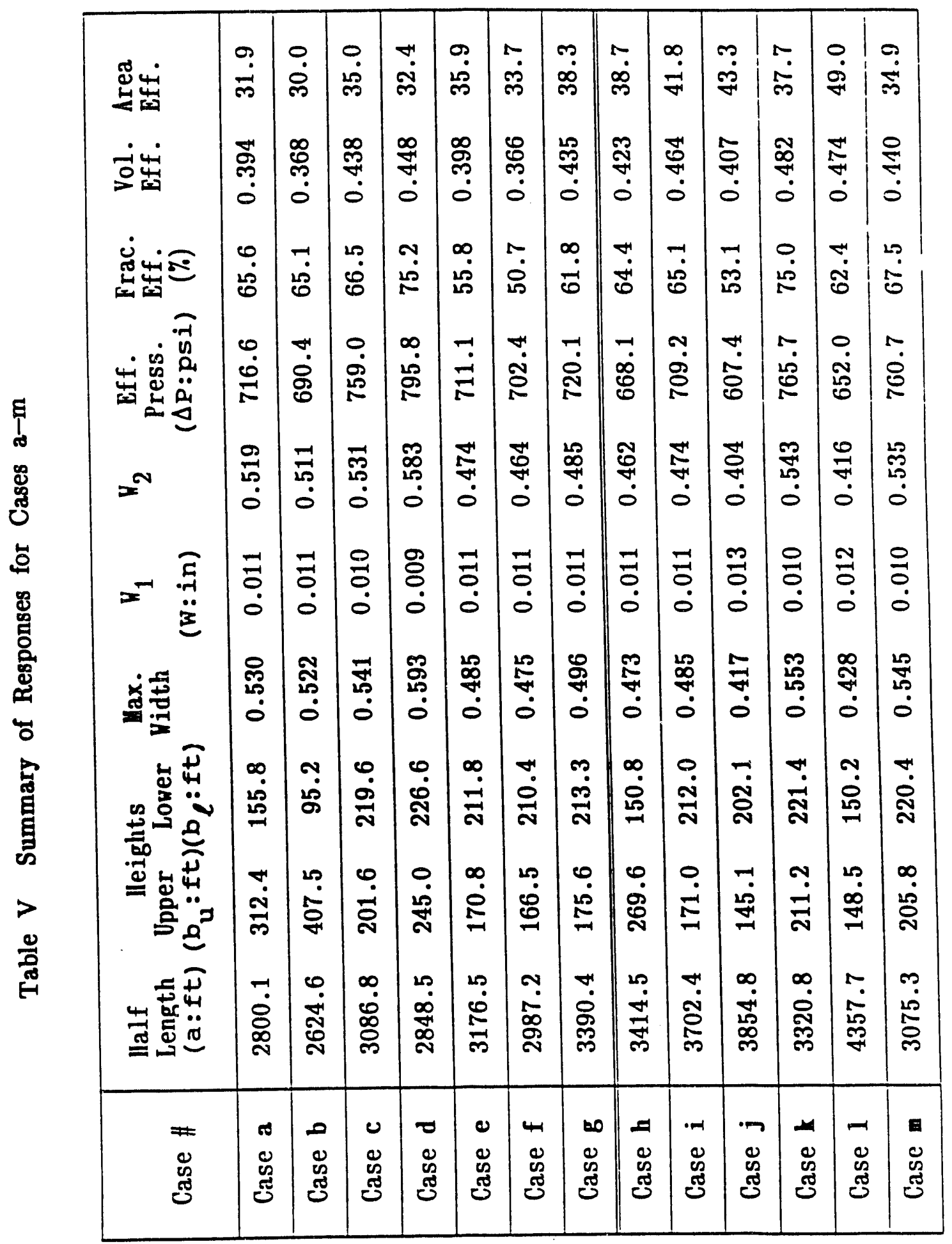




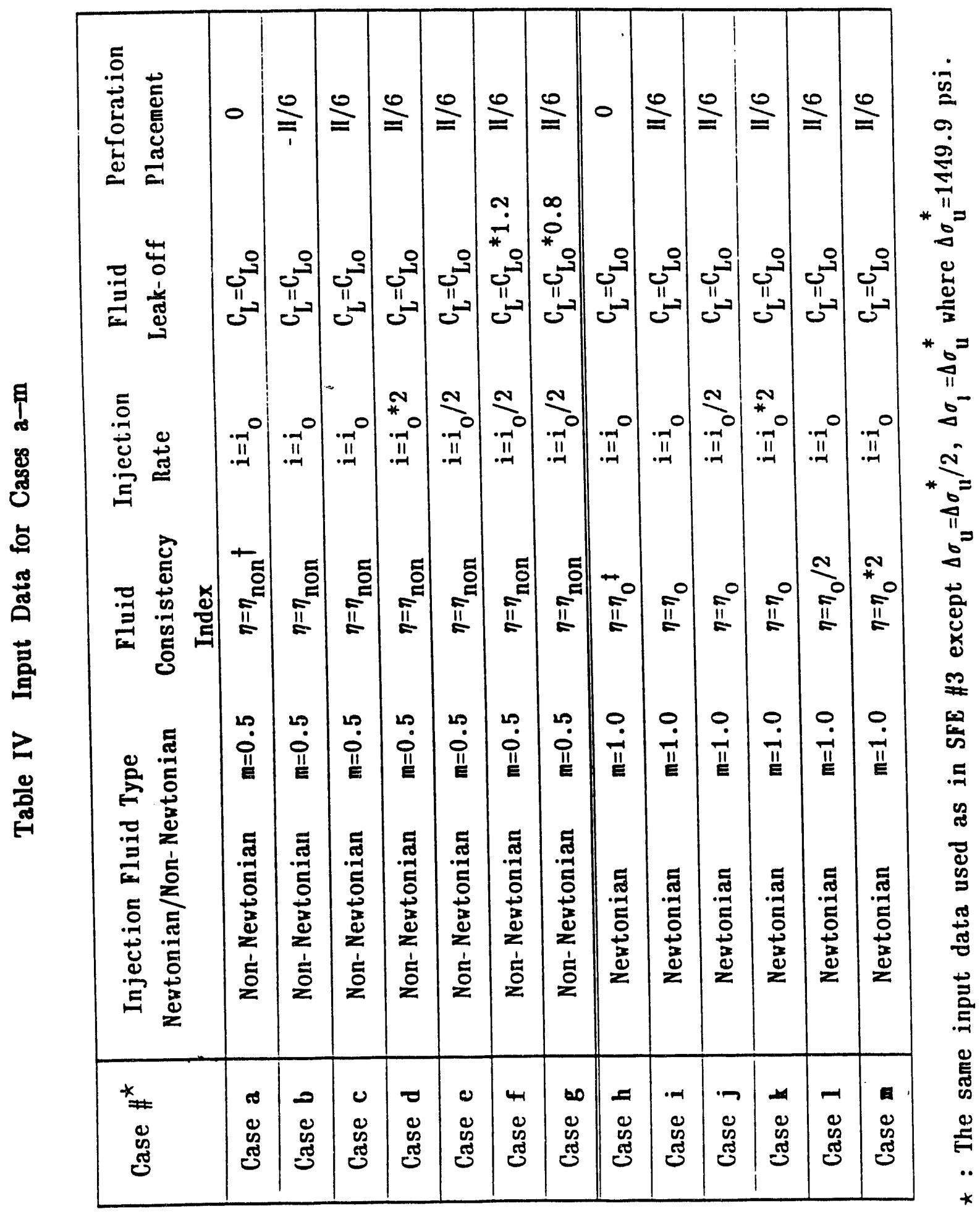




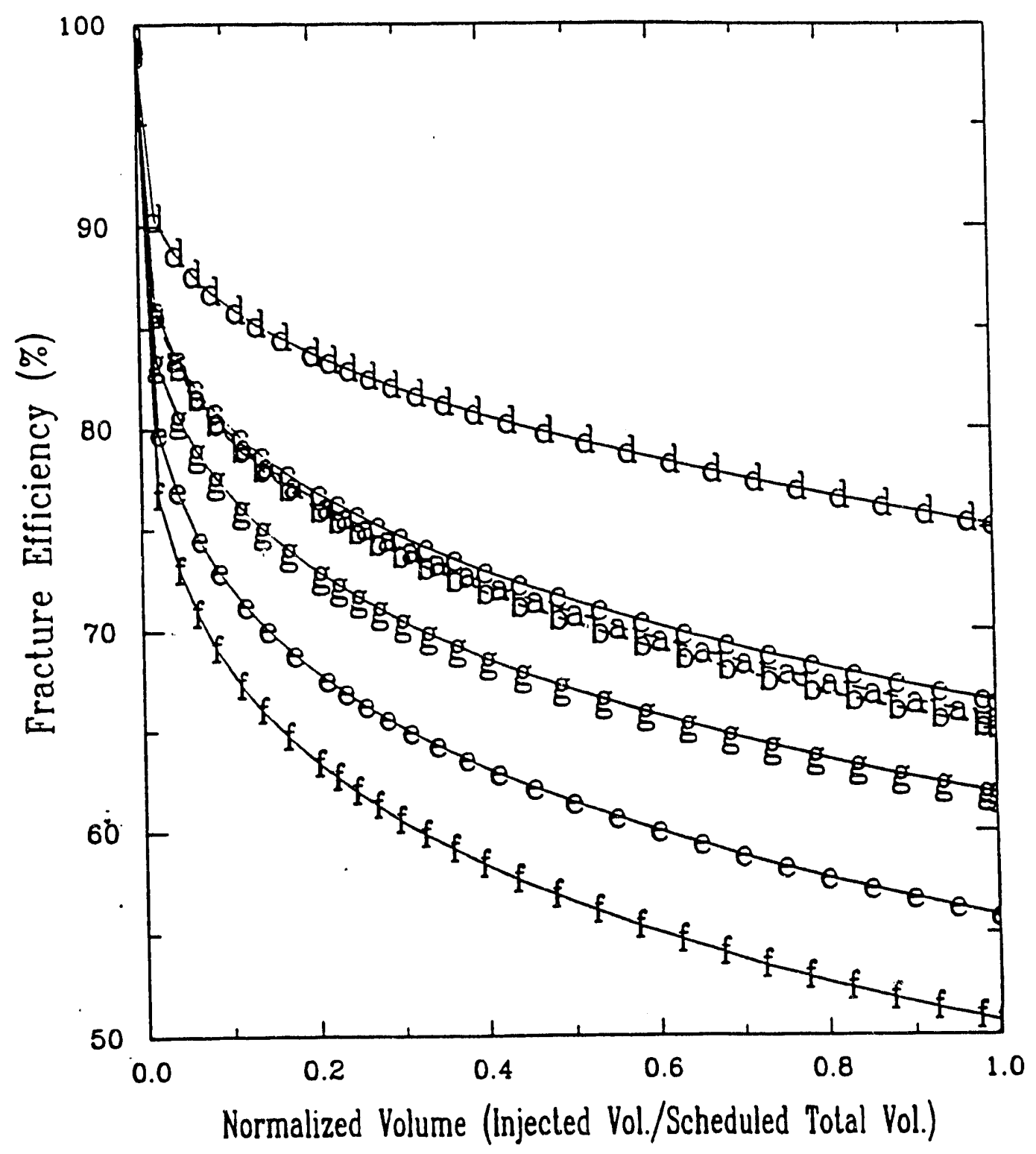

Fig. 12 Fracture Efficiency versus Normalized Volume (Non-Newtonian, Three-layered Cases a-g) 


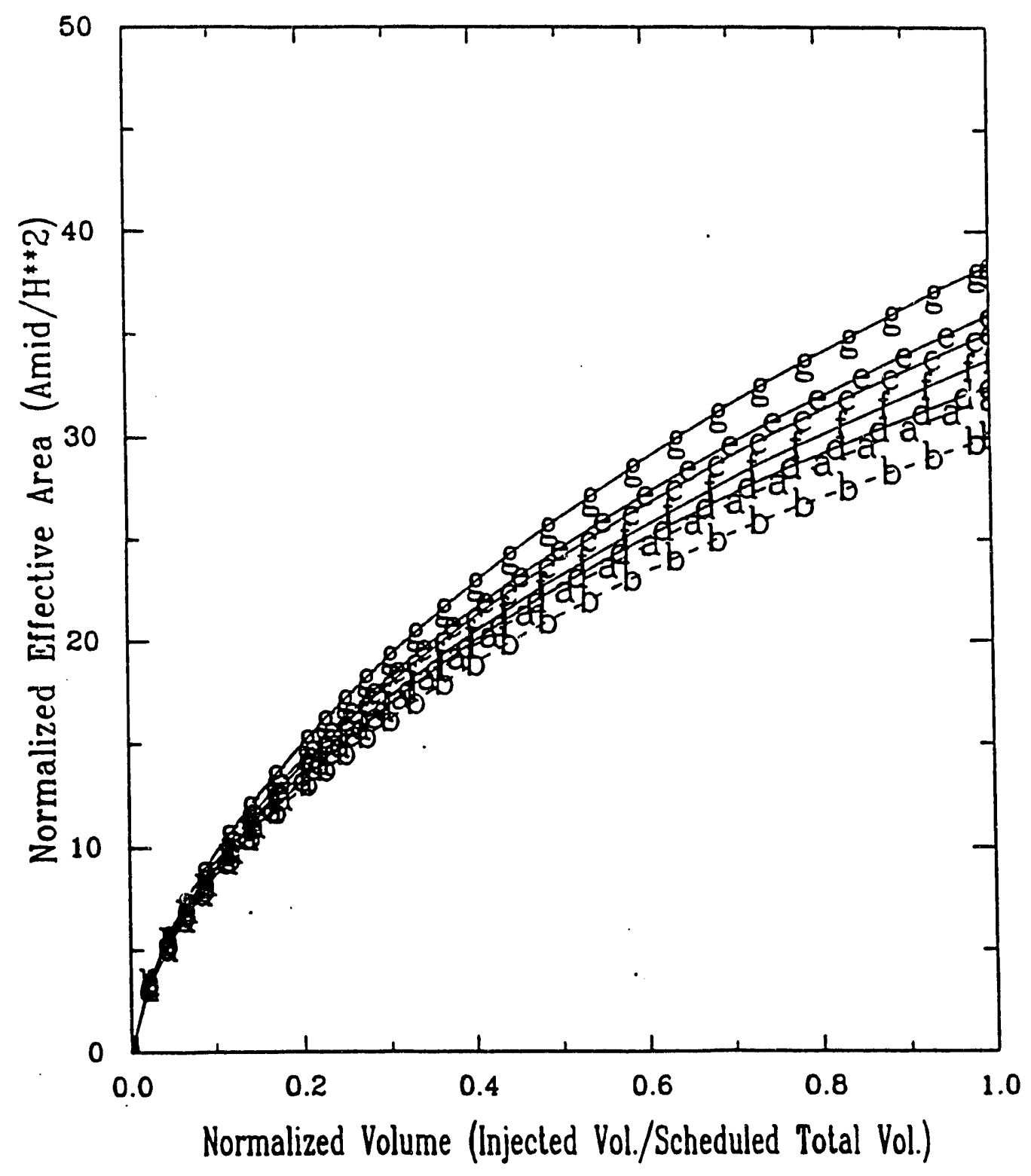

Fig. 13 Normalized Effective Area versus Normalized Volume (Non-Newtonian, Three-layered Cases a-g) 


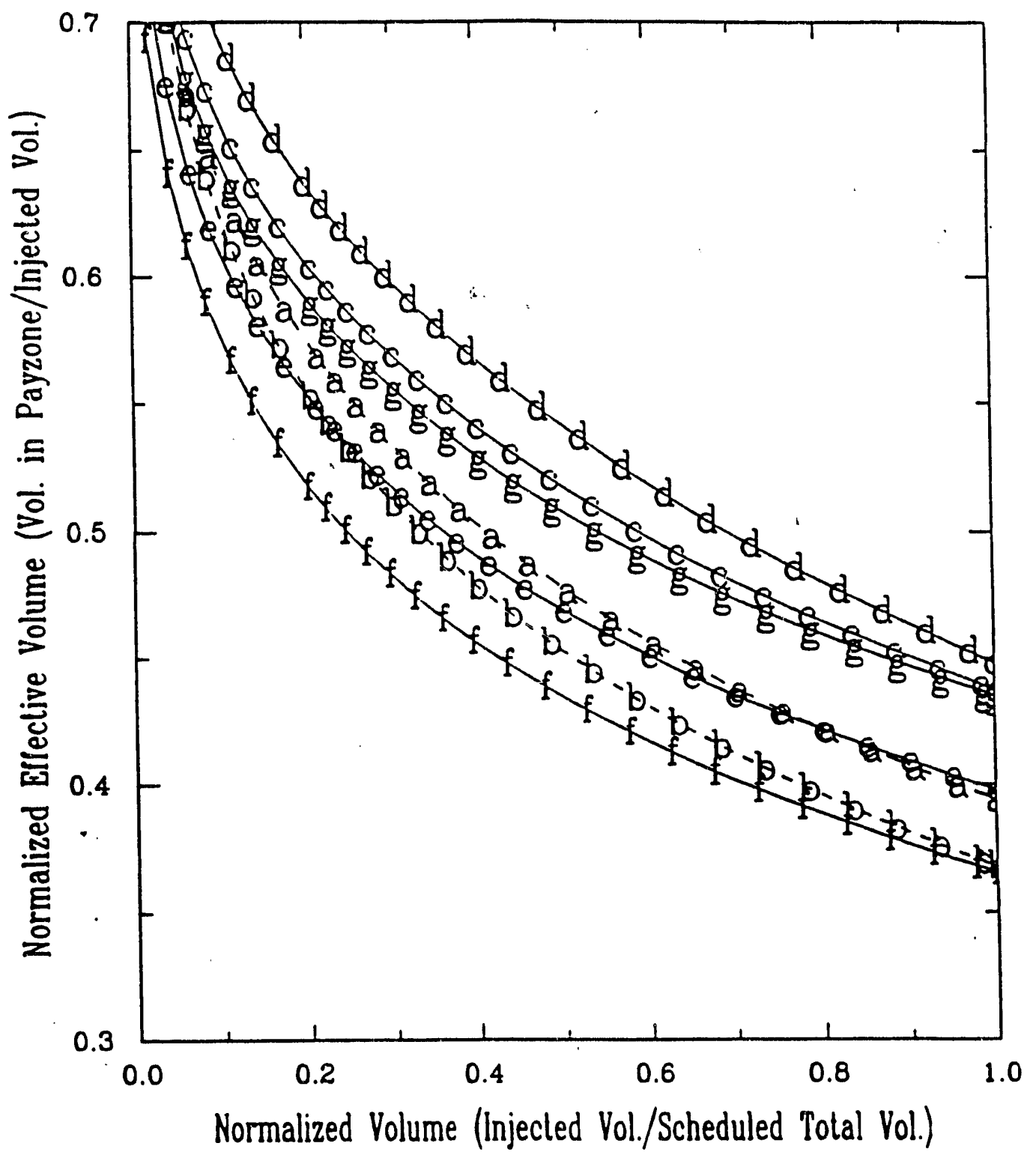

Fig. 14 Effective Volume Efficiency versus Normalized Volume (Non-Newtonian, Three-layered Cases $\mathrm{a}-\mathrm{g}$ ) 
an important variable, as evidenced by its non-linear impact on efficiencies in Table V. Since the cases in Table IV all fall in the dissipation dominant regime, the advantages derived from reduced fluid leak-off should be carefully examined relative to the disadvantages stemming from changes in the rheological and proppant transport characteristics of the fracture fluid. For illustrative comparisons, the fracture and effective volume efficiencies for the Newtonian fluid cases $1-m$ are shown in Figs. 15 and 16 respectively.

To demonstrate the importance of the energy-rate measures (Section 2.4), Fig. 17 portrays the effective available energy components (plots $q, s, 1, f$ ) using bold (three-layered) and dashed (penny-shaped) lines. Clearly, dissipation and leak-off effects are dominant. This indicates that injection flow rate, fracture fluid rheology, and leak-off coefficients have a significant effect on the fracture responses while the role of reservoir fracture toughness can be ignored. The base line in situ stress component trends designated by $S$ (strain energy-rate) and L (leak-off energy-rate) reveal the relatively large uncontrollable energy-rate expenditures during the fracturing process. Comparison of the energy-rate components for case 6 (Table I) and case a (Table IV) are shown in Fig. 18. Due to the reduced in situ stress contrast in case a, the fracture length (height) is decreased (increased) by $26.4 \%(28.3 \%)$, as listed in Tables I and IV. Therefore, the dissipation energy-rate component for case $a$ is lower than in case 6 . This difference in the dissipation energy-rate causes a commensurate change in the leak-off energy rate component, with small changes in the stored strain energy rate components.

Figs. 19 and 20 illustrate the energy-rate component trend sensitivities due to leak-off coefficient and injection rate variations. The higher leak-off coefficient case (case $f$ in Fig. 19) illustrates a large drain in the amount of available power primarily at the expense of strain energy rate. This indicates that, in the dissipation dominant regime, an increase in the leak-off component directly yields an unfavorable fracture configuration response assuming that the maximum reservoir strain energy transfer is desirable. Similarly, halving the injection rate increases the relative leak-off energy-rate component due to the reduced exposure time primarily at the expense of strain energy rate (Fig. 20). Favorable, but minor, changes are also evidenced in the dissipation energy rate component. These injection rate sensitivity trends have to be evaluated in conjunction with the effective area and volume efficiency changes discussed earlier. 


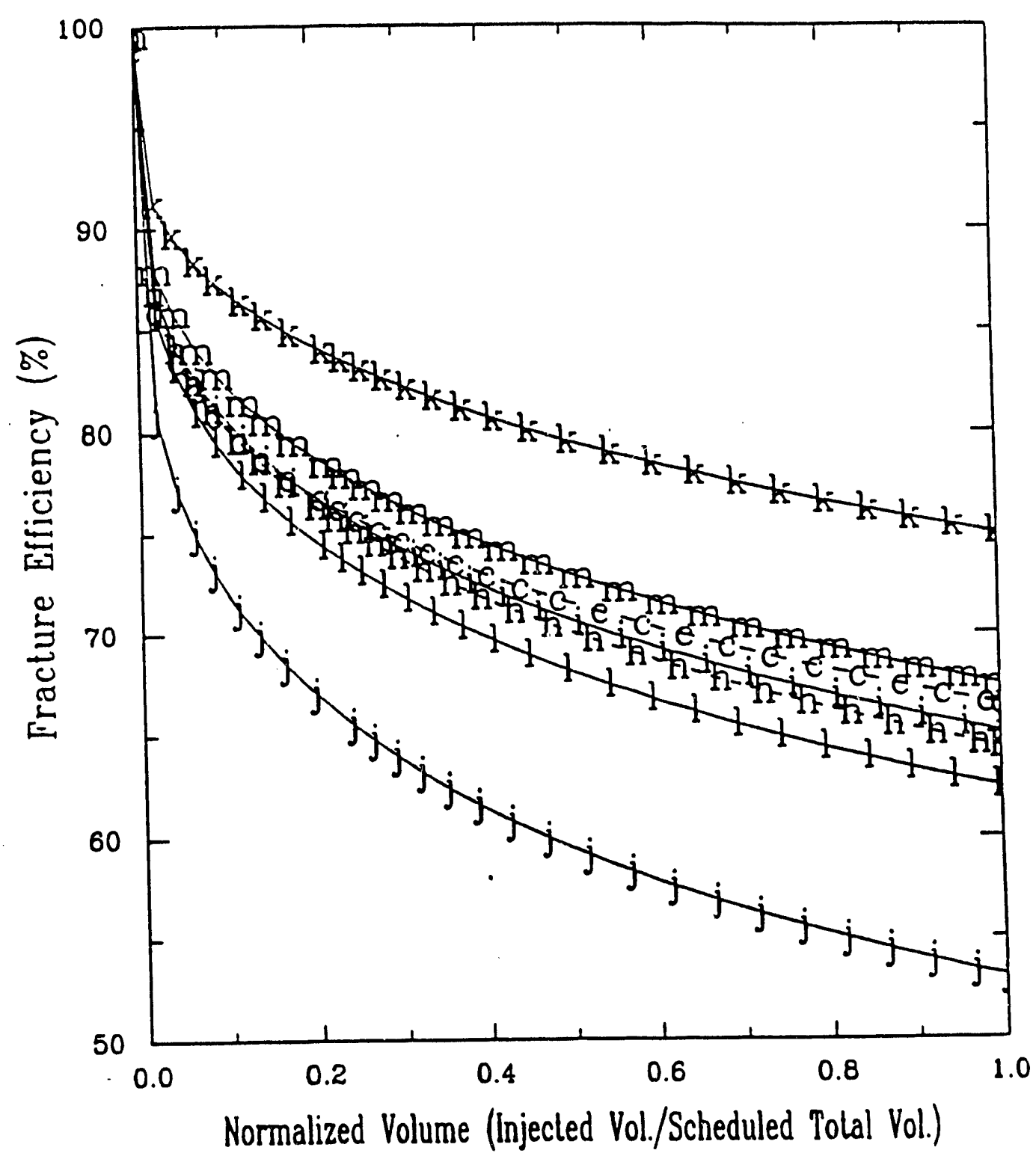

Fig. 15 Fracture Efficiency versus Normalized Volume (Newtonian, Three-layered Cases $\mathrm{h}-\mathrm{m}$ ) 


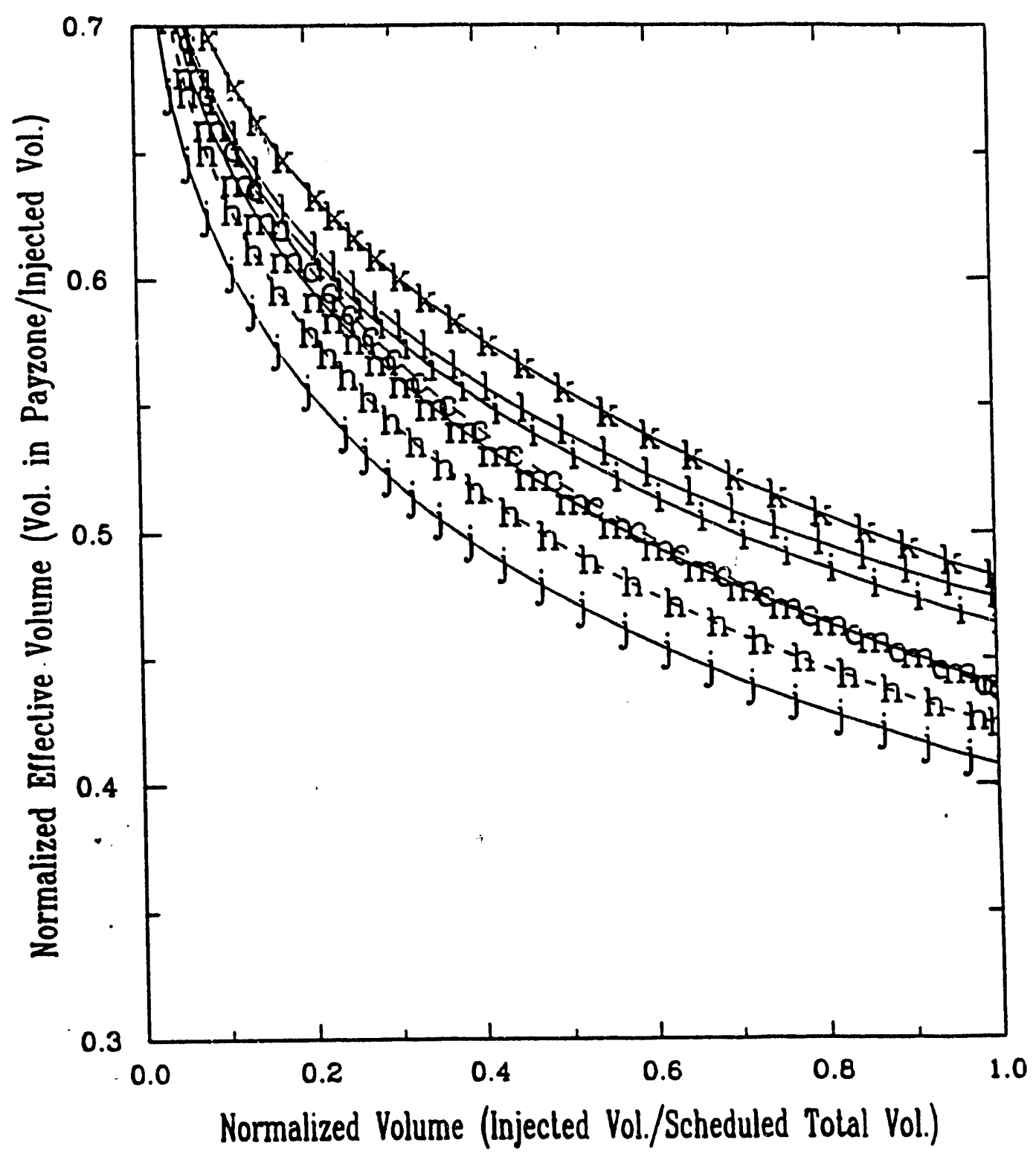

Fig. 16 Effective Volume Efficiency versus Normalized Volume (Newtonian, Three-layered Cases h-m) 


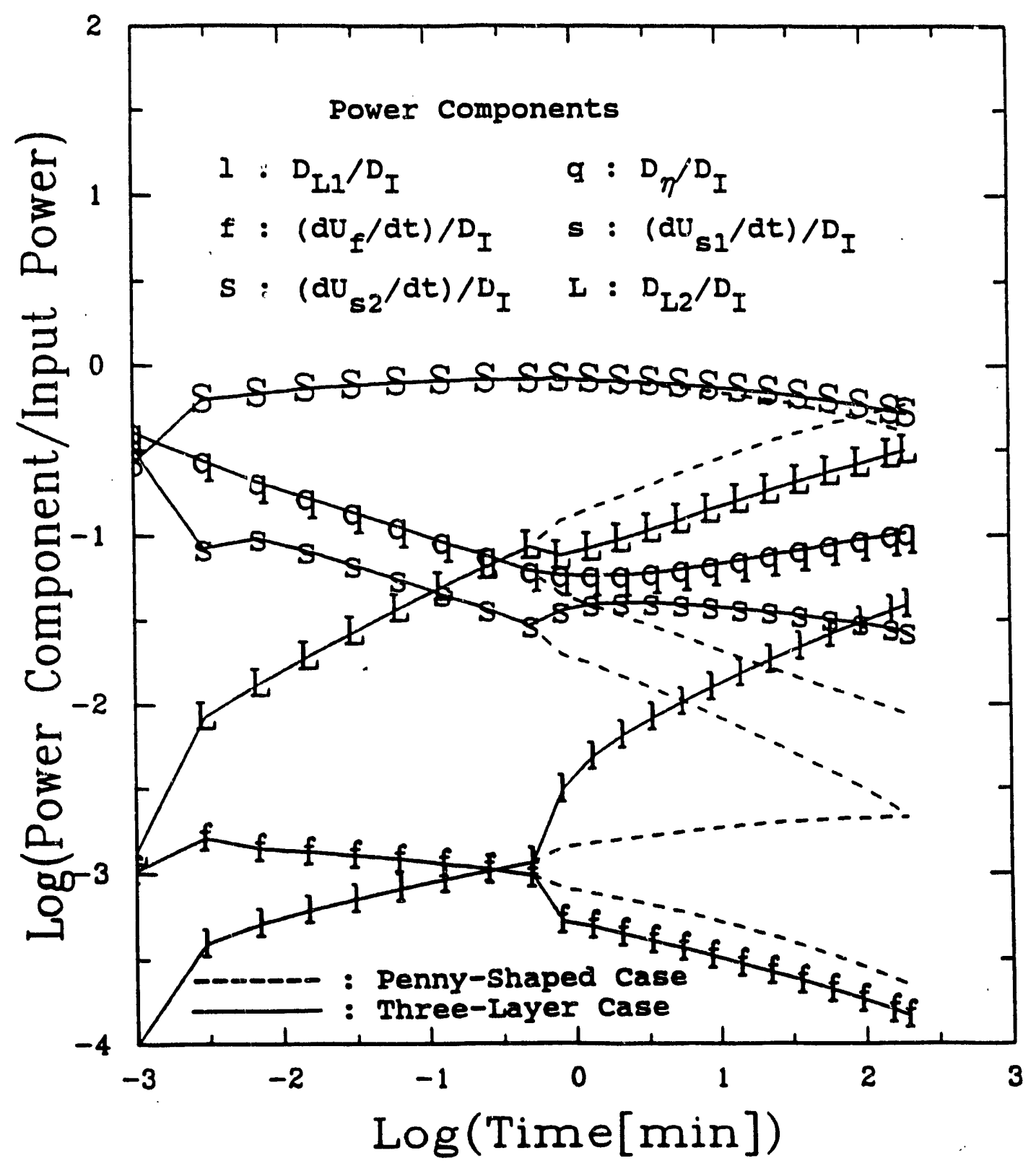

Fig. 17 Energy Rate Components versus Time for SFE \#3 Case 6 (Non-Newtonian, Three-Layered Case) 


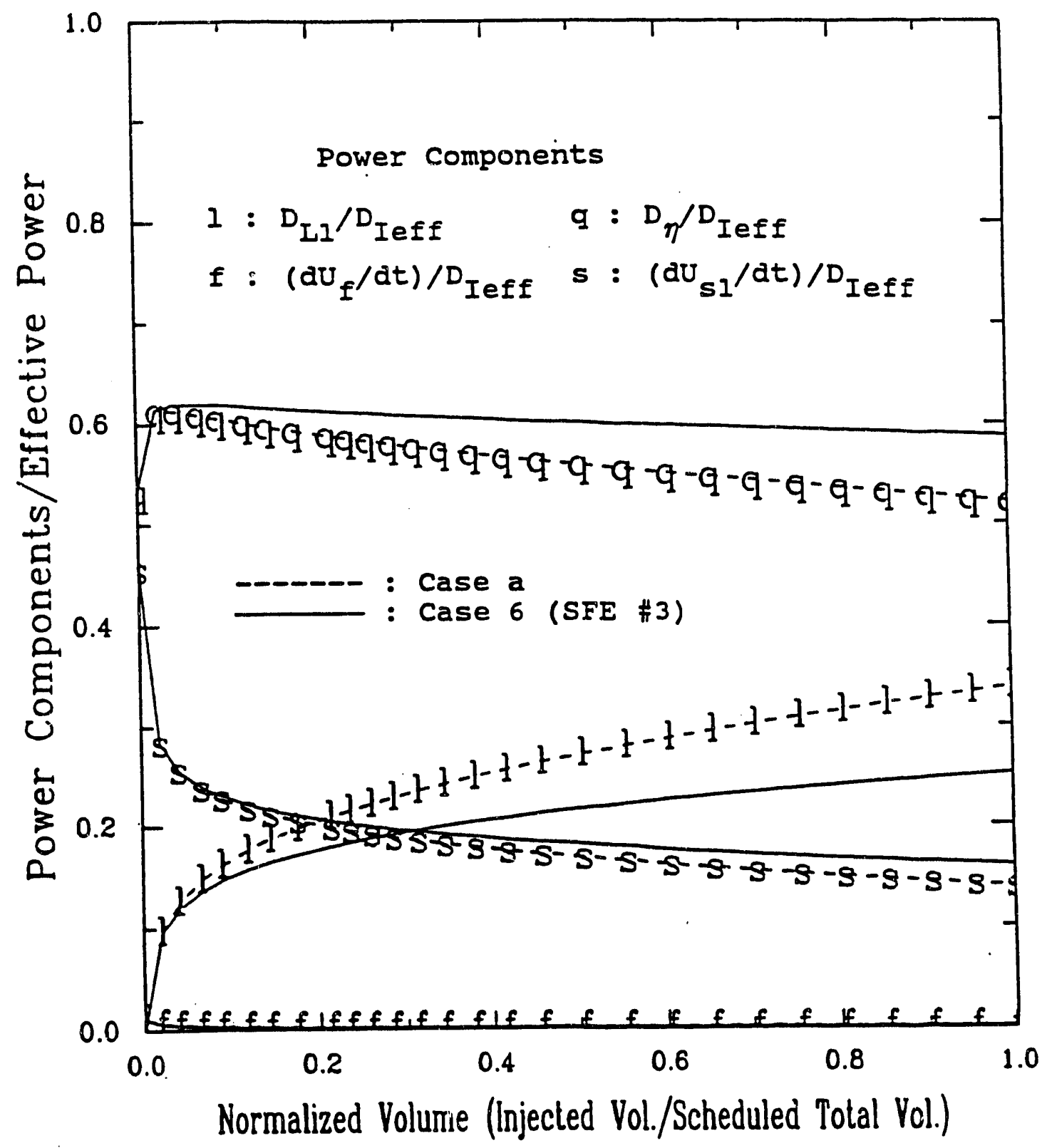

Fig. 18 Comparisons of Energy Rate Components between Case a and SFE \#3 Case 6 (In-situ Stress Effect) 


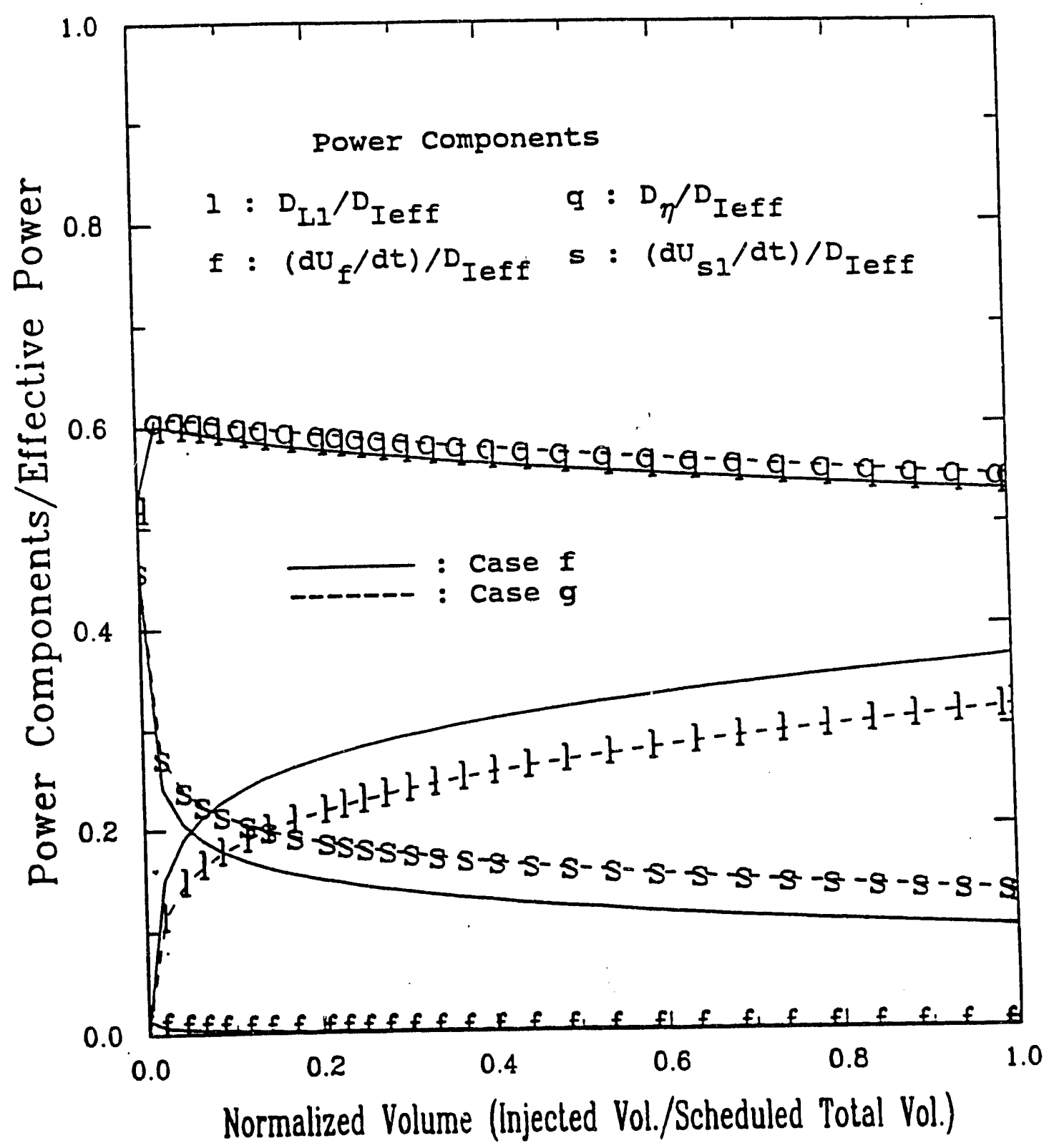

Fig. 19 Comparisons of Energy Rate Components between Cases $f$ and $g$ (Leak-off Effect) 


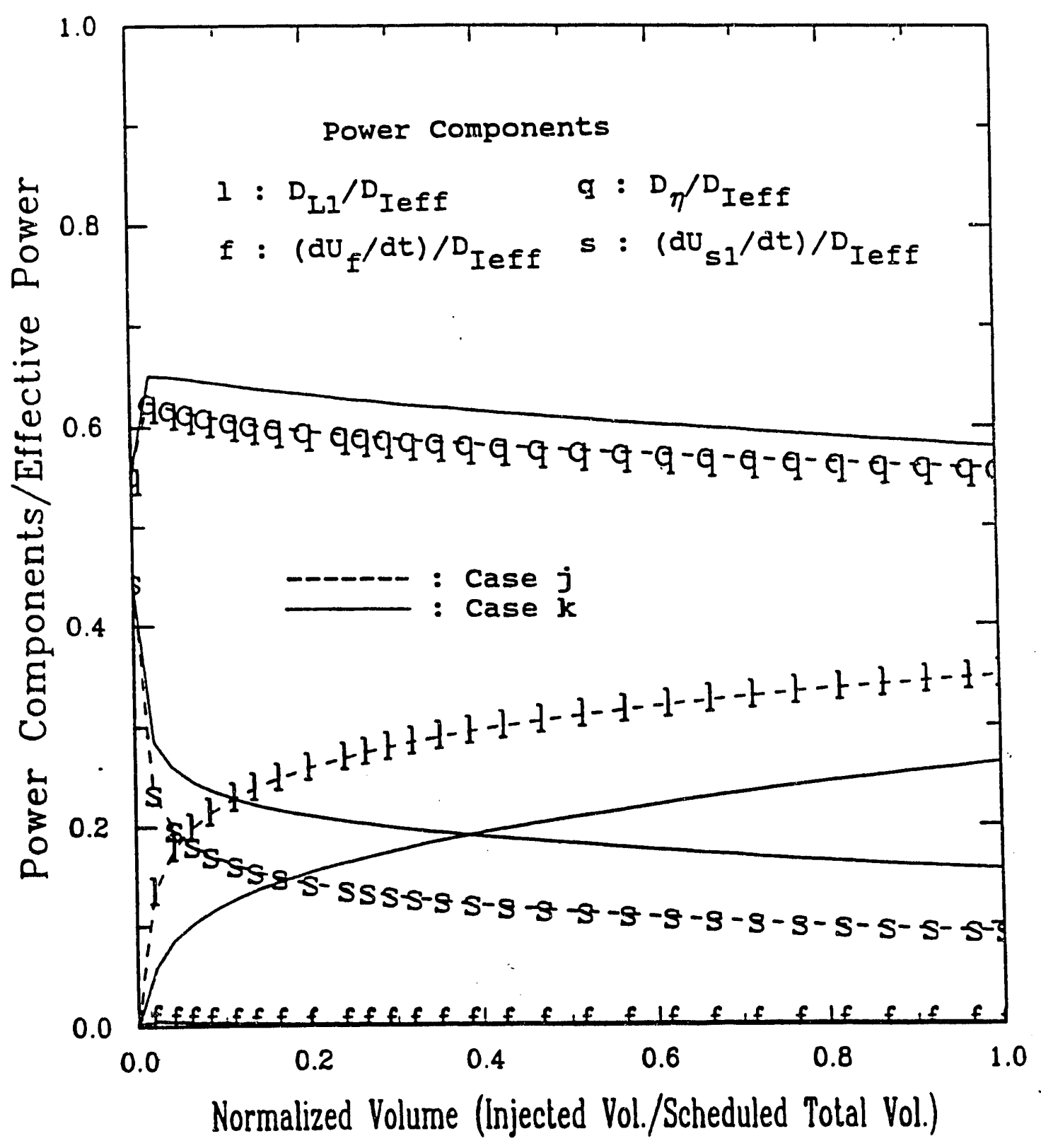

Fig. 20 Comparisons of Energy Rate Components between Cases $\mathrm{j}$ and $\mathbf{k}$ (Injection Rate Effect) 


\subsection{FRACTURE DESIGN, CONTROL, AND OPTIMIZATION GUIDELINES}

Although numerical simulations specifically tailored for the SFE3 field data are presented in Section 2.0, the following generic guidelines for hydraulic fracture configuration design, control, and optimization are proposed:

1. The characterization of the operative influence domain(s) (dissipation, fracture surface and/or leak-off energy dominant regimes) using the uncontrollable reservoir properties and range of controllable fracture fluid variables is an essential design tool (Appendix A). Asymptotic time-explicit solutions with small and large leak-off for PKN, GDK or penny-shaped models can be utilized in preliminary assessments (Appendix B).

2. Three-layered models smearing the reservoir mechanical properties, layering conditions and in situ stress contrasts are generally sufficient and computationally efficient. The unsymmetric elliptic crack models facilitate parametric sensitivity and vertical fracture penetration evaluations (Tables IV and V).

3. In situ stress contrasts (as well as layer interface conditions) play a significant role in governing fracture vertical penetration (Figs. 4 and 5) with fracture fluid viscosity and injection flow rate having a secondary influence. The effects of elastic moduli contrast are also secondary (Fig. 3) and are primarily reflected in the fracture width-effective pressure relation and resulting dissipation energy rate variations.

4. Perforation placement in relation to the prevalent in situ stress field can be an effective design tool in governing fracture evolution (Tables IV and V). The payzone fracture effective area and volume efficiencies are more realistic measures for optimum fracture design than the traditional fracture efficiency definition in the case of multi-layered media (Figs. 12, 13, and 14). Parametric sensitivity configuration studies delineating the role of fracture fluid rheology injection rate, and leak-off are useful for the optimal stimulation treatment design (Tables IV and V). A higher injection rate, for the same treatment volume size, reduces leak-off but decreases fracture containment in the payzone. Similarly, a higher 
fluid viscosity increases fracture width and fracture vertical penetration.

5. The energy rate efficiency of the hydraulic fracture process evaluated using effective bottom hole treatment pressure (BHTP) or wellhead treatment pressure (WHTP) values is an important diagnostic measure (Figs. 17 and 18). The available hydraulic horsepower $\left(i_{0} P_{0}\right)$ at the wellhead or bottom hole is converted into dissipative, strain energy storage, leak-off, and fracture surface energy rates during the fracture evolution. Transfer of fracture fluid leak-off energy to reservoir strain energy, for example, should be optimized during the dissipation dominant fracture evolution (Figs. 19 and 20). 


\subsection{REFERENCES}

1. D.E. Nierode "Fracture Treatment Design', in Recent Advances in Hydraulic Fracturing, J.L. Gidley et al, editors, Society of Petroleum Engineers, Vol. 12, Ch 11, pp 223-244, 1989.

2. J.E. Brown and M.J. Economides, "Practical Considerations for Fracture Treatment Design", in A Practical Comparison to Reservoir Stimulation, M.J. Economides, editor, Schlumberger Educational Services, pp P-1 to P-88, 1991.

3. H. Moon, "Mathematical Modeling and Simulation Analysis of Hydraulic Fracture Propagation in Three-Layered Poro-elastic Media", Ph.D. Dissertation, Department of Engineering Mechanics, The Ohio State University, 1992.

4. H.A. Van Eeklen, "Hydraulic Fracture Geometry: Fracture Continment in Layered Formations", Soc. Pet. Eng. J., Vol 22, pp 341-347, 1982.

5. Gas Research Institute Fracture Propagation Modeling Forum, Lake Conroe, TX, Feb. 26-27, 1991.

6. S.H. Advani et al, "Three Dimensional Modeling of Hydraulic Fracture in Layered Media: Part I - Finite Element Formulations", J. Energy Resources Technology, ASME, pp 1-8, 1990. 


\section{APPENDIX C}

\section{VARIATIONAL PRINCIPLES FOR HYDRAULIC FRACTURING}

S.H. Advani, T.S. Lee, and R.H. Dean

In Press, J. Applied Mechanics, 1992 


\title{
VARIATIONAL PRINCIPLES FOR HYDRAULIC FRACTURING
}

\author{
by \\ S.H. Advani $†$ ASME Fellow \\ T.S. Lee $\dagger^{\dagger}$ ASME Associate Member \\ and R.H. Dean ${ }^{\dagger \dagger}$
}

$\dagger$ Department of Engineering Mechanics, The Ohio State University, Columbus, OH 43210

t† ARCO Oil and Gas Co., Plano, TX 75075

\begin{abstract}
A new application of an energy-rate variational principle for hydraulic fracturing processes is introduced. The formation structural, fracture mechanics, and fracture fluid flow responses are integrally coupled in this treatment. This unified principle, with various specialized forms, provides a formal framework for the study of continuum as well as discrete models. The applicability of the developed formulations is demonstrated by deriving time-explicit solutions for a penny-shaped model and comparing numerical results with corresponding responses from Lagrangian and finite element methods.
\end{abstract}




\section{INTRODUCTION}

Hydraulic fracture processes involve the initiation and extension of cracks in target formations through the pressurized injection of proppant-laden viscous fluids at controlled rates (Veatch et al., 1989). Various methodologies have been employed for the evaluation of hydraulically induced fracture responses, including both energy as well as variational approaches. Perkins and Krech (1968), based on the pioneering work of Sack (1946) and Barenblatt (1956), introduced the concept of a damage zone using a modified energy balance equation for the case of a nonpenetrating fracture fluid. The computed fracture extension pressures employing laboratory determined Griffith surface energies are consistent with corresponding pressures measured in experimental models.

A variational formulation coupling the formation structural stiffness and fracturing fluid response via the crack fluid pressure was first advanced by Clifton and Abou-Sayed (1982). They employed separate variational principles for the formation structural responses and viscous fracture fluid flow, with the linear elastic fracture mechanics (LEFM) criterion expressed as an auxiliary equation. The subsequent discretizations for the crack width and pressure provide the underpinnings for the numerical solutions (Abou-Sayed et al., 1984; Clifton, 1989). A related variational technique for simulating fracture propagation has also been reported by Toubul et al. (1986).

The use of generalized coordinates, in a Lagrangian formulation, for deriving solutions associated with constant height hydraulic fracture models was motivated by Biot et al. (1986). The time dependent generalized coordinates for this discrete model are defined from the admissible functions for the assumed crack dimensions 
and pressure profile. This technique is similar to the Rayleigh-Ritz type solution procedures which have traditionally served as precursors to advanced numerical techniques. Its applicability to elliptical (Advani et al., 1986) and penny-shaped (Advani et al., 1987) fractures has also been demonstrated. In the latter context, fundamental studies on the propagation of a penny-shaped crack have been conducted by Abe et al. (1976).

The significance of different energy contributions for examining fracture response phenomena has received considerable attention. Thiercelin et al. (1987) studied the influence of fracture toughness for penny-shaped cracks. They contrasted their results with those of Wong and Cleary (1985) who studied the limiting case of zero fracture toughness value in their previously developed model. Conversely, substantially enhanced fracture toughness scaling laws have been hypothesized by Shlyapobersky et al. (1988). The relative contributions of Griffith surface and viscous dissipation energy components have been systematically investigated by Lee et al. (1989). The ensuing characteristic time measures developed in these studies serve as diagnostic indicators for parameteric sensitivity evaluation, fracture fluid selection, bottom-hole treatment pressure-flow analysis and eventual fracture configuration control in multi-layered reservoirs.

In this paper, application of a rigorous and integrated energy rate variational formulation governing the coupled structural, fluid flow and fracture mechanics responses is detailed. This unified treatment not only provides a formal framework for investigating discrete Lagrangian models (Biot et al., 1986) with pre-selected configuraticns and lumped generalized forces but it also facilitates the formulation and computational work associated with advanced finite element hydraulic fracture simulators. Applications stemming from the theoretical development are detailed for a penny-shaped fracture. 


\section{FORMULATION OF A GENERAL ENERGY RATE FUNCTIONAL}

Consider a hydraulically induced fracture represented by a planar vertical crack in a multi-layered formation, as shown in Fig. 1. We denote the volumes of the reservoir (excluding the fracture) and the fluid (occupying the entire fracture) by $\Omega_{s}(t)$ and $\Omega_{f}(t)$, respectively. The fracture surface area and the crack front are designated by $A(t)$ and $\partial A$, respectively.

A general form of an energy rate functional, coupling the elastic reservoir structural, linear elastic fracture mechanics and viscous incompressible fracturing fluid, is motivated from Appendix A. This functional, obtained from the principle of virtu? work, is

$F\left(\underline{\underline{s}}_{\mathrm{s}}, \underline{\mathbf{p}}_{\mathrm{f}}, \mathrm{p}, \dot{\mathrm{a}}_{\mathrm{n}}\right)=\frac{\mathrm{d}}{\mathrm{dt}} \int_{\Omega_{\mathrm{s}}} \mathrm{e} \mathrm{dV}+\int_{\Omega_{\mathrm{f}}} \psi \mathrm{dV}+\int_{\Omega_{\mathrm{f}}} \mathbf{v}_{\mathrm{fi}_{\mathrm{f}}}\left(\mathrm{p}_{\mathrm{i}_{\mathrm{i}}}-\mathrm{f}_{\mathrm{gi}}\right) \mathrm{dV}$

$-2 \int_{A} p v_{L} d A-2 \int_{A} p v_{s i} n_{i} d A+\frac{d}{d t} \int_{A} G_{c r} d A-\int_{\partial A_{q}} v_{f n} d A$

where $e$ is the specific strain energy for the reservoir and $\psi$ is the fracture fluid dissipation energy rate. For the crack, we note that the boundary areas for the crack surfaces are represented by $\left|\partial \Omega_{\mathrm{g}}\right|=\left|\partial \Omega_{\mathrm{f}}\right|=2|\mathrm{~A}|$. These integrals over the area $A$ in eq. (1) are calculated for one face of the fracture only; the factor of two accounts for the opposite face. Also, the energy release rate $G_{c r}=2 \Gamma$ with $\Gamma$ defined as the surface energy. In eq. (1), $\underline{\nabla}_{\mathcal{S}}, \underline{\mathbf{z}}_{\boldsymbol{f}}$, and $v_{L}$ denote the solid, fluid, and leak-off velocities, respectively, $p$ designates the fracture fluid pressure, $\underline{\underline{n}}$ is the unit vector normal to $A$ and pointing outward from $\Omega_{f}, \underline{f}_{g}$ is the fluid gravitational body force, and $v_{f n}$ is the fracture fluid injection velocity at the boundary $\partial \mathrm{A}_{\mathrm{q}}$.

One can readily identify the origin of the various terms in eq. (1) and 
pertinent mechanisms. The first term in eq. (1) represents the rate of increase in strain energy in the solid and the second term is directly related to the rate of energy loss through fluid dissipation. The $v_{f_{i}} p_{i}$ term includes the rate at which the fracture fluid does work at the boundaries $A$ and $\partial A_{q}$, and enforces the incompressibility constraint. The $-v_{\mathrm{fi}} f_{\mathrm{gi}}$ term represents the rate of increase in the gravitational potential. The terms $2 \mathrm{pv}_{\mathrm{L}}$ and $2 \mathrm{pv}_{\mathrm{si}} \mathrm{n}_{\mathrm{i}}$ account for the rate at which energy is lost through fluid leak-off, and the rate at which work is done on the solid. The term containing $G_{c r}$ in eq. (1) represents the rate at which energy goes into creating new surface area. Since $v_{f n}$ is defined to be negative for injection, $-\mathrm{pv}_{\mathrm{fn}}$ represents the rate at which energy is supplied to the fracture at the injection boundary $\partial \mathrm{A}_{\mathrm{q}}$.

We introduce, in eq. (1), the expressions

$$
e=\frac{1}{2} \epsilon_{i j} C_{i j k l} \epsilon_{k l}+\sigma_{i j}^{o} \epsilon_{i j}
$$

for the linear elastic formation subjected to initial stresses $\sigma_{\mathrm{ij}}^{0}$, and

$$
\psi=\frac{\eta_{0}}{1+m}\left(L_{i j} L_{i j}\right)^{(1+m) / 2}
$$

for the power law type non-Newtonian fracturing fluid $\left(\tau_{\mathrm{ij}}=\eta_{0}|\mathrm{~L}|^{\mathrm{m}-1} \mathrm{~L}_{\mathrm{ij}}\right)$, with $\eta_{0}$ and $m$ denoting the fluid consistency and behavior indices, respectively, and $L_{i j}$ designating the components of the fluid velocity gradient tensor (defined in Appendix A). Also, we note that the fracture energy rate term in eq. (1) can be equiyalently written as

$$
\frac{d}{d t} \int_{A(t)} G_{c r} d A=\int_{\partial A} G_{c r} \dot{a}_{n} d S
$$

with $\dot{a}_{n}$ representing the normal crack propagation velocity on $\partial A$. Eq. (1) can now be rewritten in the form 


$$
\begin{aligned}
& F\left(\underline{z}_{s}, \underline{Y}_{f}, p, \dot{a}_{n}\right)=\frac{d}{d t} \int_{\Omega_{g}}\left\{\frac{1}{2} \epsilon_{i j} C_{i j k l} \epsilon_{k l}+\sigma_{i j}^{o} \epsilon_{i j}\right\} d V+\frac{\eta_{o}}{1+m} \int_{\Omega_{f}}\left(L_{i j} L_{i j}\right)^{(1+m) / 2} d V \\
& +\int_{\Omega_{f}} v_{f_{i}}\left(p_{y_{i}}-f_{g i}\right) d V-2 \int_{A} p v_{s i} n_{i} d A-2 \int_{A} p v_{L} d A \\
& +\int_{\partial \mathrm{A}} \mathrm{G}_{\mathrm{cr}} \dot{\mathrm{a}}_{\mathrm{n}} \mathrm{dS}-\int_{\partial \mathrm{A}_{\mathrm{q}}} \mathrm{p} \mathrm{v}_{\mathrm{fn}} \mathrm{dA}
\end{aligned}
$$

We take variations with respect to the variables $\underline{z}_{s}, \underline{z}_{f}, p$, and $\dot{a}_{n}$ only. The solid displacement $\underline{\underline{n}}_{s}$ and all spatial regions $\left(\Omega_{s}, \Omega_{f}, A, \partial A\right.$ and $\left.\partial A_{q}\right)$ are not varied, and the first integral (strain energy term) in eq. (5) must be expressed in terms of $\underline{\nabla}_{s}$ and $\underline{\mathbf{n}}_{S}$ only. We also assume that $v_{f n}$ and $v_{L}$ are prescribed with $v_{f n}$ defined to be negative for injection.

The resulting Euler equations, obtained from setting the first variation of eq. (5) to zero, are :

Equilibrium equations for the reservoir

$$
\left(\sigma_{\mathrm{ij}}+\sigma_{\mathrm{ij}}^{0}\right)_{\mathrm{j}} \doteq 0 \text { in } \Omega_{\mathrm{s}}
$$

Traction boundary conditions for the reservoir

$$
\left(\sigma_{i j}+\sigma_{i j}^{0}\right) n_{j}+p n_{i}=0 \text { on } \mathbf{A}
$$

Fluid linear momentum equations for the fracturing fluid

$$
-\mathrm{p}_{\mathrm{i}_{\mathrm{i}}}+\tau_{\mathrm{ij} \mathbf{j}^{\mathrm{j}}}+\mathrm{f}_{\mathrm{gi}}=0 \text { in } \boldsymbol{\Omega}_{\mathrm{f}}
$$

Fracturing fluid incompressibility equation

$$
\mathbf{v}_{\mathbf{f}^{\prime} \mathrm{i}}=0 \text { in } \boldsymbol{\Omega}_{\mathrm{f}}
$$

Fracturing fluid and reservoir velocity relations on the crack surface

$$
v_{f_{i}} n_{i}=v_{s i} n_{i}+v_{L} \text { on } A
$$

Injection flow condition for the fracturing fluid

$$
\mathrm{v}_{\mathrm{fi}} \mathrm{n}_{\mathrm{i}}=\mathrm{v}_{\mathrm{fn}} \text { on } \partial \mathrm{A}_{\mathrm{q}} \text { and }
$$

Reservoir fracture propagation criterion

$$
\mathrm{G}=\mathrm{G}_{\mathrm{cr}} \text { on } \partial \mathrm{A}
$$


We assume that the values of $\tau_{\mathrm{ij}} \mathrm{n}_{\mathrm{j}}$ are negligible along the surface $\mathrm{A}$ and at the injection boundary, $\partial \mathrm{A}_{\mathrm{q}}$. For hydraulic fracturing studies, one can show that the deviatoric stress $\tau_{\mathrm{ij}}$ are much smaller than the pressure $\mathrm{p}$. The stationary value of the functional given by eq. (5) yields the necessary field equations and boundary conditions for investigating the overall hydraulic fracture responses.

\section{SIMPLIFIED ENERGY-RATE FUNCTIONALS}

We simplify the general functional (5), for application to hydraulic fracturing, by using the boundary integral form for the crack opening mode and invoking the lubrication flow approximation. Although the functional and associated analysis are applicable to a general state of in-situ stress $\sigma_{\mathrm{ij}}^{0}$, we assume in the sequel that the crack is planar and that it propagates perpendicular to the minimum in-situ stress, $\sigma_{0}=-\sigma_{33}^{0}$, in the $x_{3}=0$ plane (Fig. 1).

First, the boundary integral representation of the strain energy term for the crack opening mode $\left(u_{s 1}=u_{s 2}=0, u_{s 3}=w / 2\right)$ can be written as (Bui, 1977)

$$
\int_{\Omega_{\mathrm{s}}} \frac{1}{2} \epsilon_{\mathrm{ij}} \mathrm{C}_{\mathrm{ijkl}} \epsilon_{\mathrm{kl}} \mathrm{dV}=\frac{1}{2} \mathrm{~B}(\mathrm{w}, \mathrm{w})_{\mathrm{A}}
$$

with the symmetric bilinear term $B(w, w)_{A}$ defined in terms of the crack opening width, w, by

$$
\begin{aligned}
\mathrm{B}(\mathrm{w}, \mathrm{w})_{\mathrm{A}} & =\int_{\mathrm{A}} \mathrm{w} \mathrm{K}_{\mathrm{A}}[\mathrm{w}] \mathrm{dA} \\
& =\int_{\mathrm{A}} \mathrm{w}(\mathrm{x}, \mathrm{t})\left\{\frac{\mu}{4 \pi(1-\nu)} \int_{\mathrm{A}} \frac{\partial}{\partial \mathrm{x}_{\mathrm{j}}}\left(\frac{1}{\mid \mathrm{x}-\xi)}\right) \frac{\partial \mathrm{w}(\xi, t)}{\partial \xi_{\mathrm{i}}} \mathrm{dA}\right\} \mathrm{dA}
\end{aligned}
$$

where $\mathrm{K}_{\mathrm{A}}[\mathrm{w}]$ represents the boundary integral for the crack surface $A$ and $\mu$ and $\nu$ respectively are the reservoir shear modulus and Poisson's ratio. The appropriate forms for a planar fracture in a multi-layered formation, reported by Lee et al. 
(1988), have been obtained by extending the basic work of Lee and Keer (1986). We note that the integral expression (14) is defined in terms of the fracture opening width, $w$, and the fracture area, $A$, instead of the displacement, $\underline{\mathbf{n}}_{\mathbf{s}}$, and volume, $\Omega_{\mathrm{s}}$. This representation, therefore, significantly reduces the computational effort. The corresponding terms in eq. (5), obtained by using eqs. (13), (14), and Appendix $B$, for an opening mode planar crack, can be derived as

$$
\begin{aligned}
& \frac{d}{d t} \int_{\Omega_{S}}\left\{\frac{1}{2} \epsilon_{i j} C_{i j k l} \epsilon_{k l}+\sigma_{i j}^{0} \epsilon_{i j}\right\} d V \\
& =\int_{A} \dot{w}\left\{K_{A}[w]+\sigma_{0}\right\} d A+\int_{\partial A} \dot{a}_{n} \frac{\pi \mu}{8(1-\nu)} w \nabla w \cdot \underline{n} d S
\end{aligned}
$$

where the gradient, $\nabla w$, is defined with respect to the coordinates $x_{1}$ and $x_{2}$.

Next, from the lubrication flow approximation, we express the dissipation energy integral in the form

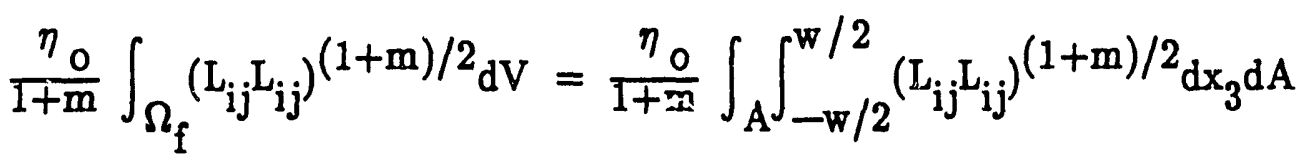

We now evaluate the volume integral for laminar Hele-Shaw flow behavior in a channel with width $w\left(x_{1}, x_{2}, t\right)$ and fluid pressure $p\left(x_{1}, x_{2}, t\right)$ using the relations (Clifton and Abou-Sayed, 1982)

$$
\begin{aligned}
& v_{f 1}=\frac{2 m+1}{m+1}\left[1-\left(\frac{\left|x_{3}\right|}{w / 2}\right)^{(1+m) / m}\right] q_{1} / w \\
& v_{f 2}=\frac{2 m+1}{m+1}\left[1-\left(\frac{\left|x_{3}\right|}{w / 2}\right)^{(1+m) / m}\right] q_{2} / w \\
& \int_{-w / 2}^{w / 2} v_{f 3} d x_{3}=0
\end{aligned}
$$

where $\mathrm{q}_{\mathrm{i}} / \mathrm{w}$ is the average velocity defined by

$$
q_{i}=\int_{-w / 2}^{w / 2} v_{f i} d x_{3}
$$

The dissipation term can now be shown to have the form

$$
\frac{\eta}{1+m} \int_{\Omega_{\mathrm{f}}}\left(\mathrm{L}_{\mathrm{ij}} \mathrm{L}_{\mathrm{ij}}\right)^{(1+\mathrm{m}) / 2} \mathrm{dV}=\frac{\bar{\eta}}{1+\mathrm{m}} \int_{\mathrm{A}} \frac{|\mathrm{g}|^{1+\mathrm{m}}}{\mathrm{w}^{2 \mathrm{~m}+1}} \mathrm{dA}
$$


where $\bar{\eta}=\eta_{0}(2+1 / \mathrm{m})^{\mathrm{m}} 2^{1+\mathrm{m}}$. Also, for a vertical planar crack, we have

$$
\int_{\Omega_{f}} v_{f}\left(p, r_{i}-f_{g i}\right) d V=\int_{A} g \cdot\left(\nabla p-f_{g}\right) d A
$$

and

$$
\int_{-w / 2}^{w / 2} \nabla_{f n} d x_{3}=Q_{n} \text { on } \partial A_{q}
$$

On the crack surface, $A$, the velocities are represented by

$$
\dot{\mathrm{w}} / 2=\underline{\mathbf{v}}_{\mathrm{s}} \cdot \underline{\mathrm{n}} \text { and } \mathrm{q}_{\mathrm{L}}=2 \mathrm{v}_{\mathrm{L}}
$$

Using eqs. (15), (21), (22), (23), and (24), the functional (5) can be rewritten in the following simplified form :

$$
\begin{aligned}
& F\left(\dot{w}, g, p, \dot{a}_{n}\right)=\int_{A} \dot{w}\left\{K_{A}[w]-p+\sigma_{0}\right\} d A+\frac{\bar{\eta}}{1+m} \int_{A} \frac{|q|}{w^{2 m+m}} d A \\
& +\int_{A} g \cdot\left(\nabla p-\underline{f}_{g}\right) d A-\int_{A} p q_{L} d A+\int_{\partial A} \dot{a}_{n}\left\{\frac{\pi \mu}{8(1-\nu)} \nabla w \cdot \underline{n}+G_{c r}\right\} d S \\
& -\int_{\partial A} p Q_{n} d S
\end{aligned}
$$

The resulting Euler equations, obtained from the first variation of only the velocity-dependent and pressure terms in (25), are

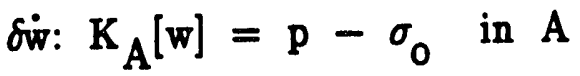

$$
\begin{aligned}
& \delta p: \nabla \cdot g+\dot{w}+q_{L}=0 \text { in } A \\
& \mathbf{q} \cdot \underline{\underline{n}}=Q_{\mathbf{n}} \quad \text { along } \quad \partial A_{q} \\
& \delta \mathrm{g}: \bar{\eta} \frac{|\mathrm{g}|^{\mathrm{m}-1}}{\mathrm{w}^{2 \mathrm{~m}+1}} \mathrm{~g}+\nabla \mathrm{p}-\mathrm{f}_{\mathrm{g}}=\underline{\mathbf{0}} \text { in } \mathrm{A} \\
& \delta \dot{a}_{\mathbf{n}}:-\frac{\pi \mu}{8(1-\nu)} \mathbf{w} \cdot \underline{\underline{n}}=G_{c r} \text { along } \partial A
\end{aligned}
$$

Another simplified form of the functional, using relation (29) and eliminating the flux, $\mathrm{g}$, from the generalized coordinates, can be derived as

$$
\begin{aligned}
\mathrm{F}\left(\dot{\mathrm{w}}, \mathrm{p}, \dot{\mathrm{a}}_{\mathrm{n}}\right)= & \int_{\mathrm{A}} \dot{\mathrm{w}}\left\{\mathrm{K}_{\mathrm{A}}[\mathrm{w}]-\mathrm{p}+\sigma_{0}\right\} \mathrm{dA}-\int_{\mathrm{A}} \mathrm{pq}_{\mathrm{L}} \mathrm{dA} \\
& -\frac{\mathrm{m}}{1+\mathrm{m}}(\bar{\eta})^{-1 / \mathrm{m}} \int_{\mathrm{A}} \mathrm{w}^{(2+1 / \mathrm{m})}\left\{\left(\nabla \mathrm{p}-\mathrm{f}_{\mathrm{g}}\right) \cdot\left(\nabla \mathrm{p}-\mathrm{f}_{\mathrm{g}}\right)\right\}
\end{aligned}
$$




$$
+\int_{\partial \mathrm{A}} \dot{a}_{\mathrm{n}}\left\{\frac{\pi \mu}{\delta(1-\nu)} \mathbf{w} \mathbf{w} \cdot \underline{\underline{n}}+G_{c r}\right\} d S-\int_{\partial A_{q}} p Q_{n} d S
$$

The Euler equations, resulting from (31) after applying the variational procedure and divergence theorem, are

$\delta \dot{w}: K_{A}[w]=p-\sigma_{0}$ in $A$

$\delta \mathrm{p}:-(\bar{\eta})^{-1 / m} \nabla \cdot\left\{w(2+1 / m)\left|\nabla p-f_{g}\right|^{(1-m) / m}\left(\nabla p-f_{g}\right)\right\}+\dot{w}+q_{L}=0$ in $A$

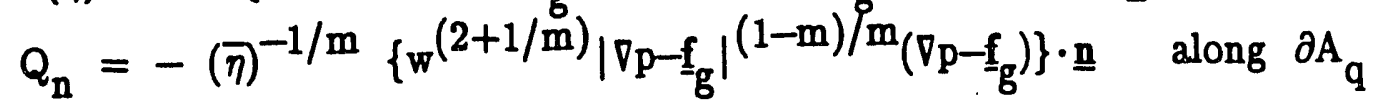

$\delta \dot{a}_{\mathbf{n}}:-\frac{\pi \mu}{8(1-\nu)} \mathbf{w} \mathbf{w} \cdot \underline{n}=G_{c r}$ along $\partial A$

In summary, the functionals representing the mechanics of hydraulic fracturing are given by eqs. (5), (25), or (31), depending on the inherent assumptions. Theoretically, the functional given by eq. (31) can be expressed in terms of two variables, by eliminating the pressure variable using eq. (32). However, this additional reduction requires the derivation of a computationally tractable expression for $\mathrm{K}_{\mathrm{A}}[\mathrm{w}]$, associated with pre-selected fracture geometries.

\section{APPLICATIONS: DISCRETE PENNY-SHAPED MODEL}

We consider the hydraulically induced growth of a penny-shaped fracture in an isotropic formation. The fracture geometry at any time instant is approximated by the fracture radius $(R(t))$ and fracture opening width profile assumed as

$$
w(r, t)=w_{1}(t)\left(1-\rho^{2}\right)^{1 / 2}+W_{2}(t)\left(1-\rho^{2}\right)^{3 / 2}
$$

where $\rho=r / R$ is the normalized radial coordinate. The first term in eq. (36) represents the crack singular behavior while the second term corresponds to the equilibrium crack growth condition (Barenblatt, 1956), satisfying a zero slope at the crack front $(\rho=1)$. The compatible polynomial expression for the effective 
pressure profile derived from the crack opening width profile (36) is

$$
p(r, t)-\sigma_{0}=P(t) \cdot\left\{1-x(t) \rho^{2}\right\}
$$

where $\sigma_{0}$ is the reservoir minimum in-situ stress. The approximate distribution in eq. (37) assumes that the fracturing fluid occupies the tip of the advancing fracture and ignores the pressure singularity at the front, arising from the lubrication approximation (Bui and Parnes, 1982).

The energy rate components and governing equations of motion corresponding to the five generalized coordinates, $\dot{\mathrm{W}}_{1}, \dot{\mathrm{W}}_{2}, \dot{\mathrm{R}}, \mathrm{P}$ and $\alpha$, are derived in Appendix C. The governing elasticity eqs. (C.11) and (C.12) can be re-expressed as

$$
\begin{aligned}
& \mathrm{W}_{1}=\frac{4(1-\nu)}{\pi \mu} \mathrm{PR}\left(1-\frac{2}{3} \alpha\right) \\
& \mathrm{W}_{2}=\frac{4(1-\nu)}{\pi \mu} \text { PR } \frac{4}{9} \alpha
\end{aligned}
$$

along with the crack propagation condition from eqs. (38), (39) and (C.13)

$$
\frac{\pi \mu}{8(1-\nu) \mathrm{R}} \mathrm{W}_{1}^{2}=\mathrm{G}_{\mathrm{cr}}
$$

The mass conservation equation, deduced from eqs. (C.14) and (C.15), is

$$
j_{0}=\frac{d}{d t}\left(\frac{2 \pi}{3} w_{1} R^{2}+\frac{2 \pi}{5} w_{2} R^{2}\right)+4 \pi C_{L} R^{2} \int_{0}^{1}\{t-\tau(\rho)\}^{-l} \rho d \rho
$$

where the last term represents the fluid leak-off volume rate. The additional equation reflecting the variation in $\alpha$ (eq. (C.15)) is

$$
\begin{aligned}
& \quad 2 \pi \mathrm{R}^{2}\left(\frac{2}{15} \dot{\mathrm{W}}_{1}+\frac{2}{35} \dot{\mathrm{W}}_{2}\right)+2 \pi \mathrm{RR}\left(\frac{8}{15} \mathrm{~W}_{1}+\frac{8}{35} \mathrm{~W}_{2}\right) \\
& -\frac{2 \pi \mathrm{m}}{2 \mathrm{~m}+\mathrm{T}}\left(\eta_{0}\right)^{-1 / \mathrm{m}_{\mathrm{R}}(\mathrm{m}-1) / \mathrm{m}} \alpha^{1 / \mathrm{m}} \mathrm{P}^{1 / \mathrm{m}} \mathrm{I}\left(\mathrm{W}_{1}, \mathrm{~W}_{2}, \mathrm{~m}\right)+4 \pi \mathrm{C}_{L^{2}} \mathrm{R}^{2} \mathrm{~J}=0
\end{aligned}
$$

where

$$
\mathrm{J}_{\ell}=\int_{0}^{1} \frac{\rho^{3}}{\{-\tau(\rho)\}^{\ell}} \mathrm{d} \rho
$$

and $\mathrm{I}\left(\mathrm{W}_{1}, \mathrm{~W}_{2}, \mathrm{~m}\right)=\int_{0}^{1}\left[\rho\left(1-\rho^{2}\right)^{1 / 2}\left\{\mathrm{~W}_{1}+\mathrm{W}_{2}\left(1-\rho^{2}\right)\right\}\right]^{(2 \mathrm{~m}+1) / \mathrm{m}} \mathrm{d} \rho$

The procedures for solving eqs. (38) through (42), utilizing an incremental time marching scheme, are detailed in Appendix C. 


\section{Asrmptotic Solutions}

In the absence of leak-off $\left(C_{L}=0\right)$, the solutions to eqs. $(38)-(42)$ are identical to the time-explicit forms derived from Lagrange's method (Lee et al., 1989). For the limiting case of negligible fracture energy $\left(G_{c r}=0\right)$, we obtain the following relations from eqs. (38) through (41):

$$
\mathrm{W}_{1}=0, \alpha=3 / 2, \mathrm{~W}_{2}=\frac{8(1-\nu)}{3 \pi \mu} \mathrm{PR}, \mathrm{i}_{0}=\frac{\mathrm{d}}{\mathrm{dt}}\left(\frac{2 \pi}{5} \mathrm{~W}_{2} \mathrm{R}^{2}\right)
$$

Substituting these values into eq. (42), we have

$$
\begin{aligned}
& \mathrm{R}(\mathrm{t})=\mathrm{C}_{1}(\mathrm{~m})\left[^{\mathrm{i}^{\mathrm{m}+2} \mu}{\frac{\mathrm{o}}{\eta_{\mathrm{o}}(1-\nu)}}^{\frac{1}{3(\mathrm{~m}+2)} \mathrm{t}^{\frac{2(\mathrm{~m}+1)}{3(\mathrm{~m}+2)}}}\right. \\
& \mathrm{W}(\mathrm{t})=\mathrm{W}_{2}(\mathrm{t})=\mathrm{C}_{2}(\mathrm{~m})\left[\frac{(1-\nu)^{2} \mathrm{i}_{0}^{\mathrm{m}+2} \eta_{\mathrm{o}}^{2}}{\mu^{2}}\right]^{\frac{1}{3(\mathrm{~m}+2)}} \mathrm{t}^{\frac{2-\mathrm{m}}{3(\mathrm{~m}+2)}} \\
& \mathrm{P}(\mathrm{t})=\mathrm{C}_{3}(\mathrm{~m})\left[\frac{\mu^{\mathrm{m}+1} \eta_{0}}{(1-\nu)^{\mathrm{m}+1}}\right]^{\frac{1}{\mathrm{~m}+2} \mathrm{t}^{\frac{-\mathrm{m}}{\mathrm{m}+2}}}
\end{aligned}
$$

The numerical constants $\mathrm{C}_{\mathrm{i}}(\mathrm{m})$ are detailed in Table 1 . The difference in the constant values using a previous Lagrangian formulation (Lee et al., 1989) can be attributed to the assumed constant crack pressure and corresponding elliptical crack opening width profile.

The other limiting threshold is characterized by zero dissipation energy rate $\left(\eta_{0}=0\right)$. This case correctly yields a constant pressure profile and, from eqs. (38) through (42), we obtain

$$
\begin{aligned}
\alpha=0, \mathrm{~W}_{2}=0, \mathrm{~W}_{1}=\frac{4(1-\nu)}{\pi \mu} \mathrm{RP}, \mathrm{i}_{0}=\frac{\mathrm{d}}{\mathrm{dt}}\left(\frac{2 \pi}{3} \mathrm{~W}_{1} \mathrm{R}^{2}\right) \\
\mathrm{R}(\mathrm{t})=0.617\left[\frac{\mu \mathrm{i}_{0}^{2}}{(1-\nu) \mathrm{G}_{\mathrm{cr}}}\right]^{1 / 5} \mathrm{t}^{2 / 5} \\
\mathrm{~W}(\mathrm{t})=\mathrm{W}_{1}(\mathrm{t})=1.254\left[\frac{\mathrm{G}_{\mathrm{cr}}^{2} \mathrm{i}_{0}(1-\nu)^{2}}{\mu^{2}}\right]^{1 / 5} \mathrm{t}^{1 / 5} \\
\mathrm{P}(\mathrm{t})=1.595\left[\frac{\mu^{2} \mathrm{G}_{\mathrm{cr}}^{3}}{(1-\nu)^{2} \mathrm{i}_{\mathrm{o}}}\right]^{1 / 5} \mathrm{t}^{-1 / 5}
\end{aligned}
$$




\section{Numerical Results}

For the cases wherein the effects of dissipation and fracture energy rate are both prevalent, the governing equations (38) through (42) do not yield closed form time-explicit solutions. Therefore, the nonlinear coupled differential equations are solved using a numerical procedure (Appendix C). To illustrate the transition of the solution behavior from the dissipation dominant regime to the fracture surface energy dominant regime, we select an example (Table 2) wherein the effects of dissipation and fracture energy are clearly evident. Figure 2 illustrates the numerical results and the transition of the bore-hole crack opening width response from the dissipation dominant regime solution (eq.(46b)) to the fracture energy dominant regime solution (eq.(48b)). The results from a previously developed 3-dimensional finite element simulator (Advani et al., 1990) are also included for comparison. The corresponding fracture radius and bottom-hole effective pressure responses are also presented in Figs. 3 and 4, respectively. The domain transition, for the fracture radius growth, is not discerned readily in Fig. 3 since the slope changes from a value of 0.44 (eq. $46 \mathrm{a}$ with $\mathrm{m}=1$ ) to 0.40 (eq. 48a). Another interpretation of this transition behavior can be found by examining the value of the pressure-width response variable $\alpha(t)$. The extreme values of $\alpha$ are 1.50 and 0 associated with the dissipation (eq. 46) and fracture energy dominant (eq. 48) regimes, respectively. The computed values of $\alpha$, for this numerical example, decrease monotonically from $1.22\left(t=5 \times 10^{-3} \mathrm{~min}\right)$ to $0.10(t=1000 \mathrm{~min})$. 


\section{CONCLUDING REMARKS}

An application of variational principles integrating the elastic reservoir structural and fracture mechanics as well as fracture fluid flow behavior are presented. The formulations yield a comprehensive set of field equations for characterizing the overall hydraulic fracture responses. They also facilitate the computation of pertinent energy rates during fracture evolution. Application of the developed methodology for a penny-shaped fracture is readily demonstrated by using a Rayleigh-Ritz type solution technique. This procedure can also be implemented for the case wherein the lag in the fracturing fluid front relative to the crack tip front is represented by an additional generalized coordinate. It is believed, however, that in-situ stress effects in the presence of the fluid lag are less significant for penny-shaped rather than rectangular fractures. Investigations on the evolution of an elliptical fracture in a three layered formation with stress contrasts and leak-off effects, using the presented variational formalism, are in progress.

\section{ACKNOWLEDGEMENT}

This research is partially supported by Chevron Oil Field Research Inc., Conoco Inc., Mobil R\&D Corp., U.S. Department of Energy, Amoco Foundation and Cray Research Inc.. The authors also acknowledge the generous support of the Ohio Supercomputer Center for use of its computational facilities. 


\section{REFERENCES}

Abe H., Mura T. and Keer L.M., 1976, "Growth Rate of a Penny-Shaped Crack in Hydraulic Fracture of Rocks," J. Geophysical Research, vol.81, pp.5335-5340.

Abou-Sayed A.S., Clifton R.J., Dougherty R.L. and Morales R.H., 1984, "Evaluation of the Influence of In-situ Reservoir Conditions on the Geometry of Hydraulic Fracture Using a 3D Model: Part2 - Case Studies", Proc. Unconventional Gas Recovery Symposium, Pittsburgh, SPE Paper No. 12878.

Advani S.H., Lee T.S. and Lee J.K., 1990, "Three-Dimensional Modeling of Hydraulic Fractures in Layered Media: Part I - Finite Element Formulations", ASME J. Energy Resources Technology, vol.112, pp.1-9.

Advani S.H , Torok J.S. and Lee J.K., 1986, "Explicit Approximate Solutions Associated with the Mechanics of Hydraulic Fracturing", ASME J.Appl. Mech., vol.53, pp.462-465.

Advani S.H., Torok J.S., Lee J.K. and Choudhry S., 1987, "Explicit Time-Dependent Solutions and Numerical Evaluations for Penny-Shaped Hydraulic Fracture Model", J. Geophysical Research, vol.92, pp.8047-8055.

Barenblatt G.I., 1956, "On Some Problems of the Theory of Elasticity Arising in Investigating the Mechanism of Hydraulic Fracture of an Oil-Bearing Stratum," Prikl. Mat. Mech., vol. 20 pp. 475-486; 1959, "Equilibrium Cracks Forming During Brittle Fracture," Doklady Akad Nauk USSR, vol. 127, pp. 47-50.

Biot M.A., Masse L. and Medlin W.L., 1986, "A Two Dimensional Theory of Fracture Propagation", SPE Production Engineering, vol.1, pp.19-30.

Budiansky B. and Rice J.R., 1973, "Conservation Laws and Energy Release Rates," Trans. ASME J. Appl. Mech., vol. 40, pp.201-203.

Bui H.D., 1977, "An Integral Equations Method for Solving the Problem of a Plane Crack of Arbitrary Shape," J. Mech. Phys. Solids, vol. 25, pp. 29-39.

Bui, H.D. and R. Parnes, 1982, "A Reexamination of the Pressure at the Tip of Fluid Filled Crack," Int. J. Engng Sci., vol. 20, no. 11, pp. 1215-1220.

Clifton R.J. and Abou-Sayed A.S., 1982, "On the Mechanics of Hydraulic Fracturing," Proc. Ninth U.S. National Congress of Applied Mechanics, p.443.

Clifton R.J., 1989, "Three-dimensional Fracture Propagation Models," in Recent Advances in Hydraulic Fracturing, eds. J.L. Gidley et al., Society of Petroleum Engineers, Richardson, Texas, Ch. 5.

Lee J.C. and Keer L.M., 1986, "Study of a Three-Dimensional Crack Terminating at an Interface," Trans. ASME J.Appl. Mech., vol.53, pp.311-316. 
Lee T.S., Advani S.H., Avasthi J.M. and Lee J.K., 1989, "Characteristic Time Concept Associated with Hydraulic Fracture Configuration Evolution and Optimization", Proc. Low Permeability Reservoirs Symposium, Denver, SPE Paper No. 19000. Also in press SPE Production Engineering.

Lee T.S., Advani S.H. and Lee J.K., 1988, "Three-Dimensional Analysis of an Arbitrary Shaped Pressurized Crack Traversing a Bi-Material Interface", Eng. Frac. Niechanics, vol.30, no.2, pp.191- 209.

Perkins T.K. and Krech W.W., 1968, "The Energy Balance Concept of Hydraulic Fracturing", Soc. Pet. Eng. J., vol.243, pp.1-12.

Sack R.A., 1946, "Extension of Griffith's Theory of Rupture to Three Dimensions," Proc. Phys. Soc. of London, vol.58, p.729.

Shah R.C. and Kobayashi A.S., 1971, "Stress Intensity Factor for An Elliptical Crack under Arbitrary Normal Loading," Engineering Fracture Mechanics, vol.3, pp.71-96.

Shylyapobersky J., Wong G.K. and Walhaug W.W., 1988, "Overpressure Calibrated Design of Hydraulic Fracture Simulations," SPE Paper No. 18194.

Thiercelin M., Jeffrey R.G. and Ben-Naceur K., 1987, "The Influence of Fracture Toughness on the Geometry of Hydraulic Fractures", Proc. Low Permeability Reservoirs Symposium, Denver, SPE Paper No. 16431.

Touboul E., BenNaceur K. and Thiercelin M., 1986, "Variational Methods in the Simulation of Three-Dimensional Fracture Propagation", Proc. 27th US Symposium on Rock Mechanics, Tuscaloosa, pp.659-668.

Veatch Jr. R.W., Moschovidis Z.A. and Fast C.R., 1989, "An Overview of Hydraulic Fracturing," in Recent Advances in Hydraulic Fracturing, eds. J.L. Gidley et al., Society of Petroleum Engineers, Richardson, Texas, Ch. 1.

Wong S.K. and Cleary M.P., 1985, "Numerical Simulation of Unsteady Fluid Flow and Propagation of a Circular Fracture", Int. J. Num. and Anal. Meth. in Geomech., vol.9, pp.1-14. 


\section{APPENDIX A}

\section{Rate Form of Principle of Virtual Work}

To demonstrate the physical relevance of the energy-rate functional (eq.(1)) and its relationship with the traditional principle of virtual work (PVW), we express the PVW for the hydraulic fracturing process in the form

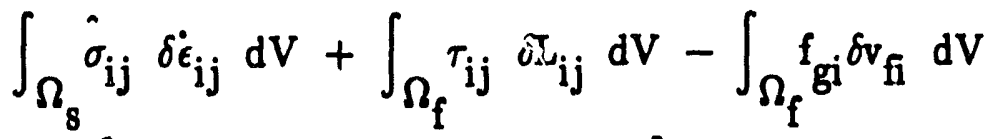

$$
\begin{aligned}
& +2 \int_{A}\left(p-n_{i} \tau_{i j} n_{j}\right) \delta v_{L} d A+\int_{\partial A}\left(G_{c r}-G\right) \delta \dot{a}_{n} d S \\
& +\int_{\partial A_{q}}\left(p-n_{i} \tau_{i j} n_{j}\right) \delta v_{f n} d A+\int_{\Omega_{f}} \lambda \delta v_{f i, i} d V=0
\end{aligned}
$$

where $\hat{\sigma}_{\mathrm{ij}}=\sigma_{\mathrm{ij}}+\sigma_{\mathrm{ij}}^{0}$ is the total formation stress tensor component and $\tau_{\mathrm{ij}}$ is the deviatoric stress tensor components for the fluid. The variations $\delta \dot{\epsilon}_{\mathrm{ij}}$ in eq. (A.1) are restricted to those values of $\delta \dot{\epsilon}_{\mathrm{ij}}$ which are compatible with the current fracture configuration. Energy contributions due to a moving fracture front are contained in the energy release rate $G$. The strain rate and velocity gradient tensor components above are defined by

$$
\dot{\epsilon}_{i j}=\frac{1}{2}\left(\frac{\partial v_{s i}}{\partial x_{j}}+\frac{\partial v_{s j}}{\partial x_{i}}\right) \text { and } L_{i j}=\frac{1}{2}\left(\frac{\partial v_{f i}}{\partial x_{j}}+\frac{\partial v_{f j}}{\partial x_{i}}\right)
$$

The Lagrange multiplier associated with the last integral in eq. (A.1), for the incompressible fracturing fluid, can be shown to be equal to the fluid pressure, i.e.

$$
\lambda=-\mathrm{p}
$$

In converting eq. (A.1) to a functional, we retain variations in the variables $\underline{\mathbf{V}}_{\mathbf{S}}$, $\underline{\mathbf{v}}_{\mathrm{f}}, \mathrm{p}$, and $\dot{\mathrm{a}}_{\mathrm{n}}$ only. We do not take variations with respect to $\underline{\underline{u}}_{\mathrm{s}}$ or the physical boundaries.

We now convert eq. (A.1) to a functional form, useful for applications. Since the fluid is incompressible, we require $v_{\tilde{f}^{\prime} \mathfrak{j}}=0$ in $\Omega_{\mathrm{f}}$ and write, after use 
of the divergence theorem and algebraic manipulations, the identity

$$
-\int_{\Omega_{f}} p \delta v_{f i}{ }^{\prime} d V=\delta \int_{\Omega_{f}} p_{i} v_{f} d V-2 \delta \int_{A} v_{f^{i}} n_{i} p d A-\delta \int_{\partial A_{q}} p v_{f^{n}} n_{i} d A .
$$

to obtain

$$
\begin{aligned}
& \int_{\Omega_{\mathrm{s}}} \hat{\sigma}_{\mathrm{ij}} \delta \dot{\epsilon}_{\mathrm{ij}} \mathrm{dV}+\int_{\Omega_{\mathrm{f}}} \tau_{\mathrm{ij}} \delta \mathrm{L}_{\mathrm{ij}} \mathrm{dV}+\delta \int_{\Omega_{\mathrm{f}}}\left(\mathrm{p}_{\mathrm{i}}-\mathrm{f}_{\mathrm{gi}}\right) \mathrm{v}_{\mathrm{fi}} \mathrm{dV}-2 \int_{\mathrm{A}} \delta \mathrm{p} \mathrm{v}_{\mathrm{L}} \mathrm{dA} \\
& +\int_{\partial A}\left(G_{c r}-G\right) \delta \dot{a}_{n} d S-\int_{\partial A_{q}} v_{f n} \delta p d A+2 \delta \int_{A}\left(v_{L}-v_{f i} n_{i}\right) p d A \\
& -2 \int_{A} n_{i} \tau_{i j} n_{j} \delta v_{L} d A-\int_{\partial A_{q}} n_{i} \tau_{i j} n_{j} \delta v_{f n} d A=0
\end{aligned}
$$

Introducing, without loss of generality of the constitutive laws, the relations

$$
\frac{\partial e}{\partial \epsilon_{i j}}=\hat{\sigma}_{i j} \text { and } \frac{\partial \psi}{\partial L_{i j}}=\tau_{i j}
$$

and the energy release rate expression (Budiansky and Rice, 1974)

$$
\delta \frac{d}{d t} \int_{\Omega_{s}} e d V=\int_{\Omega_{s}} \dot{\sigma}_{i j} \delta \dot{\epsilon}_{i j} d V-\int_{\partial A} G \delta \dot{a}_{n} d S
$$

in eq. (A.4), we obtain the desired functional form

$$
\begin{aligned}
& \delta F\left(\underline{z}_{s}, \underline{r}_{f}, p, \dot{a}_{n}\right)=\delta\left\{\frac{d}{d t} \int_{\Omega_{s}} e d V+\int_{\Omega_{f}} \psi d V+\int_{\Omega_{f}}\left(p_{i_{i}}-f_{g i}\right) v_{t i} d V\right. \\
& \left.-2 \int_{A} p v_{L} d A+\int_{\partial A} G_{c r} \dot{a}_{n} d S-\int_{\partial A_{q}} v_{f n} p d A-2 \int_{A} v_{s i} n_{i} p d A\right\}=0
\end{aligned}
$$

In eq. (A.6), the energy release rate $G$ is expressed as a function of current configuration and displacement (Appendix B). Therefore, its variation with respect to velocity term and loading are neglected. We note here that, in deriving (A.7), the velocity constraint expression $v_{f^{n}} n_{i}=v_{s i} n_{i}+v_{L}$ is used along with explicitly assumed leak-off and fluid injection velocities $\left(\delta v_{L}=\delta v_{f n}=0\right)$. Also, in considering the variation of the strain energy $e$ above, only the variations with respect to the solid velocity $v_{s i}$ and crack propagation velocity $\dot{a}_{n}$ are considered. 


\section{APPENDIX B \\ Energy Release Rate for a Planar Crack}

The principle of virtual work in Appendix A contains the term

$$
\int_{\partial A} G \delta \dot{a}_{n} \mathrm{~d} S
$$

where $G$ is the energy release rate. Assuming that the crack tip experiences plane strain, mode I loading conditions, in a neighborhood near the crack tip, we have

$$
w(d)=\frac{4(1-\nu)}{\mu} K_{I} \sqrt{d / 2 \pi}
$$

where $w(d)$ is the fracture opening at a small distance $d$ inside the fracture with d measured normal to the leading edge of the fracture.

From eq. (B.2), near the edge of the fracture, we obtain

$$
\mathrm{w} \nabla \mathrm{w} \cdot \underline{\underline{n}}=-\frac{4(1-\nu)^{2}}{\pi \mu^{2}} \mathrm{~K}_{\mathrm{I}}^{2}
$$

where n points in the direction of fracture propagation. Since

$$
\mathrm{G}=\frac{(1-\nu)}{2 \mu} \mathrm{K}_{\mathrm{I}}^{2}
$$

we can write eq. (B.1) in the form

$$
\int_{\partial \mathrm{A}} \mathrm{G} \delta \dot{\mathrm{a}}_{\mathbf{n}} \mathrm{d} S=-\int_{\partial \mathrm{A}}\left\{\frac{\pi \mu}{\delta(\hat{1}-\nu)} w \nabla w \cdot \underline{\mathfrak{n}}\right\} \delta \dot{a}_{\mathrm{n}} \mathrm{d} S
$$

The energy release rate integral above is now expressed as a function of the current crack configuration and displacement. 


\section{APPENDIX C}

\section{Governing Equations and Solution Procedure for Penny-Shaped Crack}

The energy rate components in eq. (31) are derived using the curtailed two-term crack opening width and fracture fluid profiles given by eqs. (36) and (37), respectively. The corresponding boundary integral $\mathrm{K}_{\mathrm{A}}[\mathrm{w}]$ has the form (Shah and Kobayashi, 1971)

$$
\mathrm{K}_{\mathrm{A}}[\mathrm{w}]=\frac{\pi \mu}{4(1-\nu) \mathrm{R}}\left(\mathrm{W}_{1}+\frac{3}{2} \mathrm{~W}_{2}-\frac{9}{4} \mathrm{~W}_{2} \rho^{2}\right)
$$

The general series form expression for $K_{A}[w]$ for a penny-shaped crack corresponding to a polynomial series describing the internal pressure can be obtained from the results of Shah and Kobayashi (1971) by inversion of the appropriate coefficient matrix. The crack opening width rate from eq. (36) is given by

$$
\begin{aligned}
\dot{\mathrm{w}}= & \dot{\mathrm{W}}_{1}\left(1-\rho^{2}\right)^{1 / 2}+\dot{\mathrm{w}}_{2}\left(1-\rho^{2}\right)^{3 / 2} \\
& +\dot{\mathrm{R}} / \mathrm{R} \rho^{2}\left\{\mathrm{w}_{1}\left(1-\rho^{2}\right)^{-1 / 2}+3 \mathrm{~W}_{2}\left(1-\rho^{2}\right)^{1 / 2}\right\}
\end{aligned}
$$

The pertinent energy rate components from eqs. (C.1) and (C.2) are

$$
\begin{aligned}
& \dot{\mathrm{U}}_{\mathrm{s}}=\int_{\mathrm{A}} \dot{\mathrm{w}} \mathrm{K}_{\mathrm{A}}[\mathrm{w}] \mathrm{dA}=\frac{\pi^{2} \mu \mathrm{R}}{2(1-\nu)}\left\{\dot{\mathrm{W}}_{1}\left(\frac{1}{3} \mathrm{~W}_{1}+\frac{1}{5} \mathrm{~W}_{2}\right)+\dot{\mathrm{W}}_{2}\left(\frac{1}{5} \mathrm{~W}_{1}+\frac{6}{35} \mathrm{~W}_{2}\right)\right\} \\
& +2 \frac{\pi^{2} \mu \dot{\mathrm{R}}}{2(1-\nu)}\left(\frac{2}{3} \mathrm{w}_{1}^{2}+\frac{1}{5} \mathrm{w}_{1} \mathrm{w}_{2}+\frac{3}{35} \mathrm{w}_{2}^{2}\right) \\
& \dot{\mathrm{U}}_{\mathrm{p}}=\int_{\mathrm{A}} \dot{\mathrm{w}}\left(\mathrm{p}-\sigma_{0}\right) \mathrm{dA}=2 \pi \mathrm{R}^{2} \mathrm{P}\left\{\dot{\mathrm{W}}_{1}\left(\frac{1}{3}-\frac{2 \alpha}{15}\right)+\dot{\mathrm{W}}_{2}\left(\frac{1}{5}-\frac{2 \alpha}{35}\right)\right\} \\
& +2 \pi \mathrm{RRP}\left\{\frac{2}{3}\left(1-\frac{4 \alpha}{5}\right) \mathrm{W}_{1}+\frac{2}{5}\left(1-\frac{4 \alpha}{7}\right) \mathrm{W}_{2}\right\} \\
& \mathrm{D}_{\mathrm{p}}=\frac{\mathrm{m}}{1+\mathrm{m}}(\bar{\eta})^{-1 / \mathrm{m}} \int_{\mathrm{A}} \mathrm{w}^{(2+1 / \mathrm{m})}\left\{\left(\nabla \mathrm{p}-\mathrm{f}_{\mathrm{g}}\right) \cdot\left(\nabla \mathrm{p}-\mathrm{f}_{\mathrm{g}}\right)\right\}^{(1+\mathrm{m}) /(2 \mathrm{~m}) \mathrm{dA}} \\
& =\frac{2 \pi \mathrm{m}^{2}}{(1+\mathrm{m})(2 \mathrm{~m}+1)}\left(\eta_{0}\right)^{-1 / \mathrm{m}} \mathrm{R}^{(\mathrm{m}-1) / \mathrm{m}}(\alpha \mathrm{P})^{(\mathrm{m}+1) / \mathrm{m}} \mathrm{I}\left(\mathrm{W}_{1}, \mathrm{~W}_{2}, \mathrm{~m}\right)
\end{aligned}
$$


where $\mathrm{I}\left(\mathrm{W}_{1}, \mathrm{~W}_{2}, \mathrm{~m}\right)=\int_{0}^{1}\left[\rho\left(1-\rho^{2}\right)^{1 / 2}\left\{\mathrm{~W}_{1}+\mathrm{W}_{2}\left(1-\rho^{2}\right)\right\}\right]^{(2 \mathrm{~m}+1) / \mathrm{m}} \mathrm{d} \rho$

$$
\begin{aligned}
& \dot{\mathrm{U}}_{\Gamma}=\int_{\partial \mathrm{A}} \dot{\mathrm{a}}_{\mathrm{n}}\left\{\frac{\pi \mu}{8(1-\nu)^{\mathrm{W}}} \nabla \mathrm{w} \cdot \underline{\mathrm{n}} \mathrm{dS}=-\frac{\pi^{2} \mu}{4(1-\nu)} \dot{\mathrm{RW}}_{1}^{2}\right. \\
& \dot{\mathrm{U}}_{\mathrm{f}}=\int_{\partial \mathrm{A}} \mathrm{G}_{\mathrm{cr}} \dot{\mathrm{a}}_{\mathrm{n}} \mathrm{dS}=2 \pi \mathrm{G}_{\mathrm{cr}} \mathrm{R} \dot{\mathrm{R}} \\
& \mathrm{D}_{\mathrm{I}}=\int_{\partial \mathrm{A}_{\mathrm{q}}} \mathrm{p} \mathrm{Q}_{\mathrm{n}} \mathrm{dA}=-\mathrm{j}_{0} \mathrm{P} \\
& \mathrm{D}_{\mathrm{L}}=\int_{\mathrm{A}} \mathrm{pq}_{\mathrm{L}} \mathrm{dA}=4 \pi \mathrm{C}_{\mathrm{L}} \mathrm{R}^{2} \mathrm{P} \mathrm{J}(\alpha)
\end{aligned}
$$

where $J(\alpha)=\int_{0}^{1} \frac{1-\alpha \rho^{2}}{\{t-\tau(\rho)\}^{2}} \rho \mathrm{d} \rho$.

We note that the normal boundary flux $Q_{n}$ in eq. (31) corresponds to an outward normal along the boundary $\partial A_{q}$, i.e. $Q_{n}=-i_{0}$ in eq. (C.8).

We define the functional (eq. (31)), using eqs. (C.3) through (C.9), as

$$
\mathrm{F}\left(\dot{\mathrm{W}}_{1}, \dot{\mathrm{W}}_{2}, \mathrm{P}, \alpha, \dot{\mathrm{R}}\right)=\dot{\mathrm{U}}_{\mathrm{s}}-\dot{\mathrm{U}}_{\mathrm{p}}-\mathrm{D}_{\mathrm{p}}-\mathrm{D}_{\mathrm{L}}-\mathrm{D}_{\mathrm{I}}+\dot{\mathrm{U}}_{\Gamma}+\dot{\mathrm{U}}_{\mathrm{f}}
$$

and obtain the following governing equations from the first variation :

$\delta \dot{W}_{1}: \frac{\pi^{2} \mu \mathrm{R}}{2(1-\nu)}\left(\frac{1}{3} \mathrm{~W}_{1}+\frac{1}{5} \mathrm{~W}_{2}\right)=2 \pi \mathrm{R}^{2} \mathrm{P}\left(\frac{1}{3}-\frac{2 \alpha}{15}\right)$

$\left.\delta \dot{\mathrm{W}}_{2}: \frac{\pi^{2} \mu \mathrm{R}}{2(1-\nu)}\left(\frac{1}{5} \mathrm{~W}_{1}+\frac{6}{35} \mathrm{~W}_{2}\right)\right\}=2 \pi \mathrm{R}^{2} \mathrm{P}\left(\frac{1}{5}-\frac{2 \alpha}{35}\right)$

$\delta \dot{\mathrm{R}}: \frac{\pi^{2} \mu}{2(1-\nu)}\left(\frac{2}{3} \mathrm{w}_{1}^{2}+\frac{1}{5} \mathrm{~W}_{1} \mathrm{~W}_{2}+\frac{3}{35} \mathrm{~W}_{2}^{2}\right)-2 \pi \mathrm{RP}\left\{\frac{2}{3}\left(1-\frac{4 \alpha}{5}\right) \mathrm{W}_{1}+\frac{2}{5}\left(1-\frac{4 \alpha}{7}\right) \mathrm{W}_{2}\right\}$

$$
-\frac{\pi^{2} \mu}{4(1-\nu)} W_{1}^{2}+2 \pi G_{c r} R=0
$$

$\delta \mathrm{P}:-2 \pi \mathrm{R}^{2}\left\{\dot{\mathrm{W}}_{1}\left(\frac{1}{3}-\frac{2 \alpha}{15}\right)+\dot{\mathrm{W}}_{2}\left(\frac{1}{5}-\frac{2 \alpha}{35}\right)\right\}-2 \pi \mathrm{R} \dot{\mathrm{R}}\left\{\frac{2}{3}\left(1-\frac{4 \alpha}{5}\right) \mathrm{W}_{1}\right.$

$$
\begin{aligned}
& \left.+\frac{2}{5}\left(1-\frac{4 \alpha}{7}\right) \mathrm{W}_{2}\right\}-\frac{2 \pi \mathrm{m}}{2 \mathrm{~m}+1}\left(\eta_{0}\right)^{-1 / \mathrm{m}} \mathrm{R}^{(\mathrm{m}-1) / \mathrm{m}} \alpha^{(\mathrm{m}+1) / \mathrm{m}} \mathrm{P}^{1 / \mathrm{m}} \mathrm{I}\left(\mathrm{W}_{1}, \mathrm{~W}_{2}, \mathrm{~m}\right) \\
& -4 \pi \mathrm{C}_{\mathrm{L}} \mathrm{R}^{2} \mathrm{~J}(\alpha)+\mathrm{i}_{0}=0
\end{aligned}
$$

$\delta \alpha: 2 \pi \mathrm{R}^{2} \mathrm{P}\left(\frac{2}{15} \dot{\mathrm{W}}_{1}+\frac{2}{35} \dot{\mathrm{W}}_{2}\right)+2 \pi \mathrm{R} \dot{\mathrm{R}}\left(\frac{8}{15} \mathrm{~W}_{1}+\frac{8}{35} \mathrm{~W}_{2}\right)-\frac{2 \pi \mathrm{m}}{2 \mathrm{~m}+1}\left(\eta_{0}\right)^{-1 / \mathrm{m}}$

$$
\mathrm{R}^{(\mathrm{m}-1) / \mathrm{m}} \alpha^{1 / \mathrm{m}} \mathrm{P}^{(\mathrm{m}+1) / \mathrm{m}} \mathrm{I}\left(\mathrm{W}_{1}, \mathrm{~W}_{2}, \mathrm{~m}\right)+4 \pi \mathrm{C}_{\mathrm{L}} \mathrm{R}^{2} \mathrm{P} \mathrm{J}_{\ell}=0
$$

where $J_{\ell}=\int_{0}^{1} \frac{\rho^{3}}{\{t-\tau(\rho)\}^{\ell}} d \rho$. 
Equations (C.10) through (C.15) can be rewritten in the form

$$
\begin{aligned}
& \mathrm{f}_{1}=\frac{\pi \mu}{4(1-\nu)} \mathrm{W}_{1}-\mathrm{PR}\left(1-\frac{2}{3} \alpha\right)=0 \\
& \mathrm{f}_{2}=\frac{9 \pi \mu}{16(1-\nu)} \mathrm{W}_{2}-\mathrm{PR} \alpha=0 \\
& \mathrm{f}_{3}=\frac{\pi \mu}{8(1-\nu)} \mathrm{W}_{1}^{2}-\mathrm{G}_{\mathrm{cr}} \mathrm{R}=0
\end{aligned}
$$

$\mathrm{f}_{4}=2 \pi \frac{\mathrm{d}}{\mathrm{dt}}\left\{\mathrm{R}^{2}\left(\frac{1}{3} \mathrm{~W}_{1}+\frac{1}{5} \mathrm{~W}_{2}\right)\right\}+4 \pi \mathrm{C}_{\mathrm{L}} \mathrm{R}^{2} \int_{0}^{1}\{\mathrm{t}-\tau(\rho)\}^{-\ell} \rho \mathrm{d} \rho-\mathrm{i}_{0}=0$

$$
\begin{aligned}
\mathrm{f}_{5}= & \left(\eta_{0} \mathrm{R}^{\mathrm{m}+2}\right)^{1 / \mathrm{m}}\left(\frac{2}{15} \dot{\mathrm{W}}_{1}+\frac{2}{35} \dot{\mathrm{W}}_{2}\right)+\left(\eta_{0} \mathrm{R}^{2}\right)^{1 / \mathrm{m}} \dot{\mathrm{R}}\left(\frac{8}{15} \mathrm{~W}_{1}+\frac{8}{35} \mathrm{~W}_{2}\right) \\
& -\frac{\mathrm{m}}{2 \mathrm{~m}+1}\left\{\frac{9 \pi \mu}{16(1-\nu)} \mathrm{W}_{2}\right\}^{1 / m} \mathrm{I}\left(\mathrm{W}_{1}, \mathrm{~W}_{2}, \mathrm{~m}\right)+2 \mathrm{C}_{\mathrm{L}}\left(\eta_{\mathrm{c}} \mathrm{R}^{\mathrm{m}+2}\right)^{1 / \mathrm{m}_{\mathrm{J}}}=0
\end{aligned}
$$

The developed numerical solution procedure is devised so that Eqs. (C.16) through (C.20) are simultaneously satisfied i.e. $f_{j}^{t+\Delta t}=0$ at time $t+\Delta t$ using the implicit time marching sheme. We note that eqs. (C.18), (C.19), and (C.20) can be solved for $W_{1}, W_{2}$, and $R$ using the standard Newton-Raphson iterative method. The iteration is terminated when the convergence, expressed in terms of relative error is achieved within a tolerance of $0.1 \%$. The pressure, $P$, and variable $\alpha$ are obtained from eqs. (C.16) and (C.17) using the converged solutions. The solutions are, then, updated for the subsequent time step. 
Table 1. Constants for Dissipation Dominant Solutions

\begin{tabular}{llll}
\hline $\mathrm{m}$ & $\mathrm{C}_{1}(\mathrm{~m})$ & $\mathrm{C}_{2}(\mathrm{~m})$ & $\mathrm{C}_{3}(\mathrm{~m})$ \\
\hline 0.1 & 0.797 & 1.252 & 1.851 \\
0.2 & 0.774 & 1.327 & 2.020 \\
0.3 & 0.758 & 1.385 & 2.153 \\
0.4 & 0.745 & 1.434 & 2.267 \\
0.5 & 0.734 & 1.476 & 2.369 \\
0.6 & 0.725 & 1.515 & 2.461 \\
0.7 & 0.717 & 1.550 & 2.548 \\
0.8 & 0.709 & 1.582 & 2.628 \\
0.9 & 0.702 & 1.613 & 2.705 \\
1.0 & 0.696 & 1.641 & 2.777 \\
\hline
\end{tabular}


Table 2. Selected Input Parameters and Characteristic Values (Lee et al., 1989)

Unit Value

\section{INPUT PARAMETERS}

Shear modulus $(\mu)$

$\mathrm{GPa} \quad 2.0$

Poisson's ratio $(\nu)$

$\begin{array}{ll}- & 0.2\end{array}$

Consistency index $\left(\eta_{0}\right)$

$\mathrm{Pa}-\min ^{\mathrm{m}}$

$1.6 \mathrm{E}-4$

Behavior index(m)

$\mathrm{m}^{3} / \mathrm{min}$

1.0

Injection rate $\left(i_{0}\right)$

$\mathrm{Pa}-\mathrm{m}$

5.0

Critical Energy

Release Rate ( $\mathrm{G}_{\mathrm{Cr}}$ )

200

\section{CHARACTERISTIC VALUES}

Time $(\tau)$

$\min$

1.0

Opening Width $\left(W_{0}\right)$

m

$2.0 \mathrm{E}-3$

Radius $\left(\mathrm{R}_{0}\right)$

m

50

Pressure $\left(\mathrm{P}_{0}\right)$

$\mathrm{MPa}$

0.1 


\section{List of Figures}

Fig. 1 Hydraulically induced planar crack with arbitrary shape

Fig. 2 Fracture opening width versus time comparisons for penny-shaped model

Fig. 3 Fracture radius versus time comparisons for pensy-shaped model

Fig. 4 Bottom-hole pressure versus time comparisons for penny-shaped model 


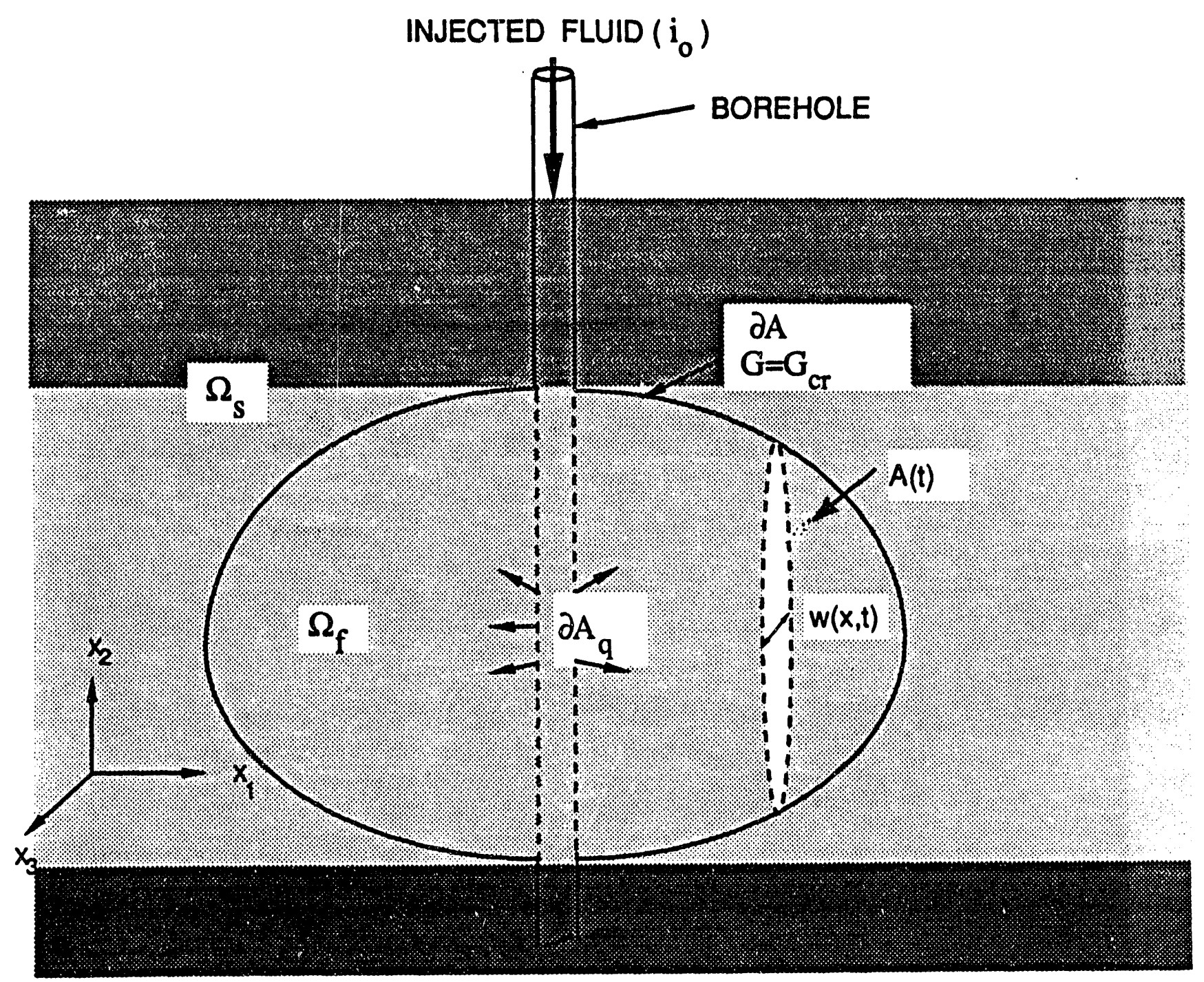

Fig. 1 


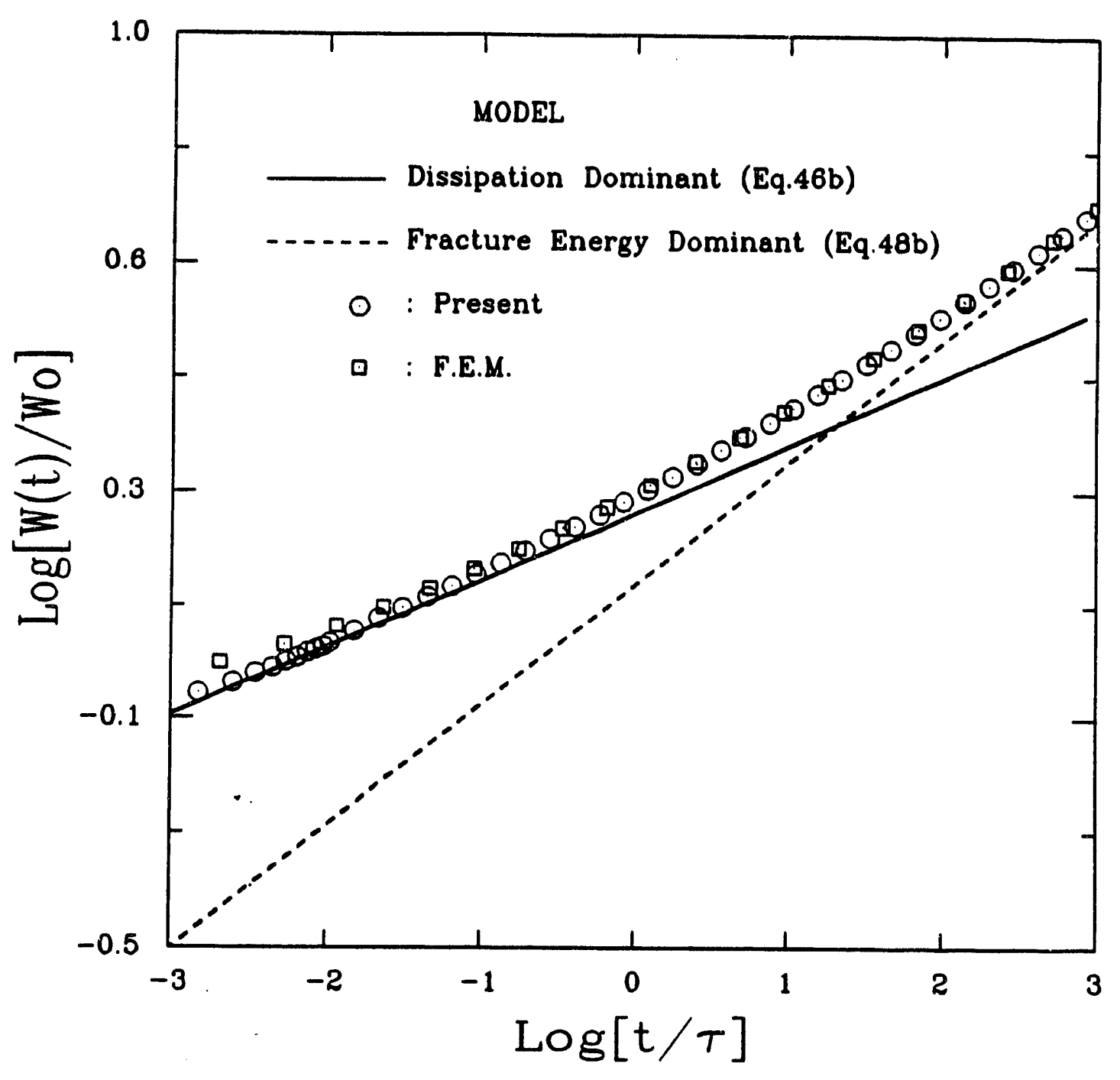

Fig. 2 


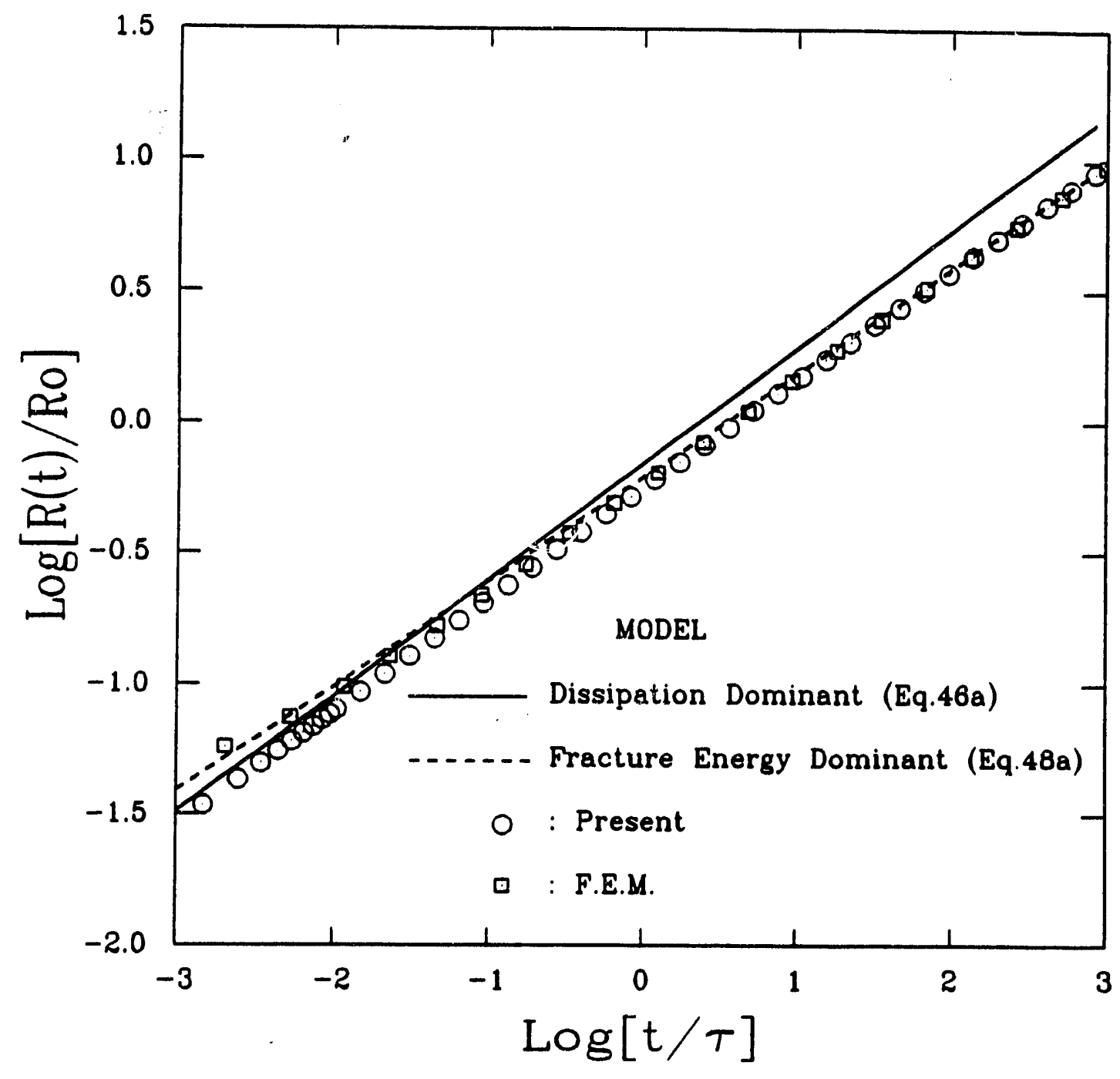

Fig. 3 


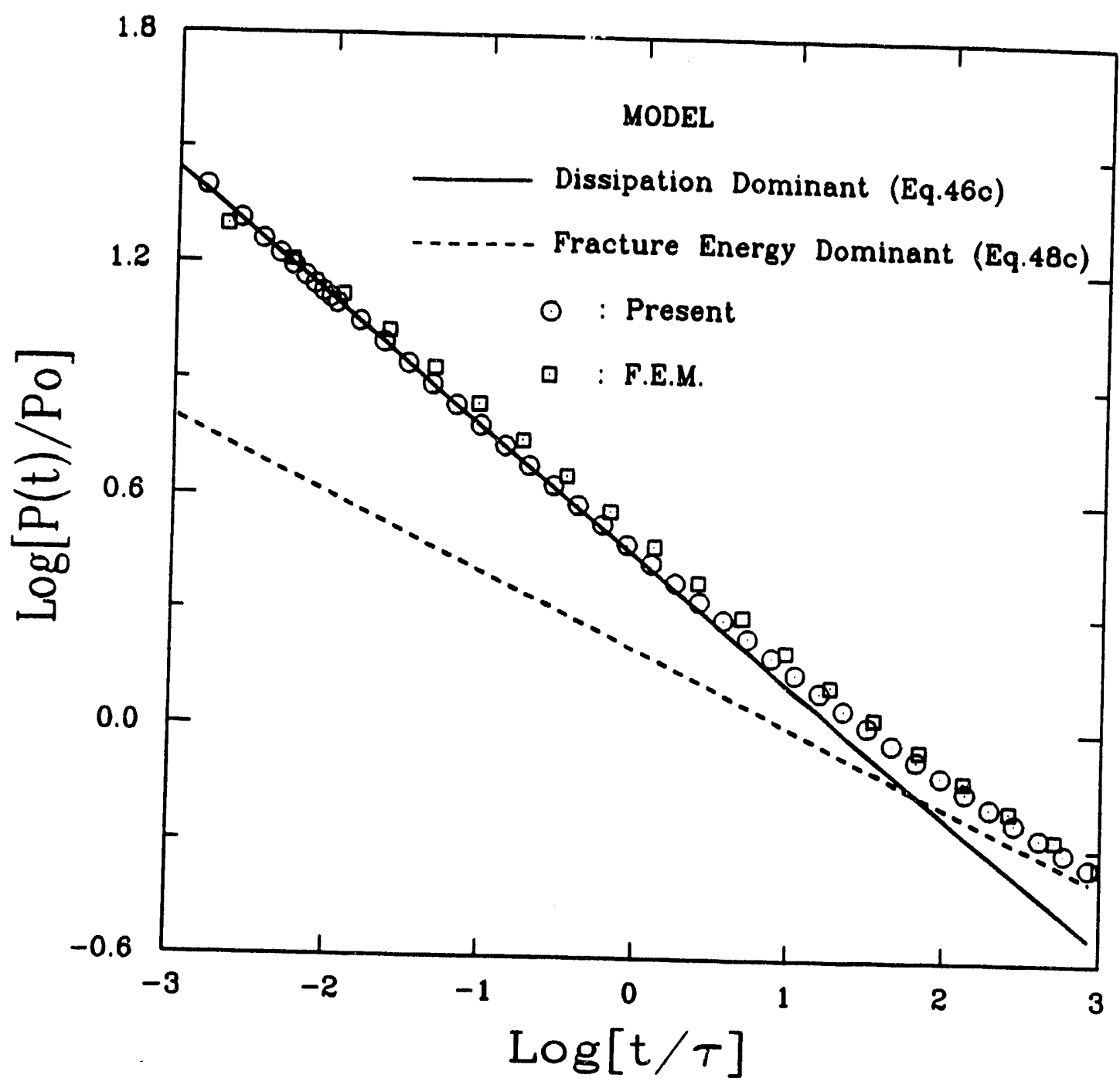

Fig. 4 

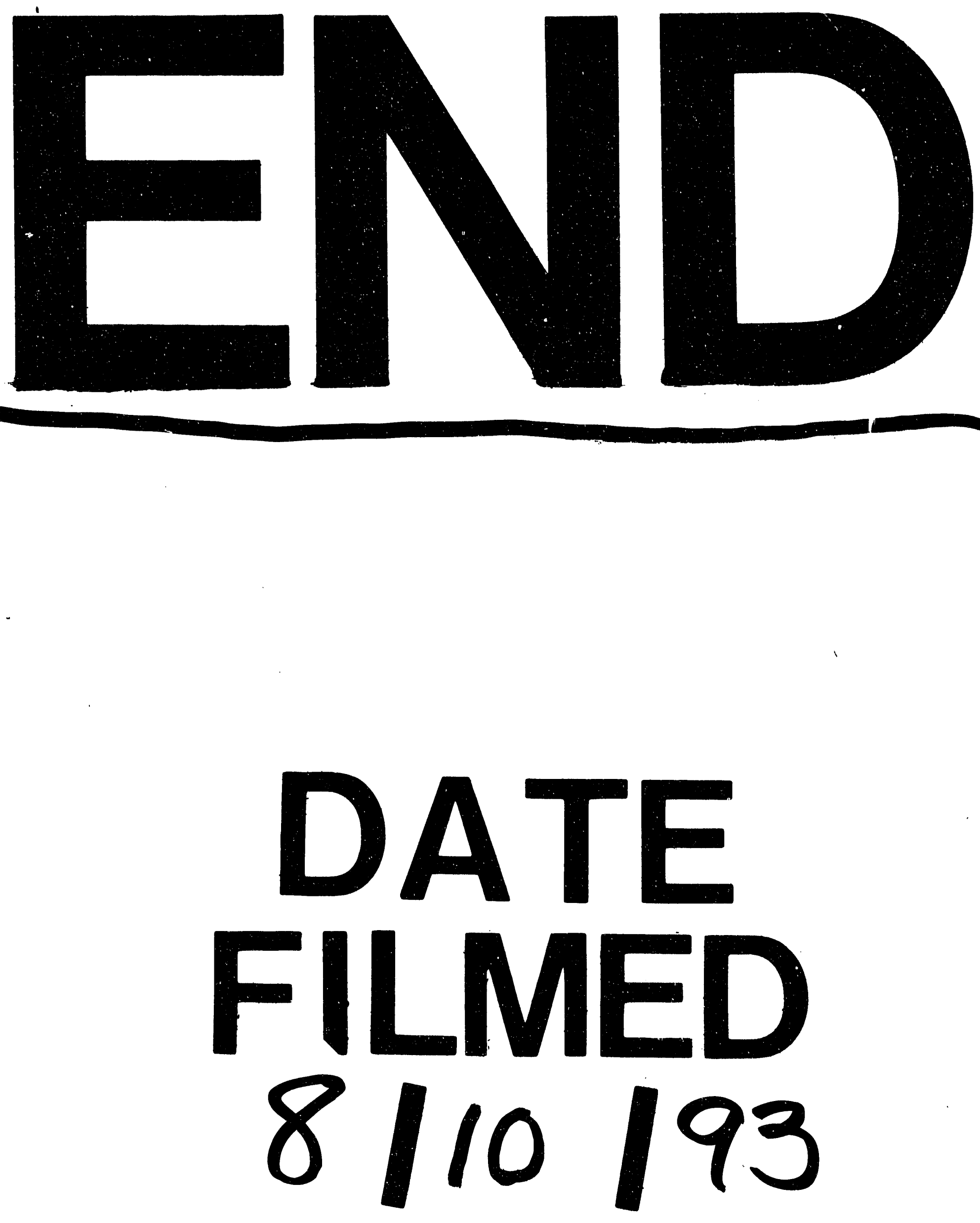
